High Performance Commercial Building Systems

\title{
Comparative Guide to Emerging Diagnostic Tools for Large Commercial HVAC Systems
}

Hannah Friedman and Mary Ann Piette

Ernest Orlando Lawrence Berkeley National Laboratory

May 2001
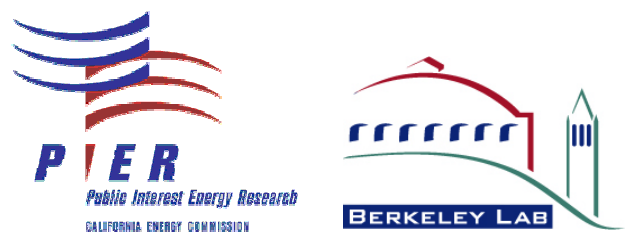


\section{DISCLAIMER}

This document was prepared as an account of work sponsored by the United States Government. While this document is believed to contain correct information, neither the United States Government nor any agency thereof, nor The Regents of the University of California, nor any of their employees, makes any warranty, express or implied, or assumes any legal responsibility for the accuracy, completeness, or usefulness of any information, apparatus, product, or process disclosed, or represents that its use would not infringe privately owned rights. Reference herein to any specific commercial product, process, or service by its trade name, trademark, manufacturer, or otherwise, does not necessarily constitute or imply its endorsement, recommendation, or favoring by the United States Government or any agency thereof, or The Regents of the University of California. The views and opinions of authors expressed herein do not necessarily state or reflect those of the United States Government or any agency thereof, or The Regents of the University of California.

This report was prepared as a result of work sponsored by the California Energy Commission (Commission). It does not necessarily represent the views of the Commission, its employees, or the State of California. The Commission, the State of California, its employees, contractors, and subcontractors make no warranty, express or implied, and assume no legal liability for the information in this report; nor does any party represent that the use of this information will not infringe upon privately owned rights. This report has not been approved or disapproved by the Commission nor has the Commission passed upon the accuracy or adequacy of the information in this report. 


\title{
Comparative Guide to Emerging Diagnostic Tools for Large Commercial HVAC Systems
}

\author{
High Performance Commercial Building Systems Program \\ Element 5 - Integrated Commissioning and Diagnostics \\ Task 2.2.1 - Fault Detection and Diagnosis Procedures
}

\author{
Hannah Friedman and Mary Ann Piette \\ Commercial Building Systems \\ Building Technologies Department \\ Environmental Energy Technologies Division \\ Ernest Orlando Lawrence Berkeley National Laboratory \\ University of California \\ 1 Cyclotron Road \\ Berkeley, California 94720
}

MAY 2001

This report describes results from our task with the High Performance Commercial Buildings Systems Program. For information about other reports and other tasks, please visit buildings.lbl.gov/CEC/

This work was supported by the California Energy Commission, Public Interest Energy Research Program, under Contract No. 400-99-012 and by the Assistant Secretary for Energy Efficiency and Renewable Energy, Office of Building Technology, State and Community Programs, Office of Building Research and Standards of the U.S. Department of Energy under Contract No. DE-AC03-76SF00098. 



\section{TABLE OF CONTENTS}

1.0

Introduction

$1.1 \quad$ Purpose and Benefits of Diagnostic Tools ...................................................... 1

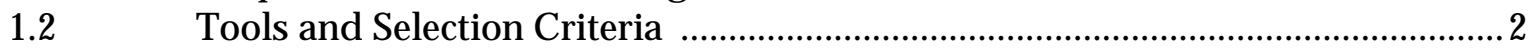

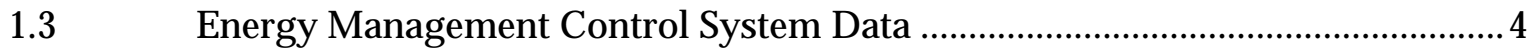

1.4 Techniques for Building Performance Assessment ................................................5

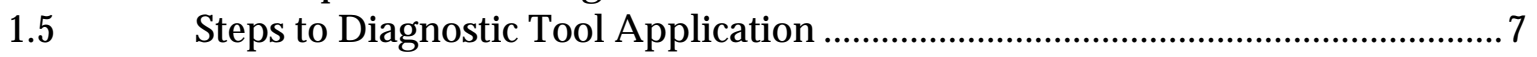

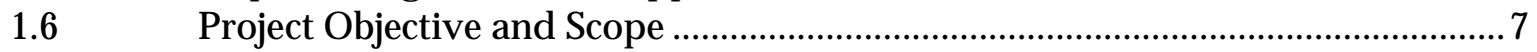

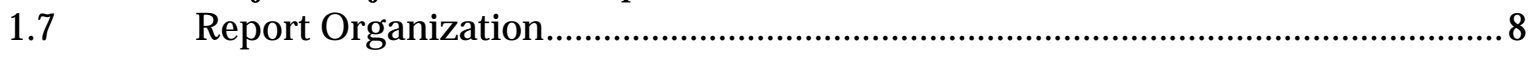

$\begin{array}{lll}2.0 \quad \text { Literature Review } & 9\end{array}$

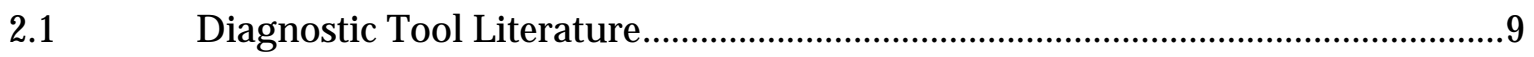

2.2 California Studies Related to Commissioning and Diagnostics .......................10

2.3 Diagnostic Tool Characterization Framework ...................................................11

$\begin{array}{lll}3.0 & \text { Study Methods } & 13\end{array}$

\section{0}

Tool Overview

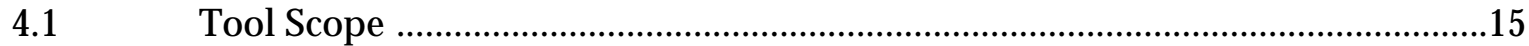

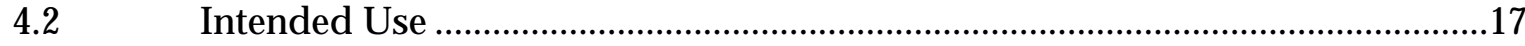

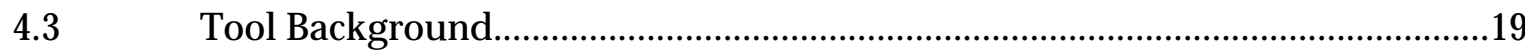

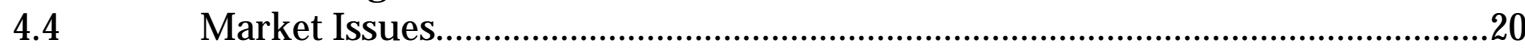

$5.0 \quad$ Comparison of Operational Use 23

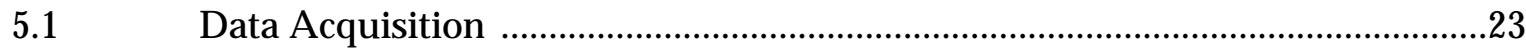

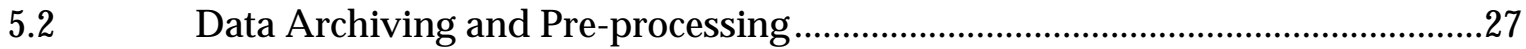

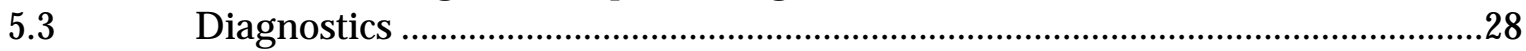

5.3.1 Summary of Problems Detected ...........................................................28

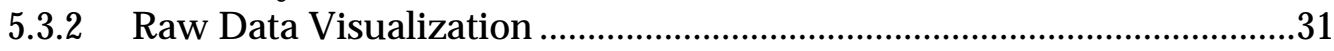

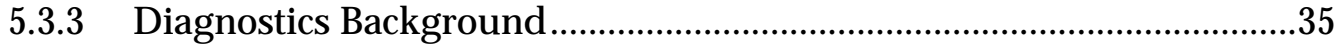

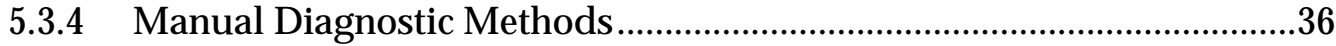

5.3.5 Automated Diagnostic Methods .........................................................40

5.3.6 Treatment of Uncertainty .................................................................. 


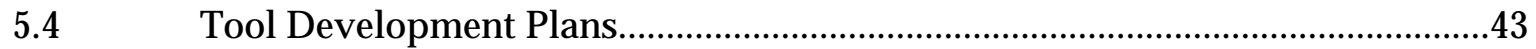

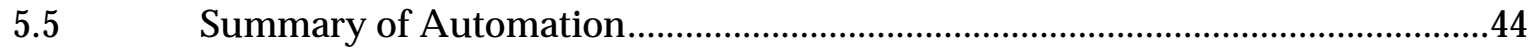

$\begin{array}{lll}6.0 & \text { Tool Evaluation } & 45\end{array}$

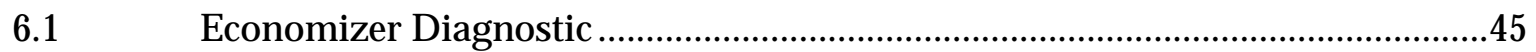

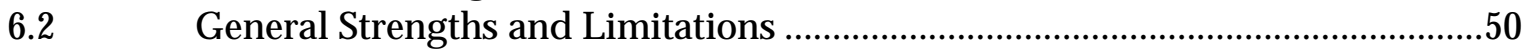

6.3 Challenges in Diagnostic Tool Use....................................................................52

$\begin{array}{lll}7.0 & \text { Conclusions } & 55\end{array}$

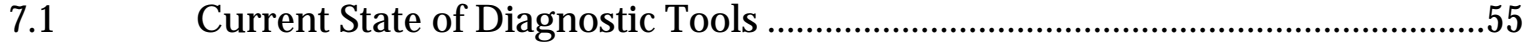

7.2 Tool Research and Development Perspectives................................................55

7.3 Future Work to Assess and Improve Tools ....................................................57

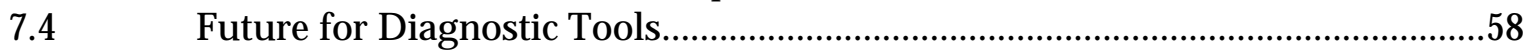

$\begin{array}{ll}\text { Acknowledgements } & 59\end{array}$

$\begin{array}{ll}\text { Sources Cited } & 61\end{array}$

\section{Appendices}

Appendix A Abbreviations ...........................................................................................67

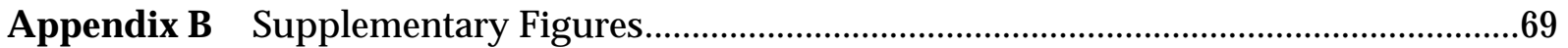

Figure B1 Sample ASCII input file for the ENFORMA software "Retrieve from file" utility

Figure B2 Electric Eye time-series data visualization

Figure B3 EEM Suite, Single point time-series trending with historical data

Figure B4 WBD Outdoor Air Economizer Diagnosis screen

Figure B5 Universal Translator economizer module data graph

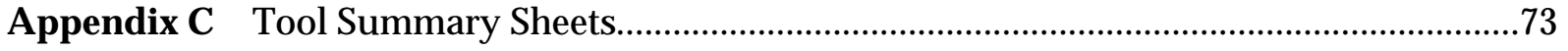


Table 1 Building Performance Assessment Techniques ............................................. 6

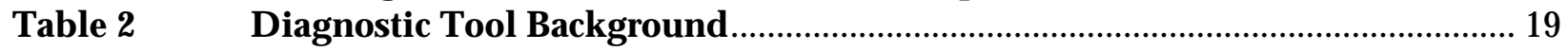

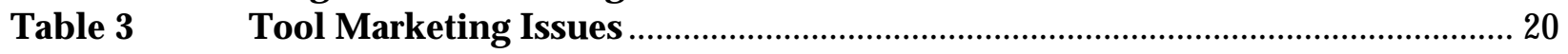

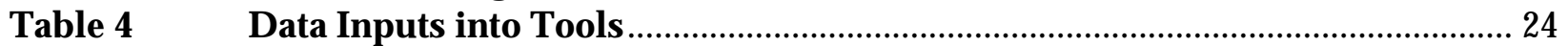

Table 5 Problems Detected through Manual and Automated Diagnostics ..................... 29

Table 6 Master List of Problems Detected by the Diagnostic Tools .............................. 30

Table $7 \quad$ Raw Data Visualization Techniques ............................................................. 31

Table $8 \quad$ Manual and Automated Diagnostic Methods................................................. 36

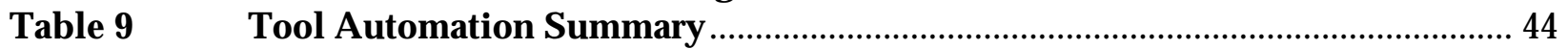

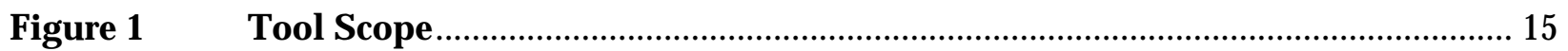

Figure 2 EEM Suite 24-hour Line Plot, average hourly load profile................................ 32

Figure 3 UC Berkeley Fan System Analysis Tools, motor load factor plot ..................... 33

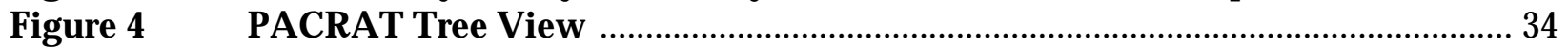

Figure 5 ENFORMA Software Economizer plot with example reference plot................ 37

Figure $6 \quad$ UT Performance Graph, Economizer diagnostic module ................................. 38

Figure $7 \quad$ PACRAT Chiller Performance plot............................................................... 39

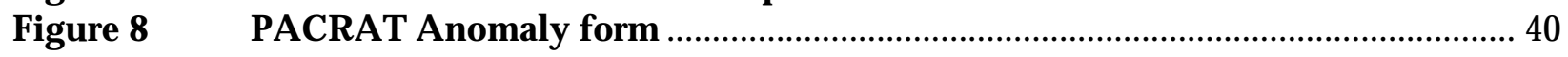

Figure 9 WBD's Outdoor air economizer module problem state notification .................. 41

Figure 10 WBD's Whole building energy module energy consumption index ................ 42

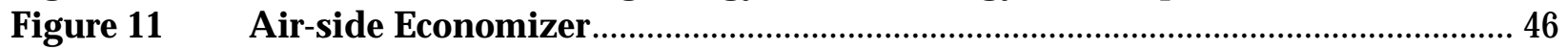

Figure 12 UC Berkeley Fan Tool Economizer Diagnostic Plot, MAT vs. OAT................. 49 


\section{Executive Summary}

Major opportunities for decreased energy consumption exist for commercial buildings through improving the performance of existing systems. Previous case studies have found that "tuning up" an existing building's heating, ventilating, and air conditioning (HVAC) systems, referred to as retro-commissioning, results in an average savings of $5 \%-15 \%$ of total energy consumption. These energy saving opportunities have not been not realized by a large percentage of commercial buildings.

This guide compares emerging diagnostic software tools that aid detection and diagnosis of operational problems for large HVAC systems. We have evaluated six tools for use with energy management control system (EMCS) or other monitoring data. The diagnostic tools summarize relevant performance metrics, display plots for manual analysis, and perform automated diagnostic procedures. There are two main purposes in writing this guide: 1) to help potential tool users gain an understanding of key diagnostic capabilities that could affect tool implementation with EMCS data, and 2) to provide tool developers with feedback by identifying important features and needs for future research.

The six diagnostic tools included in our analysis are:

- $\quad$ ENFORMA ${ }^{\circledR}$ Portable Diagnostic Solutions, Architectural Energy Corporation

- Analysis Tools for Built-up Fan Systems (UCB Tools), Univ. of California, Berkeley

- Universal Translator (UT), Pacific Gas and Electric

- Whole Building Diagnostician (WBD) outdoor air economizer module (OA/E) and whole building energy module (WBE), Pacific Northwest National Laboratory

- Performance And Continuous Recommissioning Analysis Tool (PACRAT), Facility Dynamics Engineering

- Enterprise Energy Management Suite (EEM Suite ${ }^{\mathrm{TM}}$ ), Silicon Energy Corp.

We summarize the existing diagnostic tool literature and present the background work that guided our comparison framework. Interviews and demonstrations with tool developers and inputting data into some of the tools gave us a detailed understanding of tool features and performance in the following categories:

- Tool intent and scope

- Development history

- Market issues: cost, intended users, number of current users

- Data needed for diagnostics

- Data acquisition procedures

- Archiving and pre-processing

- Problems detected

- Raw data visualization techniques

- Methods for manual and automated diagnostics

- Treatment of uncertainty

- Development plans 
We present a comparative analysis using nine summary tables with supporting explanatory text. Our evaluation of specific system diagnostics focuses on the air-side economizer, since this is the most common diagnostic area across the tools. We show sample diagnostic screens for each tool.

The tools have great potential to save time by automating data analysis tasks. All of the tools help manipulate and manage data by creating graphs and metrics to more easily evaluate HVAC system performance. The tools designed for manual diagnostics (ENFORMA, UCB Tools, and the UT) provide aids to detection through reference lines, statistics, performance metrics, benchmarking, and written guides. Most of the tools pre-process the data to prepare it for diagnostic procedures through synchronizing timestamps, filtering for erroneous data, and filling in missing data. The tools designed for continuous analysis (WBD, PACRAT, and EEM Suite) also automate HVAC data acquisition, archive the data, and use the data in automated diagnostics. Automated diagnostic procedures detect and diagnose problems using embedded system knowledge into the software. Additionally, some tools use historical data to model baseline operations and detect deviations from this baseline. The level of automation that each tool provides is summarized in the table below.

Summary of Tool Automation

\begin{tabular}{|c|c|c|c|c|c|}
\hline & & $\begin{array}{c}\text { Data } \\
\text { Acquisition }\end{array}$ & $\begin{array}{l}\text { Archive and } \\
\text { Pre-process }\end{array}$ & Detection & Diagnosis \\
\hline \multicolumn{6}{|c|}{ ENFORMA } \\
\hline \multicolumn{6}{|c|}{ UCB Tools } \\
\hline \multicolumn{6}{|c|}{ UT (PG\&E) } \\
\hline \multirow{2}{*}{ WBD } & WBE & & & & \\
\hline & OA/E & & & & \\
\hline \multicolumn{6}{|c|}{ PACRAT } \\
\hline \multicolumn{6}{|c|}{ EEM Suite } \\
\hline
\end{tabular}

While the tools currently process data for a limited number of system types and components, they are in continuous development. This report provides a side-by-side comparison of the features of each tool in its current stage. In the future, case studies of tool implementation and user interviews will be necessary to gain an understanding of the cost effectiveness and accuracy of the tools as well as preferences for tool features by different users.

This report can be downloaded at http:/ / buildings.lbl.gov / cec under "Integrated Commissioning and Diagnostics", "News and Links" page. This website is currently under development, so the location of publications is subject to change. 


\section{$1.0 \quad$ Introduction}

\subsection{Purpose and Benefits of Diagnostic Tools}

Commercial buildings consume one-third of primary energy and two-thirds of electricity in the U.S. each year (EIA, 1995). Major opportunities for decreased energy consumption exist for commercial buildings through improving the performance of existing systems. Case studies have found that "tuning up" an existing building's heating, ventilating, and air conditioning (HVAC) systems, referred to as retro-commissioning, results in an average savings of $5 \%-15 \%$ of the whole building energy use (Gregerson, 1997). At thirty-four buildings on the Texas A\&M campus, the Energy Systems Laboratory has demonstrated an average chilled water savings of $28 \%$, heating savings of $54 \%$, and electricity savings of $2 \%-20 \%$ (Claridge et al., 2000). These energy saving opportunities have not been not realized by a large percentage of commercial buildings, as less than $0.03 \%$ of existing buildings are estimated to be commissioned annually (Dodds et al., 1998).

If these energy savings are clearly available, what prevents building owners and managers from retro-commissioning or continuously assessing building performance? The difficulty in detecting and diagnosing operational problems is a main factor. EMCS typically have limited embedded diagnostic capabilities. As a result, EMCS data are underutilized for diagnostics. Given the limited tools available to manage the large amounts of data from an EMCS, building operators rarely have the time or training required to collect and analyze trend logs for performance problems. Building operators and energy engineers can use diagnostic tools to streamline and guide the use of EMCS data.

To address these needs and issues, new diagnostic software tools are becoming available that facilitate the detection and diagnosis of energy and other performance problems in commercial buildings. Diagnostics has been defined as the process of detecting incorrect operation and diagnosing the cause of the problem (Haves, 1999). Diagnostic tools can be used to assess existing building operations for retro-commissioning as a single event or continuously over time.

For over twelve years, researchers have developed automated diagnostic methods for HVAC systems. Automated diagnostics research has produced model-based methods for detecting deviations from normal operation and rule-based expert systems to detect and diagnose problems (Anderson et al. 1989, Haberl et al. 1989, Culp 1989, Norford et al. 1990, Kreider and Wang 1991, Benouarets et al. 1994). With varying degrees, the emerging commercial tools have drawn upon these methods.

Detecting and diagnosing problems with building operations can lead to improved building control and occupant comfort, energy savings, increased equipment life, and decreased maintenance costs. Beyond their diagnostic capabilities, these commercial tools provide a data management framework by organizing information from volumes of underutilized time-series data. These data are collected through energy management control systems (EMCS), utility demand metering, and dedicated monitoring systems. Using these data, diagnostic tools can summarize relevant performance metrics, display plots for manual analysis, and perform 
automated diagnostic procedures. A diagnostic tool creates value by summarizing and organizing large amounts of data and efficiently extracting useful information. By combining newer EMCS logging capabilities with advances in information technology, there is great potential to assess building performance.

Automating the process of detection and diagnosis saves time in reviewing raw data. The use of automated diagnostics can improve data analysis, detecting problems that go unnoticed for long periods of time. For example, these tools help uncover energy waste that does not affect occupant comfort. Automated tools can be used to continuously review data, improving the probability that performance problems are detected compared to manual techniques. While expert engineers may initially be needed to configure the tool, less experienced users can perform high-level performance assessment using the tool's embedded expertise.

Although there have been research efforts to develop diagnostic methodologies for building HVAC systems for over a decade, only recently have commercial software tools become available. Consequently, there has been little detailed characterization of the tools and a limited awareness of their differences and capabilities by potential users. This study assesses diagnostic tools for use with large commercial building EMCS data, comparing the features of the tools for two audiences. First, a side-by-side tool comparison and evaluation attempts to give potential users (building operators, energy managers, engineers, energy service companies, and commissioning agents) an understanding of each tool's capabilities to help a user better assess options for implementation. Secondly, as feedback for ongoing diagnostic tool development, this work identifies important tool features and proposes direction for future work to assess and improve the tools. Tremendous potential exists for the utilization of data visualization and diagnostics techniques, and each tool offers valuable capabilities for diagnostic analysis.

This section introduces the tools selected in our comparison. Our study focuses on the implementation of third-party software tools with existing EMCS data, though some tools are intended mainly for short-term use with data loggers.

\section{Manual and Automated Diagnostics Defined}

The distinction between manual and automated diagnostic tools is not straightforward, since tools have various levels of automation in their data collection procedures, management and processing of data, and diagnostic use. We define manual diagnostic tools as aids to diagnostics that help extract information from raw data. Manual diagnostic tools require a knowledgeable user to identify problems using plots and information automatically generated by the tool. In contrast, automated diagnostics reduce or eliminate the need for human reasoning in detection and diagnosis of problems by automating the process of analyzing data (Brambley and Pratt, 2000). Automated diagnostic tools use a combination of models, statistical methods, and physical and expert rules to detect operational problems. Physical rules are derived from first principles, for example, from the laws of thermodynamics. Expert rules are "rules of thumb" 
gained from HVAC experts in the field. The following list shows the tools we have compared, which are organized by the primary level of diagnostic automation.

\section{Manual Diagnostic Tools}

- $\quad$ ENFORMA ${ }^{\circledR}$ Portable Diagnostic Solutions (ENFORMA software), Architectural Energy Corporation (AEC) (Frey, 1999)

- Universal Translator (UT), Pacific Gas and Electric's (PG\&E) Pacific Energy Center (Stroupe, 2000)

- Analysis Tools for Built-up Fan Systems (UCB Tools), University of California, Berkeley, Center for Environmental Design Research (Webster et al., 1999)

- Enterprise Energy Manager Suite (EEM Suite ${ }^{\mathrm{TM}}$ ), Silicon Energy (Silicon Energy, 2001)

\section{Automated Diagnostic Tools}

- Whole Building Diagnostician (WBD), Pacific Northwest National Laboratory (Brambley et al., 1998)

- Performance and Continuous Recommissioning Analysis Tool (PACRAT), Facility Dynamics Engineering (Santos and Brightbill, 2000)

The main features of each tool have been summarized in Appendix $C$ for easy reference. The tools selected for comparison were narrowed from a larger set of diagnostic tools based on the following criteria:

- The tool aids HVAC diagnostics with, at minimum, automatically created diagnostic plots or programmable alarms. More complex tools also automate detection and diagnosis.

- The tool has diagnostic capabilities for central plants and/or built-up air handlers, typical equipment found in large commercial buildings.

- The tool has the ability to import EMCS data (as opposed to only using data loggers).

Although Silicon Energy's EEM Suite has little focus on diagnostics, we have included this software as an example of a web-based tool. EEM Suite brings together remote data acquisition from EMCS and utility meters with visualization tools. Competitors to EEM Suite are ABB Energy Interactive, which acquires and analyzes interval meter data, and Tridium Niagara, an Internet-based distributed architecture for real-time access, automation, and system control.

In addition to purchasing software tools to analyze data, some control vendors market their diagnostic services. For example, Honeywell's Atrium provides remote, multiple site data acquisition coupled with the diagnostic services of Honeywell analysts. Atrium has developed tools mainly for internal use by their analysts. 
We briefly discuss the Information Monitoring and Diagnostic System (IMDS) developed by Supersymmetry and demonstrated by Lawrence Berkeley National Laboratory (LBNL) and partners through a CIEE project ${ }^{1}$ (Piette et al., 2000). The IMDS consists of a dedicated data acquisition system, separate from the control system, and a robust platform (high quality sensors, web-based remote access, high frequency archive) to which automated diagnostics can be implemented in the future. The IMDS does not incorporate pre-defined diagnostics, and therefore is not included as a diagnostic tool in our study. Electric Eye, advanced data visualization software utilized by the IMDS, is included in our comparison as an example of a high quality visualization tool.

The ACRx tool, developed by Rossi and Braun (1997), is a statistical, rule-based diagnostic tool for rooftop air conditioners. This tool is not covered by this assessment since it does not evaluate built-up air handlers.

These diagnostic tools are relevant for all climates and thus, are of national interest. In their current phase of development, the tools focus on air handler diagnostics, specifically, the outdoor-air economizer. Since the mild climate in California is conducive to economizer cooling, the tools have direct relevance to California.

\section{Energy Management Control System Data}

A goal of this report is to describe the current ability of software tools to utilize EMCS data. Each tool selected has the ability to use EMCS data, but this does not need to be their intended data source. For example, the tools meant for short term monitoring are built for use with data loggers, but have the capability to input EMCS data. While inputting EMCS data into these short-term tools is a less streamlined process than with the continuous monitoring tools, using the short-term tools to continuously detect performance problems can be valuable.

Newer EMCS have ability to extensively monitor a building using digital controls. There is great potential to use EMCS trend logs to assess building performance, but the use of this data for diagnostics must be evaluated on a site-by-site basis due to differences in EMCS trending and archiving capabilities (Heinemeier, 1994). Typically, even the new EMCS do not have embedded automated diagnostics, and it is often time consuming to export data from the EMCS into another software program (i.e., spreadsheets) for analysis.

This paper focuses on how to use EMCS data with diagnostic tools since these data points are often available for continuous trending. A data collection method like data loggers or a dedicated data acquisition system could be used to provide data for the specific purpose of diagnostics, although these methods may have a high initial cost depending on the quality of the system.

\footnotetext{
${ }^{1}$ California Institute for Energy Efficiency, Diagnostics for Building Commissioning and Operation Project. Collaborators include Lawrence Berkeley National Laboratory (LBNL), Supersymmetry, A. Sebald, and C. Shockman. See http://eetd.lbl.gov/ea/iit/diag/index.html
} 
While EMCS data are widely available for diagnostic use at no additional hardware cost, the data can be prone to problems with reliability, accuracy, and storage. EMCSs often report missing data, which can be caused by control system bottlenecks if too many points are trended at a high frequency. The EMCS generally provide only limited storage space for data archives.

EMCS are designed to control the building, not to provide data for diagnostics. Therefore, the EMCS may not have all the points required by a diagnostic tool. Additional points may need to be added, such as chilled water flow rate and whole building power. In this report, the adequacy of EMCS data for diagnostic analysis is not addressed (the PG\&E measurement study begins to examine these issues, see Section 2.2). The data are assumed to be reliable enough for use with diagnostic tools. Instead, we describe how the tools convert EMCS data into useful information.

\subsection{Techniques for Building Performance Assessment}

Before the tool comparison is presented, it is important to show how diagnostic tools fit within the spectrum of building performance assessment tools available. In the progression from macroscopic to microscopic assessment, building assessment tools can be organized into three categories: benchmarking, energy tracking, and diagnostics. The placement of each tool in this spectrum can extend into multiple categories. For example, diagnostic tools may provide benchmarking as well as diagnostics, but tools generally focus on one of the three areas. Table 1 summarizes this performance assessment hierarchy of techniques. 
Table 1 Building Performance Assessment Techniques

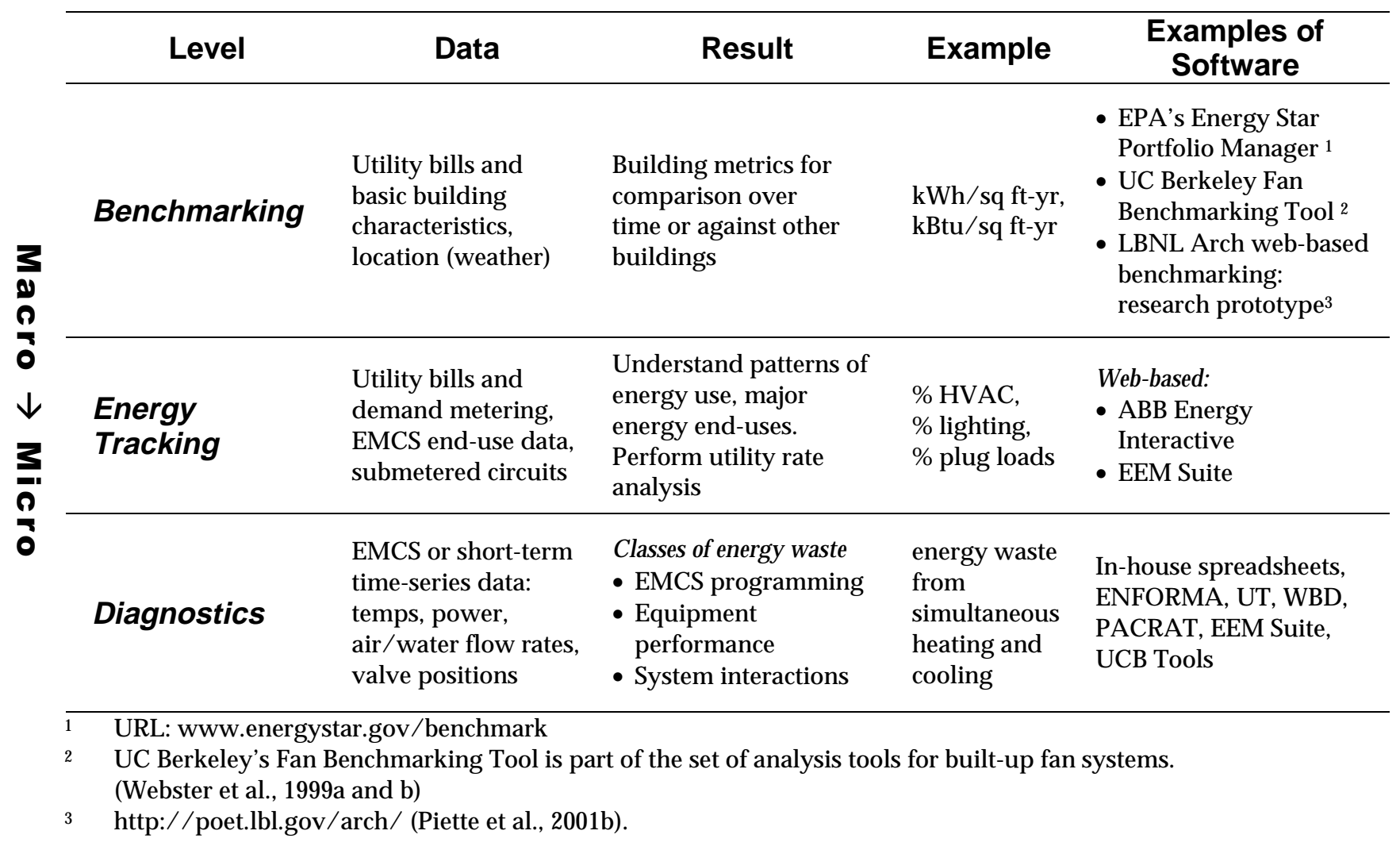

Benchmarking is a macroscopic level of performance assessment, where metrics are used to measure performance relative to others. Buildings are typically benchmarked using coarse data, often from utility bills, and some procedure for normalization for variables such as weather and floor area. One widely used tool is the Energy Star Buildings Label Portfolio Manager. This tool focuses on whole building energy benchmarking and calculates the building's percentile rank compared to a population of similar buildings. LBNL is also developing a web-based benchmarking tool for California buildings called Arch, which compares energy use intensity to a database of buildings (Piette et al., 2001b). In an effort to move benchmarking to a component-level, the UCB Fan Tools include fan performance benchmarking using one-time measurements. This fan benchmarking is briefly discussed in Section 4.2 on Tool Intent.

Tracking energy performance over time is a logical enhancement of one-time benchmarking. Energy tracking can result in an overall understanding of load shapes. Submetering to disaggregate whole building power measurements can help focus diagnostic efforts on major energy end-uses.

After these simple approaches to performance assessment, performing diagnostics is the next step for a better understanding of HVAC system performance. Diagnostics involve the evaluation of specific system and component operations. Although the data needed for diagnostics are more extensive than for energy tracking, this jump in complexity is essential to obtain the information needed to aid in correcting problems. Benchmarking and energy 
tracking are useful in identifying inefficiency at the whole building level and focusing efforts toward large energy end-uses, while diagnostics allows detection of specific problems and helps target the causes of these problems.

\subsection{Steps to Diagnostic Tool Application}

This comparative guide is organized around the progression of steps applied when using diagnostic tools. These steps are carried out in order, although the approaches that the tools take to each step ranges from manual to automated.

\section{Steps to diagnostics:}

1. Data acquisition

2. Data management and pre-processing

3. Problem detection

4. Problem diagnosis

\subsection{Project Objective and Scope}

The main objective of this report is to provide a clear comparison among current diagnostic tools, outlining their key features and assessing their capabilities. We limit the assessment to tools that can use EMCS data to diagnose HVAC systems typically found in large commercial buildings (built-up air handlers and central plants). The comparison is intended for two audiences. First, potential users can gain an understanding of the key capabilities of each tool. Second, this work gives tool developers feedback by identifying important features and next steps for tool research.

It is important to specify what our study does and does not assess. This report focuses on the comparison of diagnostic tool features, capabilities, and methods for use in existing buildings. Additionally, based on our experience operating the tools and observations of detailed demonstrations, we evaluate the tools and briefly identify barriers to implementation. It is not our intent to assess the market for these tools, nor study potential user acceptance of the features compared. A cost-benefit analysis for implementing the tools and a comprehensive analysis of case studies are also beyond our scope.

To make the information in this report available to a wide audience, sections of the report have been published in the proceedings of two conferences. For the 9 th National Conference on Building Commissioning in May 2001, we presented a comparison of diagnostic tool features (Friedman and Piette, 2001a). We focused on the economizer diagnostic evaluation and a general tool evaluation in our paper for the International Conference for Enhancing Building Operations in July 2001 (Friedman and Piette, 2001b). 
This report defines a comprehensive set of characteristics and compares them across a number of emerging diagnostic tools. Section 2 reviews the existing diagnostic tool literature, as well as literature that formed the starting point for our characterization framework. Section 3 sets forth the methods used to assess the tools, and Section 4 presents an overview and background for each tool, focusing on the scope, intent, and marketing. A detailed explanation of tool diagnostic features is presented in Section 5. While Section 4 and 5 characterize and compare the tools, Section 6 extends into an evaluation of each tool, including strengths, limitations, and challenges to use. A common tool diagnostic, the outdoor air economizer, is discussed in detail. Conclusions about the current state of diagnostic tools and perspectives on future research and development are set forth in Section 7. 


\section{$2.0 \quad$ Literature Review}

The literature review begins with a background of the information currently available about each tool. Next, we review diagnostic tool information from two recent reports on commissioning and diagnostics in California. Last, diagnostic tool characterization literature is introduced, which provided guidance for the comparison categories chosen in this report. Through this literature review, we identify the lack of comparative assessment of emerging diagnostic tools.

\subsection{Diagnostic Tool Literature}

While the need for and benefits of commissioning are beginning to be understood, less is known about tools to assist commissioning and diagnostics. Each of the tools evaluated have been described in previous literature, but few formal case studies or comparative analyses have been performed. The tool installations that have been documented do not give detailed cost information, as they focus almost exclusively on the benefits of using the tools. The tool literature and case studies are summarized below.

The WBD has been well described, with an extensive website that contains case studies from field test sites. The WBD outdoor air economizer module's basic function has been presented (Brambley et al., 1998), with an overview of the logic tree used to determine economizer states (Katipamula et al., 1999). One case study at a large hotel in San Francisco reported that the outdoor air economizer module identified a total of $\$ 6000 /$ year in energy waste for two 10,000 cfm air handlers (Pratt et al., 2000).

Potential interest in implementing and challenges in marketing the WBD were assessed through a focus group in 1998 (Heinemeier, 1999). The marketability assessment of the WBD was a product of a partnership between researchers at Pacific Northwest National Laboratories and Honeywell. The focus group participants had some reservations about the ability of the tool to save energy cost and time, and indicated that demonstration projects should be done to decrease uncertainty about the tool's effectiveness.

Descriptions of the ENFORMA software were initially published in 1994 (Waterbury et al., Arney and Frey). Additional publications give further tool details and describe the results of a case study (Frey 1999, Arney and Frey 1999). One office building that utilized ENFORMA diagnostic tools identified potential savings of over $17 \%$ of monthly energy costs. The developers have also developed brief case histories for use in their marketing materials, which show simple payback periods of less than one year with about $10 \%$ energy savings achieved using the ENFORMA software (ENFORMA, 1999). These case studies use the ENFORMA software as an aid to detection, but require additional HVAC expertise for the identification and diagnosis of problems.

The EEM Suite has sales literature that includes little detail about specific tool features. Silicon Energy provides potential customers one-page "Success Stories" that include quantitative and qualitative benefits to implementation of EEM Suite modules (Silicon Energy, 2001). No conference or related papers are available for this tool. 
A paper reporting on PACRAT describes the main features and one case study in limited detail (Santos and Brightbill, 2000). This case study gives an overview of the energy waste of equivalent to $\$ 250,000$ /year identified through the implementation of PACRAT at a National Security Agency building. These field results do not include supporting documentation of specific problems detected or diagnosed. Details about PACRAT installations exist on a password protected section of Facility Dynamics Engineering's website.

Pacific Northwest National Laboratory (PNNL) scientists have written two papers that include information on diagnostic tools in addition to the WBD. They describe the WBD's outdoor air economizer module, with brief reference to other commissioning tools, including the ENFORMA software, ACRx, the IMDS, and EMCS trending (Brambley et al., 1999). This work presents a paragraph with the major features of each tool. In addition, Brambley and Pratt (2000) have explained the use of automated diagnostic tools in the context of energy service business opportunities. In this paper, they provide definitions for automated and manual diagnostics and list benefits to automating diagnostics.

\subsection{California Studies Related to Commissioning and Diagnostics}

Recently, two commissioning-related studies were completed in California. Each of these projects included elements related to the use of tools for commissioning and diagnostics in commercial buildings.

In 1999, Pacific Gas and Electric (PG\&E) published a report for the California Energy Commission that detailed a method for determining the measurement accuracy and storage frequency necessary for data acquisition in HVAC systems (Fromberg et al., 1999). A costbenefit analysis based on energy simulations (spreadsheet analysis) of buildings in two climate zones was performed to assess potential energy waste due to sensor inaccuracies. Additionally, the study determined appropriate data storage frequencies based on an assessment of example plots. As a part of the HVAC system background for the assessment, plots for use in chiller and air handler system diagnostics are also presented. This report points to and begins to address the need for a rigorous assessment of data quality requirements for diagnostics.

PG\&E also funded a California commissioning market characterization project, prepared by Portland Energy Conservation, Inc. (PECI, 2000). Surveys of commissioning providers and building owners showed that tools were desired to aid commissioning. A literature review for commissioning presented a brief background of commissioning tools, including the WBD, the ENFORMA software, the IMDS, and the Virtual Mechanic (ACRx). 
The framework for our diagnostic tool comparison has drawn upon two previous efforts to characterize diagnostic tools. To identify a framework for assessing the value and usability of a diagnostic tool, marketability requirements for commercial building diagnostic tools were developed (Heinemeier, 1998). Heinemeier evaluated eight categories for tool marketability:

- Intent of system: short-term or long-term, level and scope of diagnostics

- System value: systems diagnosed, probability and consequences of problem, detection alternatives

- Action to be taken: identify action with diagnostic

- Required system reliability: probability of false alarm and correct failure detection

- Notification: means of notifying the user of a fault.

- User: Building operator, on-site expert, remote expert

- System Cost: Hardware, software, services

- Market: building size and type

These categories influenced our methodology for characterizing and comparing the tools, but we have organized our tool assessment differently. First, we provide an overview of key features and characteristics such as tool intent, users, market, and system cost. Then, we present an operational assessment, which is organized around our view of the progression of steps to diagnostics (see Section 1.5 for the list of steps). Each of Heinemeier's categories is covered in this report within this alternative organization.

The second body of work that influenced the comparative framework for this report is the CIEE Project on Diagnostics for Building Commissioning and Operation (Piette et al., 2000). The CIEE project studied the attributes of diagnostic systems and developed continuous performance measurement techniques for field-testing in a prototype system, referred to as the Information Monitoring and Diagnostic System (IMDS). The CIEE Phase I work assessed the state of diagnostics technology and defined the focus of the IMDS (Sebald and Piette, 1997). The diagnostic system architecture (top-down/bottom-up, automatic/manual, temporary/continuous monitoring) was presented as well as important performance metrics and plots for manually diagnosing faults in chillers and cooling towers. The architecture representation and the diagnostic techniques highlighted (i.e., performance metrics, load shapes, load duration curves) influenced the design of our characterization framework.

The need for a more comprehensive analysis of diagnostic tools is apparent, since no detailed comparison of the tools has been performed. The individual papers and supporting product marketing literature do not provide detail on tool features. This lack of information is due in part to the relatively recent development of the tools. The recent market characterization study for PG\&E found that many potential users do not realize that the tools exist (PECI, 2000). An evaluation can provide this information. 


\subsection{Study Methods}

Our analysis of diagnostic tools utilizes three methods to gain an understanding of the tools and form a framework for characterization and comparison. First, where possible, the tools were acquired by LBNL for our own use. We attempted to input data into the tools in order to evaluate their features. Next, the tool developers were extensively interviewed regarding tool background, implementation, features, underlying methods, and future development. Last, throughout the information gathering process, a framework for characterization was developed to focus on important tool features. In this report, the comparative analysis is summarized in a series of tables.

Our initial strategy was to enter a dataset with known faults into each tool to test its diagnostic accuracy and ease of use. We were not able to complete this task for several reasons. First, only four of the six tools were obtained. PACRAT and the EEM Suite were not purchased because of their high price. Second, we were not able to input data into the WBD, which required PNNL assistance for implementation. Therefore, the initial methods were modified to focus on using the tools where available, and testing was not done in a formal sense. We were able to enter data into the UT, the ENFORMA software, and the UCB Tools. A comparison of the ease of use or formal diagnostic testing has been left for future work.

With varying levels of completion and commercialization, many tools do not have detailed documentation or manuals, so the process of using and understanding the tools was difficult. Interviews with the tool developers and demonstration and training sessions provided the needed assistance in understanding the tools. We attended a day of training on PACRAT, and also received a two-hour demonstration of PACRAT's features. Silicon Energy also demonstrated their EEM Suite modules. Tool developer interviews and subsequent follow-up communication were performed during winter 2000-2001.

Defining the categories to characterize the tools required a detailed understanding of both tool operations and important features for different users. A comprehensive set of features has been compared, including tool background, costs, data acquisition, data pre-processing and management, and manual and automated diagnostic methods. It has been left up to the reader to recognize what characteristics are important for their particular application. The characterization categories were loosely based on Heinemeier's work $(1998,1999)$. The CIEE Phase I work was also drawn upon for its diagnostic technology assessment criteria (Sebald and Piette 1997).

A parallel comparison of these diagnostic tools is difficult since the diagnostic tools are intended for different users and systems, with differing levels of automation. Even though the tools have many scenarios for implementation, all tools have a common focus on improving building operations.

The comparison framework required explicit definitions for terms that are often used loosely, such as benchmarking, diagnostics, manual diagnostics, and automated diagnostics. Future comparisons of diagnostic tools will be facilitated by our terminology definitions and comparison structure. 


\subsection{Tool Overview}

Section 4 presents an overview of the scope, intent, background, and current market status of each tool. Since these tools have different levels of commercialization and different diagnostic purposes, it is important to approach the analysis of the diagnostic tools with an understanding of these overview issues. This overview sets the context for the comparisons of operational use in Chapter 5.

\subsection{Tool Scope}

One purpose for comparing diagnostic tools is to present the spectrum of tool capabilities and place each tool within that spectrum. The following graphic describes the different pieces of a diagnostic system. The EMCS provides the data for the tools studied and, therefore, the tool scope begins with the acquisition of this data from EMCS control points. To place the IMDS project in this context requires a widening of the diagnostic system scope to include sensors and additional control points separate from the EMCS. Some tools can automatically acquire data from the EMCS and use databases for archiving this data. Pre-processing is used to prepare the data for analysis through synchronization, averaging, and filtering for erroneous and missing data. Most tools then allow various raw data visualization techniques for manual diagnostics. Additional manual and automated diagnostic procedures help detect and diagnose problems. Figure 1 depicts how the tools fit into this representation of system architecture.

\begin{tabular}{|c|c|c|c|c|c|c|c|}
\hline Sensors & $\begin{array}{l}\text { Control } \\
\text { points }\end{array}$ & $\begin{array}{l}\text { Auto data } \\
\text { acquisition }\end{array}$ & Archive & $\begin{array}{c}\text { Pre- } \\
\text { process }\end{array}$ & $\begin{array}{c}\text { Data } \\
\text { Visualize }\end{array}$ & Detect & Diagnose \\
\hline \multicolumn{7}{|c|}{ IMDS } & \\
\hline \multicolumn{8}{|c|}{ EEM Suite } \\
\hline \multicolumn{8}{|c|}{ PACRAT } \\
\hline & & \multicolumn{3}{|c|}{ WBD } & Limited & & \\
\hline & & & & \multicolumn{3}{|c|}{ UT } & Limited \\
\hline & & & & \multicolumn{3}{|c|}{ ENFORMA } & \\
\hline & & & & & \multicolumn{2}{|c|}{ UCB Tools } & \\
\hline
\end{tabular}

Figure 1 Tool Scope

As indicated in Figure 1, the EEM Suite, PACRAT, and the WBD have automated data acquisition and archiving for continuous analysis. By contrast, the UT, the ENFORMA software, and UCB Tools require manual data acquisition and do not have archiving capabilities.

The IMDS includes high quality sensors and advanced visualization using the Electric Eye software. Since the IMDS does not have pre-defined diagnostic plots, we do not include it in our analysis except in the comparison of data visualization techniques. 
The shaded region for the WBD represents their limited data visualization capabilities compared to the other tools. To focus on the needs of operators, the WBD has been designed for communication of diagnostic results, without requiring interpretation of diagnostic plots. The UT's treatment of diagnosis is much less complex than PACRAT or the WBD, and therefore this area is also shaded. PACRAT and the WBD focus on providing automated detection and diagnosis. Even though most tools do not diagnose problems, they are still considered diagnostic tools since they provide automation to problem detection.

\section{Overview of Major systems served}

Since the focus of this study is large commercial buildings, the comparison focuses on the diagnostics that apply to the typical systems found in these buildings: built-up air handlers, central cooling plants, and distribution systems. The following list is an overview of the major systems served by the tools. The data required, problems detected, and methods used to detect the problems are detailed in Chapter 5 on operational use.

- The ENFORMA software is used for short-term analysis to aid diagnostics in many system types, including air handlers, cooling towers, chillers, heating plants, and zone distribution systems. The tool processes data and requires the user to manually compare data to predefined reference plots.

- The UT's primary strength is in synchronization of multiple data sources such as EMCS data and data loggers. The tool also has diagnostic modules for outdoor air economizers and equipment run-time and cycling.

- The UCB Fan Tools have unique capabilities to benchmark fans using one-time measurements, but since we have limited our analysis to time-series data, we do not review this feature. We focus on UC Berkeley's five spreadsheet modules for time-series data that include the analysis of fan power, system temperatures, zone temperatures, reheat, and static pressure.

- The WBD is an automated tool for continuous analysis of economizers (outdoor air economizer module-OA/E) and whole building or central plant energy consumption (whole building energy module - WBE).

- PACRAT provides continuous analysis and is both broad and in-depth in its automated diagnostic capabilities. PACRAT's automated diagnostics address the air handlers, chillers, hydronic system, whole building energy, and zone distribution.

- The EEM Suite uses a web-interface for continuous display and manipulation of utility, EMCS, and related time-series data connected through gateways. The tool provides data visualization, but there are no pre-defined diagnostic plots. The EEM Suite consists of ten modules. The modules of interest to diagnostics are the Energy Analyst, Data Analyst, Enterprise Navigator, Alarm Manager, and Universal Calculation Engine. 


\section{Top-Down or Bottom-Up Diagnostics}

The scope of each tool is related to its diagnostic approach, which can be described as "topdown" or "bottom-up". A top-down approach starts with high-level data (i.e., whole building electric consumption) to reason about causes of equipment-level problems. A bottom-up approach uses lower level performance data to detect problems (i.e., temperatures, pressures, valve position) and then may approximate an aggregated effect for the whole building (House, 2000). Tools that use both approaches provide more options for users to investigate problems.

The WBD's whole building energy (WBE) module and PACRAT utilize a top-down approach by creating a baseline for historical energy use for whole building energy and other submetered components. The WBE and PACRAT create baselines for systems and individual pieces of equipment, which can be thought of as "intermediate level top-down" diagnostics.

EEM Suite's strength is in top-down analysis as an energy tracking tool, but the tool has the capability to collect EMCS data for manual bottom-up analysis. The WBD's outdoor air economizer module and the prime strength of PACRAT's diagnostic capabilities focus on bottom-up approaches to pinpoint system problems. The ENFORMA software, the UCB Tools, and the UT are bottom-up tools, relying exclusively on component-level data from an EMCS or dataloggers.

\section{Software Platform}

The tools use a variety of software platforms. PACRAT, WBD, and the UT utilize SQL databases (Microsoft Access) to store data. PACRAT also has extensive visualization features from a third-party graphing tool. The ENFORMA software stores data in a proprietary binary format. The UCB Tools utilize spreadsheets, but plan to move to a database format in the future.

The EEM Suite's SQL database is located on a remote server, giving ample hard-disk space for long-term data collection. The EEM Suite uses an OLAP (on-line analytical processing) technology that works with the database to roll data into hourly, daily, and monthly bins to allow for faster calculations. The front end of the EEM Suite utilizes a graphing tool as well as a web-browser.

\subsection{Intended Use}

The scope of each diagnostic tool is directly related to its intended use. As described in the introduction in Section 1.3, some of the tools were not developed for utilization with EMCS data, but they all have the capability to analyze such data. The short-term tools (ENFORMA, UT, and the UCB Tools) are intended for commissioning or retrofit analysis using data loggers, but these tools can also import formatted data files from any source, including EMCS data. In contrast, the WBD, PACRAT, and EEM Suite were designed to continuously evaluate EMCS data. EEM Suite's web-based platform allows comparisons across campuses of buildings accessed remotely. The WBD and PACRAT are able to assess data from multiple buildings 
connected to a network. PACRAT and EEM Suite can directly compare diagnostic results for multiple buildings.

The diagnostic tools have different levels of automation, which are directly related to their intended function. If the tool is intended for short-term use, automated features may not be as crucial, since data are not analyzed in daily operations. If tool users are experienced in energy analysis or if the tool is used for one-time commissioning or retrofit projects, there may be less need for automated methods of diagnosis. For continuous data analysis, fully automated diagnostic procedures are valuable for both efficient detection and to enable less technically knowledgeable users to perform diagnostics. For both short-term and continuous analysis tools, automation can greatly reduce the time needed to acquire data and examine the data for problems.

\section{Additional Features}

Many of the tools perform more analyses than are included in our definition of diagnostics. Examples of applications beyond diagnostics include competitive energy procurement, monitoring and verification for performance contracting, and retrofit analysis. This paper focuses on the features of the tools as they relate to diagnostics for operations, and we do not evaluate these additional features. These features are beneficial to certain users and give more versatility to the tools, but are outside the scope of this study. For completeness, the additional features are described briefly below.

- Monitoring and verification (M\&V): Many of the tools have the capability for use in monitoring energy savings for performance contracting purposes, limited by the required level of sophistication of the M\&V. PACRAT and the WBD are the most extensive $M \& V$ tools since their models can be used to define baseline consumption. The second ENFORMA module, the Lighting Evaluation System, estimates annual savings from lighting retrofits using short-term monitored or estimated data.

- Retrofit analysis: In addition to the verification of retrofit savings, some tools have modules that provide retrofit screening analysis. The UT has modules that calculate cost savings from installing occupancy sensors for efficient control of lighting and plugloads. The ENFORMA Lighting Evaluation tool outputs lighting load shapes and calculates energy conservation potential from scheduling changes and retrofits, including changes in cooling and heating energy consumption.

- Energy procurement: One of EEM Suite's strengths lies in its use as an energy accounting tool, with capabilities in utility bill analysis, rate analysis, load forecasting, and load curtailment communications to aid building participation in utility load-shedding programs.

- Control capability: Silicon Energy's gateways have the capability for two-way control with the existing EMCS. This allows users to implement limited control from a remote location through a web browser. 
- Fan Benchmarking: One of UC Berkeley's Fan Tools assesses fan performance using onetime power, flow, pressure, and fan speed measurements for benchmarking against fans of similar type. The Fan Performance Analysis tool compares speed-corrected fan metrics for measured and design data to calculate fan efficiency, motor load factor, system operating point, flow density (cfm/sq ft), specific fan power (watts/cfm), and fan efficiency ratio (measured efficiency/design efficiency). This application of component-level benchmarking is unique.

- Design decisions: PACRAT developers suggest that archived metrics from the performance characterization module can be used to inform future design decisions (i.e., measuring actual cooling load/sq ft and downsizing future cooling plants).

\subsection{Tool Background}

A summary of the status of the tools is presented in Table 2. The commercialization stage is given here for reference, with detail discussed in Section 4.4 on market issues. All tools are relatively new and are continuing to be enhanced.

Table 2 Diagnostic Tool Background

\begin{tabular}{|llll|}
\hline & \multicolumn{1}{c}{ Developer } & \multicolumn{1}{c|}{ Stage } & \multicolumn{1}{c|}{ Funding } \\
\hline ENFORMA & Architectural Energy Corporation & Commercialized in 19966 & $\begin{array}{l}\text { EPRI* cost-share } \\
\text { and private }\end{array}$ \\
\hline UCB Tools & $\begin{array}{l}\text { Center for Environmental Design } \\
\text { Research, UC Berkeley }\end{array}$ & Prototype in 1999 & CIEE, CEC** \\
\hline UT & $\begin{array}{l}\text { Pacific Energy Center, Pacific Gas \& } \\
\text { Electric Company (PG\&E) }\end{array}$ & Beta testing in 2000 & $\begin{array}{l}\text { California public } \\
\text { goods charges }\end{array}$ \\
\hline WBD & $\begin{array}{l}\text { Pacific Northwest National Laboratory } \\
\text { (PNNL), Honeywell, and University of }\end{array}$ & $\begin{array}{l}\text { Prototype with pilot } \\
\text { projects in 1998 }\end{array}$ & $\begin{array}{l}\text { U.S. Dept. of } \\
\text { Energy }\end{array}$ \\
\hline PACRAT & Folorado & Commercialized in 1999 & Private \\
\hline EEM Suite & Silicon Energy & Commercialized in 1998 & Private \\
\hline IMDS & $\begin{array}{l}\text { Supersymmetry, LBNL, En-Wise, } \\
\text { C. Shockman, A. Sebald }\end{array}$ & $\begin{array}{l}\text { Prototypes in } \\
1998 \text { and 2000 }\end{array}$ & $\begin{array}{l}\text { CIEE, U.S. Dept. of } \\
\text { Energy, CEC }\end{array}$ \\
\hline
\end{tabular}

* Electric Power Research Institute

** California Institute for Energy Efficiency, California Energy Commission

The ENFORMA software was one of the first diagnostic tools commercially available and has been utilized for commissioning and retrofits using the AEC MicroDataLogger® product. The UCB Tools are a part of a research project to develop measurement and analysis protocols for detecting problems in built-up air handling systems. The UT is intended for use with data loggers, which are available to PG\&E customers through the Tool Lending Library at PG\&E's Pacific Energy Center. The WBD development was led by researchers at PNNL who saw the need for automated diagnostic tools for use with EMCS data. PACRAT was developed by HVAC controls engineers to streamline the process of providing retro-commissioning services 
and is now available for use as a stand-alone tool. Silicon Energy has developed the EEM Suite mainly for remote web-based energy tracking and energy rate structure analysis at large buildings or groups of buildings. The IMDS has been demonstrated in an office building in San Francisco (Piette et al., 2000), and is currently being implemented at a second building in Sacramento.

Four of the six tools (the UCB Tools, the UT, the WBD, and the IMDS) have had government funding for research and development. The ENFORMA tool, though not publicly funded, was funded through EPRI for use by utilities and utility commissioning programs. It is important to note that all the tools studied are leaders in the emerging field of diagnostic tools.

\subsection{Market Issues}

Now that the basic scope and intent of the tools have been discussed, it is important to understand the current user base and the implementation cost of the diagnostic tools. Again, the tools offer a wide range of capabilities beyond diagnostics and have had different levels of public funding.

Table 3 Tool Marketing Issues 1

\begin{tabular}{|c|c|c|c|c|c|}
\hline & Stage & Users & $\begin{array}{c}\text { Software } \\
\text { cost }\end{array}$ & $\begin{array}{l}\text { Config. \& } \\
\text { training } \\
\text { cost }\end{array}$ & $\begin{array}{l}\text { Software } \\
\text { upgrades \& } \\
\text { support }\end{array}$ \\
\hline ENFORMA & $\begin{array}{l}\text { commercialized } \\
1996\end{array}$ & $\begin{array}{l}\text { - internal use: } \sim 300 \text { buildings } \\
\text { - Over } 50 \text { software licenses } \\
\text { - HVAC service providers, } \\
\text { energy managers, } \\
\text { engineering consultants }\end{array}$ & $\begin{array}{l}\$ 495 \text { per } \\
\text { license (two } \\
\text { installations) }\end{array}$ & $\begin{array}{l}\$ 800 / \text { day + } \\
\text { travel }^{3}\end{array}$ & $\begin{array}{l}\text { Phone support } \\
\text { with software. } \\
\text { Consulting } \\
\text { services } \\
\text { available for } \\
\text { fee. }\end{array}$ \\
\hline UCB Tools & prototype 1999 & $\begin{array}{l}\text { - Plans to populate database } \\
\text { by demonstration projects } \\
\text { - Potential: ESCO, energy } \\
\text { managers }\end{array}$ & free & not available & not available \\
\hline UT & beta testing 2000 & $\begin{array}{l}\text { - Over } 50 \text { users } \\
\text { - Engineering consultants, } \\
\text { energy managers }\end{array}$ & free & not available & not available \\
\hline WBD & $\begin{array}{l}\text { prototype with } \\
\text { pilot projects } \\
1998\end{array}$ & $\begin{array}{l}\text { - } \sim 10 \text { sites, } 200 \text { buildings } \\
\text { - Operators, HVAC service } \\
\text { providers }\end{array}$ & not available & not available & not available \\
\hline PACRAT & $\begin{array}{l}\text { commercialized } \\
1999\end{array}$ & $\begin{array}{l}\text { - } ~ 10 \text { sites, } 50 \text { buildings } \\
\text { - Operators, energy managers, } \\
\text { facility planners and } \\
\text { designers. }\end{array}$ & $\begin{array}{l}\$ 10 \mathrm{~K}-30 \mathrm{~K} \\
\text { (includes } \\
\text { training) }\end{array}$ & $\begin{array}{l}\$ 400-800 \text { per } \\
\text { system }\end{array}$ & not available \\
\hline EEM Suite & $\begin{array}{l}\text { commercialized } \\
1998\end{array}$ & $\begin{array}{l}\text { - } 1000 \text { sites and } 2500 \text { buildings } \\
\text { - } 25 \text { utilities and energy } \\
\text { service providers and } 15 \text { end } \\
\text { users }\end{array}$ & $\begin{array}{l}\text { Basic } 2: \\
\$ 40-50 \mathrm{~K} \\
\text { additional } \\
\text { modules: } \\
\$ 10-25 \mathrm{~K}\end{array}$ & $\begin{array}{l}\text { Approx. } 35 \% \\
\text { of software } \\
\text { cost }\end{array}$ & $\begin{array}{l}18 \% \text { of } \\
\text { software cost }\end{array}$ \\
\hline
\end{tabular}

All costs and user figures are approximate.

Basic includes one module, server, and gateway for 250 points.

ENFORMA software training is optional. 


\section{Tool Users}

Few tools have been implemented at a large number of site to date, as the development process continues in custom installations. The future utilization of these tools may include different versions tailored to many types of users, including engineers, energy managers, operators, commissioning agents, and energy service companies.

The intended users for the short-term monitoring focus of the ENFORMA software, the UCB Tools, and the UT are consulting engineers and facility managers that wish to retro-commission their building. The ENFORMA software has been used extensively through the developer's consulting services. Several HVAC technical service providers and other engineering consultants have also used the ENFORMA software. The UCB Tools are a research prototype, currently without external users. The UT is further along in testing than the prototype tools, with approximately 50 active beta testers. The UT is being licensed to the Pacific Energy Center and will be made available to the public. The tool is targeted to engineers and energy managers using multiple data collection devices (data loggers and EMCS).

The long-term monitoring tools (WBD, PACRAT, EEM Suite) are currently used by operators and energy managers at large buildings or campuses with central direct digital control systems. PACRAT developers anticipate a wide variety of users, including building operators, energy managers, facility planners and designers, and energy service companies. While PACRAT is the most advanced in its scope and automated diagnostic capabilities, it is also a complex tool that requires significant involvement from the developers to apply it. PACRAT has been implemented mainly at universities and government facilities.

The WBD was installed through pilot projects at PNNL's laboratory campus, as well as at a large hotel, large office building, and at 90 Department of Energy buildings at the Hanford, Washington site. A municipal district heating and cooling plant has also implemented the WBD WBE module, serving around 100 buildings.

The EEM Suite has been implemented at large campuses or companies with buildings located at multiple sites, referred to as an "enterprise". In addition, utilities purchase EEM Suite modules to distribute to their customers, mainly for energy and load reduction tracking.

\section{Tool Stage and Cost}

All of the tools are undergoing constant development. Data acquisition algorithms and diagnostic modules are updated and added as implementation at the initial sites occur. The ENFORMA software and EEM Suite are currently commercially available. PACRAT developers provide custom installation and program additional features based on user needs. The prototype WBD is intended to be commercialized through a third-party and is currently available for licensing for commercialization. Through another California Energy Commission Public Interest Energy Research project (CEC PIER), the WBD will soon be demonstrated in three modes of use: by operators of a large office building (Symphony Towers in San Diego), by the manager of multiple buildings from a central site (Alameda County, California), and by an HVAC service provider. The UT is public domain software and will remain free of charge after 
licensing to the Pacific Energy Center occurs. The UCB Tools are an early prototype, with intent for an external commercialization path.

The cost categories are broken down in Table 3 by software license cost, configuration and training, and upgrades and support. It is difficult to compare prices across tools, since each tool has different capabilities. PACRAT is the most advanced diagnostic tool commercially available and EEM Suite is the most extensive data acquisition and management tool, and therefore, these tools cost more. The WBD is not yet commercialized, so its cost is marked "not available" in Table 3.

With the purchase of some tools, the user also receives the HVAC expertise of the developers in the configuration process. This service aspect is especially true with PACRAT, as the developers guide the configuration and initial use of the tool. The EEM Suite developers provide installation support, but diagnostics support is not included. The ENFORMA software provides HVAC consulting with the initial tool configuration and training. The WBD developers have had extensive involvement with installation and the interpretation of diagnostic results at each pilot site. 


\subsection{Comparison of Operational Use}

A detailed explanation and comparison of tool diagnostic features is presented in Section 5. This section is organized around the four steps to diagnostic tool application, previously presented in Section 1.5. The characteristics we compare include data acquisition and preprocessing, problems detected, data visualization techniques, and diagnostic capabilities and methods.

\subsection{Data Acquisition}

Inputting data into the diagnostic tools is the first step in their operation. Each tool calls for numerous EMCS trended points and one-time set-up data. Potential tool users should evaluate the requirements for trending and configuration to make sure these requirements are appropriate for use with their EMCS data acquisition capabilities. The following section details issues for data acquisition.

What points do you need to run the software?

Table 4 identifies the data points for collection by the EMCS and the set-up information needed to run each system diagnostic module. The system set-up data can include schedules, setpoints, and design information. These data enable the tools to detect the problems listed in Table 5 in Section 5.3.1.

EMCS control functions may be inhibited when large numbers of points are trended at high frequencies, depending on the limitations of the EMCS. Operators should be aware of this possibility when selecting the number of points and frequency to trend. 


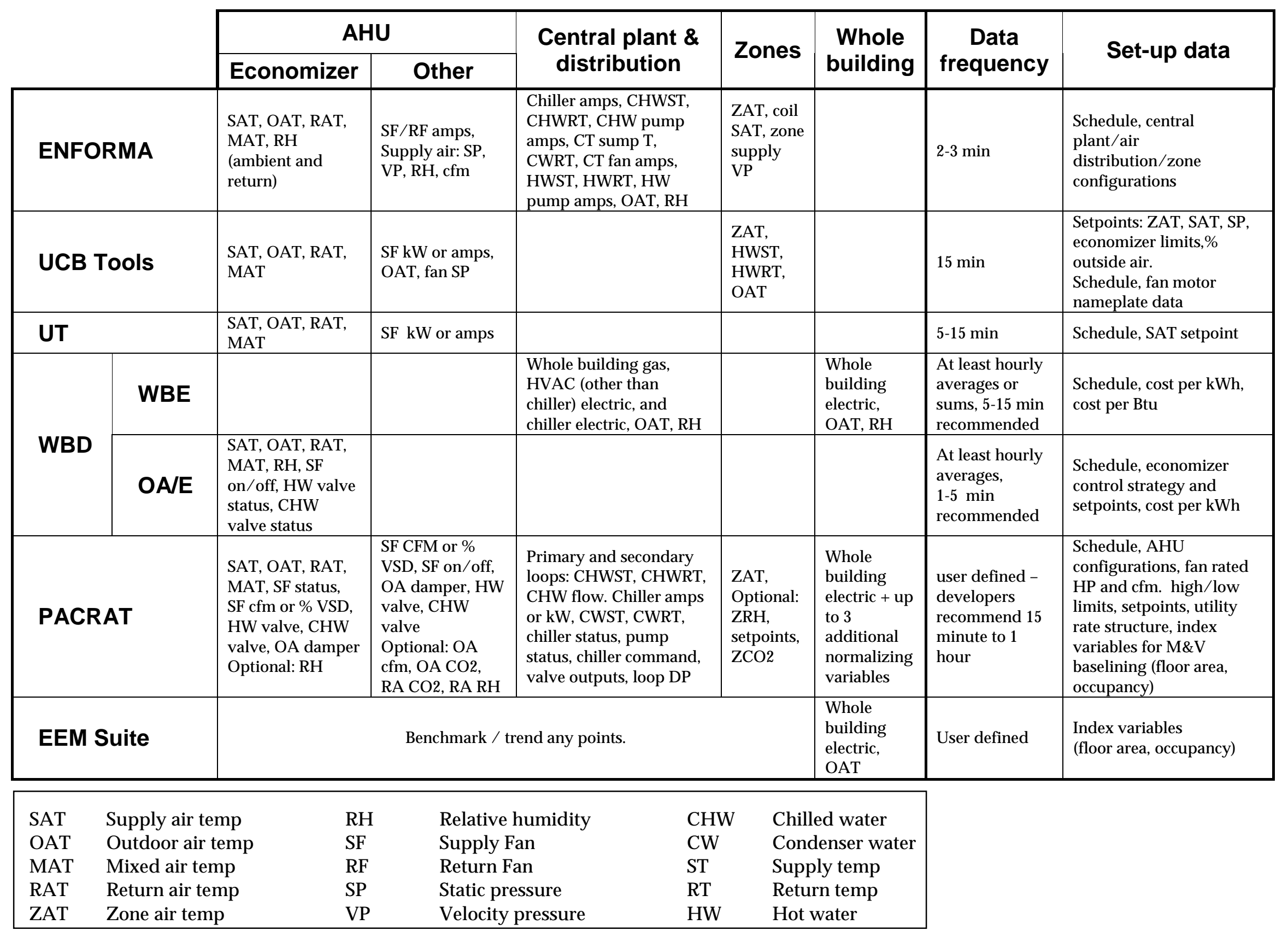


The EEM Suite differs from the other tools since specific EMCS points are not required. Automated diagnostics are not available without alarms being programmed by the user. Through benchmarking functions, energy can be indexed to floor area or occupancy rates, or normalized for outdoor air temperature.

The airside economizer is the common system evaluated by all of the tools except the EEM Suite. Each tool needs system temperature data (mixed air, outdoor air, return air, and supply air) to calculate the outdoor air fraction ${ }^{2}$ for the economizer diagnostic (see Section 6.1 for a detailed discussion). The ENFORMA software, PACRAT, and the WBD utilize enthalpy data for enthalpy-controlled economizers. Additionally, PACRAT checks the outdoor air damper output for a faulty signal. PACRAT's and WBD's economizer diagnostics use fan status and cooling/heating valve status in the energy waste calculation. The other air handler diagnostics generally require fan data, duct static pressure, and damper and valve control signals (PACRAT only).

The ENFORMA software and PACRAT utilize many temperature, flow, and power measurements for the central plant. The WBE requires central plant energy consumption data and ambient temperature and humidity for normalization. Few tools focus on zone terminal units except when detecting deviation from setpoints (the ENFORMA software, the UCB Tools, and PACRAT) and the analysis of reheat temperatures (UC Berkeley). Whole building power is necessary for use in the EEM Suite's benchmarking function and in both WBD and PACRAT's energy baseline models. PACRAT and EEM Suite also provide whole building power load shapes for manual analysis.

Tool developers recommend time-series data collection frequencies based on the type of system diagnostics and the data processing power of the tool. For all tools, the frequency is constrained by the limitations of the user's EMCS data collection process. The EEM Suite is operated with polling frequencies based on the EMCS capabilities and the frequency that the utility server updates the interval meter data. The WBD's sub-hourly data collection is important to help eliminate noise and improve diagnostic results, even though diagnostic processing and display of results is done on an hourly basis. All of the other tools generally require data at a 15-minute frequency.

The HVAC (or occupancy) schedule is required as set-up information for all of the tools. The UCB Tools, UT, WBD's OA/E, and PACRAT require setpoints for system temperatures and economizer controls. PACRAT requires more extensive system information such as high/low operational ranges for most points.

There are no minimum data requirements to run the ENFORMA software. The set-up variables describe the system type, which the software uses to create a data collection plan. If trended data are input according to this plan, all relevant diagnostic plots are automatically created. If not, then the tool produces a subset of the plots. All of the other tools except EEM Suite have minimum data requirements.

\footnotetext{
${ }^{2}$ outdoor air fraction $(\mathrm{OAF})=($ MAT-RAT $) /(\mathrm{OAT}-\mathrm{RAT})$
} 


\section{How is the tool configured?}

Moving time-series data into a diagnostic tool is a critical step that may require technical assistance for new users. The short-term tools import text files, while the continuous analysis tools rely on automated data acquisition through links to the EMCS data.

The ENFORMA software requires specifically formatted headers in ASCII text files that specify the collection frequency and time range. The ENFORMA software assumes that the data are sequential (see sample input file in Appendix B1). The UT has an interface that helps import data from text files so the date and time are not required in a predefined configuration. Unlike the ENFORMA software, the UT retains the timestamp with each point. To input data into the UCB Tools, the user simply pastes data into the input screen in the spreadsheet.

EEM Suite, PACRAT, and the WBD can acquire data by directly polling the EMCS for each data point, or by using the EMCS to create trend logs of selected data points, and "grab" this data from the trend files and into the tool. These tools have routines to capture EMCS data, programmed separately for each controls manufacturer. The tools add to the list of control systems to which they are able to link as the software gateways and interfaces to help access the EMCS data are developed.

Although the WBD can access trended data from EMCS trend logs, the tool typically makes direct connections to bring the data into the WBD database as it becomes available rather than using the EMCS trending capability. To use a direct connection to the data, the EMCS data polling network must be robust enough to withstand network traffic from the polling, which can potentially disrupt the core control functions of the EMCS. EEM Suite also polls the data from the EMCS directly through the gateways. In contrast, PACRAT uses only data that has been trended by the EMCS.

PACRAT has extensive help files that describe configuration, but since the process is quite involved, a Facility Dynamics engineer typically performs the configuration. Trends must be created within the EMCS and then the engineer assigns each point to the appropriate database tables and inputs operational thresholds for problem reporting. The user can run the PACRAT analysis on an computer on-site, or the tool developers can download the data from an file transfer protocol (ftp) site, process it, and send the results back to the user. For this method, the user is equipped with a "viewer" version of PACRAT, which permits diagnostic output viewing and visualization, but excludes the processing step.

PNNL scientists configure the WBD at each pilot facility, linking the control system data to the tool. For the pilot facilities, the WBD is run off-line at PNNL for the initial analysis, after which the tool is installed on site for the operators to use in real-time. The Architectural Energy Corporation typically trains users and configures the ENFORMA software, including assistance with initial analysis. The Pacific Energy Center supports beta testing questions about the UT and occasionally has free training seminars. The EEM Suite software includes gateway installation, consulting on which points to include, and training on applications, with additional consulting available. 
The tools vary in the time and effort required for configuration. Since current tool users were not surveyed, this question was not studied in detail.

\subsection{Data Archiving and Pre-Processing}

Once the tools access the data, the data are archived, and pre-processed for use in diagnostics. Since EMCS data have the potential for missing and erroneous values, some tools include time stamp synchronization and data validation procedures.

\section{Archiving}

To streamline the analysis of historical data and create a data management structure, some tools archive data. In a database, PACRAT archives all raw data, as well as summary data such as performance metrics and diagnostic results. On a remote server, the EEM Suite archives raw data and the alarm states in a database. The WBD archives hourly average data and energy consumption in its database.

The archiving capabilities of the short-term tools are limited to the amount of data run in each project and the memory limitations of the software platform. The ENFORMA software and the UCB Tools save periods of data as separate project files. The data are not stored in a single location within these tools. Similarly, the UT does not store data within the program, but stores the path to the data file. Each time a point is selected for diagnostic analysis, the data are accessed from a file in an external location to the UT and inserted into a temporary database within the software.

\section{Pre-Processing}

Some EMCS may not provide common timestamps for multiple trended datapoints, which can be problematic for X-Y scatter and 3-D plots or performing diagnostic analyses. The UT is the only tool that synchronizes data through interpolation. Timestamps are synchronized across all data streams through an algorithm that examines data every second. A time-weighted average is used to interpolate the value of each data point for the user-specified timestamp. This capability enables the use of multiple data sources, such as EMCS and dataloggers.

Synchronization is also useful for processing EMCS data points that do not have the identical starting times or data collection frequency.

PACRAT and the EEM Suite preserve the real timestamp with each data point or can use algorithms that converge the data onto a single timestamp interval. PACRAT joins data by converging onto one interval or changing the timestamp to the beginning of the interval. These joining methods do not keep the exact timestamp with each data point, but do permit data synchronization. For example, data from two different control manufacturers may report time differently, one including seconds and one without seconds. The data would not be considered coincident until the joining process discards the seconds reading from the first data stream. The EEM Suite can synchronize data by changing the timestamp to the nearest synchronous value. This method is typically not employed and the data are kept with the true timestamp, except for plots that need coincident timestamps for multiple data streams (X-Y scatter, 3-D). The 
ENFORMA software assumes sequential data and does not import timestamps. The WBD typically polls data at a 5-15 minute polling frequency and uses hourly averages of this data in diagnostics. Therefore, timestamps do not need to be synchronized in its pre-processing routine.

Data validation is essentially pre-diagnostics filtering to address the problem of erroneous data. Since EMCS data may report unreasonable values, it can be useful to pre-filter data outside a specified range for use in analysis. PACRAT, WBD, the ENFORMA software, and EEM Suite can automatically pre-filter data. In addition, PACRAT has algorithms that fill and recreate data through interpolation, distribution, or based on the difference between values. A UT user can build missing sections of a dataset using a routine that performs regression with the incomplete dataset and a full dataset. The UT can also identify repeated timestamps, apply time shifts to data, and make slope and offset adjustments.

\subsection{Diagnostics}

The last two steps for diagnostic tool use are problem detection and diagnosis. As previously discussed, detection requires a comparison to the "correct" operation of the system using either quantitative (modeling) or qualitative (expert knowledge) baselines. Diagnosis specifies possible causes and remedies of the problem detected.

\subsubsection{Summary of Problems Detected}

The problems that diagnostic tools detect focus on energy waste, comfort control, and equipment operation. Table 5 summarizes the problems that can be detected by each tool, organized by system categories (whole building, central plant, air handler, and zones). The column for "General across systems" lists problems detected by multiple system categories and references them by column heading. This table lists problems detected through both manual and automated diagnostics. To reiterate, manual diagnostics refers to the manual interpretation of results from plots that are automatically created by the tool. Automated diagnostics detect (and often diagnose) problems without user knowledge or intervention.

Table 6 is a master list of the problems detected by the tools with brief descriptions.

Most tools focus problem detection on air handlers and central cooling and heating plants. These systems are typically the most widely instrumented and are large energy consumers. The only common diagnostic area across the tools (except EEM Suite) is the airside economizer operation. Each tool performs this analysis differently as described in Section 6. PACRAT has automated detection of the largest number of problems, while the WBD focuses on a few specific system diagnostics.

The ENFORMA software has additional diagnostic reference plots for many types of standalone systems not within the scope of this report such as fan coils, hydronic baseboard, DX cooling, thermal energy storage, and heat pumps. UC Berkeley's Fan Power Analysis tool has the unique ability to compare nameplate data to measured values and calculate motor load factor. 


\begin{tabular}{|c|c|c|c|c|c|c|}
\hline & & $\begin{array}{l}\text { I. Whole } \\
\text { building }\end{array}$ & II. Central Plant & III. Air Handler (AHU) & IV. Zones & General across systems* \\
\hline \multirow{3}{*}{ 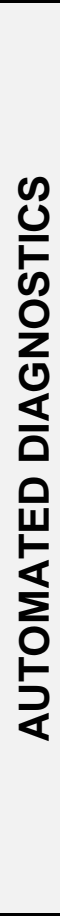 } & PACRAT & $\begin{array}{l}\text { Utility deviation } \\
\text { from baseline } \\
\text { model } \\
\text { (kWh, therms, } \\
\text { ton-hours) }\end{array}$ & $\begin{array}{l}\text { Chiller diagnostics } \\
\text { - Chilled water temp control } \\
\text { - Poor load factor } \\
\text { - Poor condenser, evaporator } \\
\text { performance } \\
\text { - Chiller efficiency degradation } \\
\text { - Excess cycling } \\
\text { - Chiller electric deviation from } \\
\text { baseline model } \\
\text { Distribution (hydronic) } \\
\text { - Failed valve } \\
\text { - Struggling pumps, valves } \\
\text { - Primary/secondary system } \\
\text { problems }\end{array}$ & $\begin{array}{l}\text { - Lack of economizer cooling } \\
\text { - Outdoor air excess or inadequate } \\
\text { - Simultaneous heating/cooling } \\
\text { - Unnecessary mechanical cooling } \\
\text { - Leaking/struggling coils } \\
\text { - Control instability, excess cycling } \\
\text { of all controlled components }\end{array}$ & $\begin{array}{l}\text { Temp, } \\
\text { humidity, } \\
\text { and CO2 } \\
\text { control }\end{array}$ & $\begin{array}{l}\text { - Unoccupied operation (I,II,III) } \\
\text { - } \text { Failed/miscalibrated sensors } \\
\text { (II,III) } \\
\text { - Run-time threshold met (II,III) } \\
\text { - } \text { Deviation from baseline (I,II, III) } \\
\text { - Alarm occurrence (I,II, III) } \\
\text { - Override occurrence (II, III) } \\
\text { - Additional proprietary detection } \\
\text { algorithms (I, II, III, IV) } \\
\text { MANUAL DIAGNOSICS } \\
\text { - Performance characterization } \\
\text { - }(\mathrm{I}, \mathrm{II}, \mathrm{III})\end{array}$ \\
\hline & $\begin{array}{l}\text { WBD, } \\
\text { WBE }\end{array}$ & $\begin{array}{l}\text { Electric and gas } \\
\text { deviation from } \\
\text { baseline model }\end{array}$ & $\begin{array}{l}\text { Chiller electric deviation from } \\
\text { baseline model }\end{array}$ & & & \\
\hline & $\begin{array}{l}\text { WBD, } \\
\text { OA/E }\end{array}$ & & & $\begin{array}{l}\text { - Lack of economizer cooling } \\
\text { - Outdoor air excess, inadequate } \\
\text { - Simultaneous heating/cooling } \\
\text { - Unnecessary mechanical cooling } \\
\text { - Failed/miscalibrated sensors }\end{array}$ & & \\
\hline \multirow{4}{*}{ 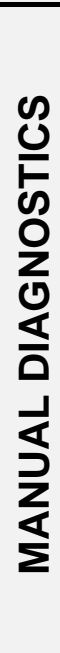 } & EEM Suite & $\begin{array}{l}\text { - High energy } \\
\text { - Unoccupied } \\
\text { operation } \\
\end{array}$ & & & & $\begin{array}{l}\text { - Program conditional alarms for } \\
\text { any data point. } \\
\text { - Run-time (on/off) }\end{array}$ \\
\hline & ENFORMA & & $\begin{array}{l}\text { Boiler: see general } \\
\text { Cooling tower (CT) capacity } \\
\text { Chiller } \\
\text { - Condenser performance } \\
\text { - Interlock with AHU and CT } \\
\text { - Chiller kW temp dependence }\end{array}$ & $\begin{array}{l}\text { - Lack of economizer cooling } \\
\text { - Simultaneous heating/cooling } \\
\text { - Humidifier operation } \\
\text { - Evap cooler performance } \\
\text { - Static pressure \& fan control } \\
\text { - Duct heat gain/loss }\end{array}$ & $\begin{array}{l}\text { Terminal unit } \\
\text { operation }\end{array}$ & $\begin{array}{l}\text { - Unoccupied operation (II, III, IV) } \\
\text { - Temperature control (II, III, IV) }\end{array}$ \\
\hline & $\begin{array}{l}\text { UCB } \\
\text { Tools }\end{array}$ & & & $\begin{array}{l}\text { - Lack of economizer cooling } \\
\text { - Motor load factor problems } \\
\text { - Static pressure } \\
\text { - Run-time }\end{array}$ & $\begin{array}{l}\text { Reheat } \\
\text { operations }\end{array}$ & Temperature control (III, IV) \\
\hline & UT & & & - Lack of economizer cooling & & $\begin{array}{l}\text { - Run-time (II,III) } \\
\text { - Cycling analysis (II,III) }\end{array}$ \\
\hline
\end{tabular}

${ }^{*}$ I, II, III, IV in parenthesis denote column headings that include these diagnostics. 
Table 6 Master List of Problems Detected by the Diagnostic Tools

\begin{tabular}{|c|c|}
\hline \multicolumn{2}{|l|}{ General Across Systems } \\
\hline Unoccupied operation & $\begin{array}{l}\text { Use of load profiles, time-series data, or automated rules to determine system } \\
\text { operation during unoccupied hours. }\end{array}$ \\
\hline Failed/miscalibrated sensors & Sensors have erroneous readings. \\
\hline Run-time threshold met & A piece of equipment has reached a user-defined run-time threshold. \\
\hline Alarm occurrence & Frequency of alarm occurrence is reported. \\
\hline Override occurrence & Frequency of operator override of controls is reported. \\
\hline Performance characterization & Archive of performance measures over time. \\
\hline Program conditional alarms & User-defined rules can be input for automated detection using alarms. \\
\hline Temperature control & The ability to meet setpoint and/or control stability. \\
\hline Run-time & $\begin{array}{l}\text { Calculation of total and percent run-time for an analog point above a } \\
\text { threshold or for a status point (on/off). }\end{array}$ \\
\hline Cycling analysis & Counts number of times a point crosses threshold and calculates cycling rate. \\
\hline Excess cycling & Automated detection of equipment that cycles on and off. \\
\hline \multicolumn{2}{|l|}{ Whole Building } \\
\hline High energy & Whole building energy is indexed and compared across buildings. \\
\hline Deviation from baseline & $\begin{array}{l}\text { Historical data used to created a baseline using a multi-variable bin model. } \\
\text { Measured data are compared to baseline. }\end{array}$ \\
\hline \multicolumn{2}{|r|}{ (2) } \\
\hline Chilled water temp control & Determine if chilled water supply temperature meets setpoint. \\
\hline Poor load factor & Chiller is running at low load. \\
\hline $\begin{array}{l}\text { Poor condenser, evaporator } \\
\text { performance }\end{array}$ & Poor heat exchange on the condenser or evaporator. \\
\hline Chiller efficiency degradation & Track chiller efficiency over time. May use multi-variable model. \\
\hline Interlock with AHU and CT & $\begin{array}{l}\text { Assess interlocks that prevent chiller operation without a load or heat } \\
\text { rejection method. }\end{array}$ \\
\hline Chiller kW temp. dependence & Determine if chiller modulates with outdoor temp and meets cooling loads. \\
\hline Cooling tower capacity & The ability of the cooling tower to meet the heat rejection load. \\
\hline \multicolumn{2}{|l|}{ Hydronic Distribution } \\
\hline Failed valve & Detect failed or poorly performing valves. \\
\hline Struggling pumps, valves & Assess when valves or pumps are not able to meet load. \\
\hline Primary/secondary system & Comparison of primary and secondary load. Reverse flow in bridge. \\
\hline \multicolumn{2}{|l|}{ Air Handlers } \\
\hline Lack of economizer cooling & Not fully utilizing outside air to provide free cooling. \\
\hline Outdoor air excess & Excess outside air that creates need for mechanical cooling or heating. \\
\hline Outside air inadequate & Inadequate outside air for ventilation and air quality. \\
\hline Simultaneous heating and cooling & Detect when single duct systems heat and cool the supply air. \\
\hline Leaking coils & Coil valve is commanded closed, but cooling or heating occurs. \\
\hline Struggling coils & Coil not able to meet load. \\
\hline Control instability & Unstable or oscillating control of valves. \\
\hline Humidifier operation & Verify correct humidification. \\
\hline Evap cooler performance & Verify evaporative cooler effectiveness. \\
\hline Static pressure \& fan control & Assess duct static pressure and supply and return fan control. \\
\hline Duct heat gain/loss & Excessive heat gain or loss between the air handler and the zones. \\
\hline Motor load factor problems & Determine hours at load factor bins for occupied/unoccupied hours. \\
\hline Static pressure setpoint & Verify static pressure meets setpoint. \\
\hline \multicolumn{2}{|l|}{ Zones } \\
\hline Temp, humidity, and CO2 control & Track statistics on zone thermal control and ventilation. \\
\hline Terminal unit operation & Zone and supply air velocity modulation, reheat modulation. \\
\hline Reheat operations & Analyze hot water reheat with respect to OAT and ZAT. \\
\hline
\end{tabular}




\subsubsection{Raw Data Visualization}

The most basic method of detecting problems is through raw data visualization techniques. Tool users can detect problems manually by viewing time-series data in different ways. Table 7 summarizes techniques in which the tools help users view data. This table does not show the tool interface for visualizing the results of diagnostic processing, but only the techniques for raw data visualization. These data visualization methods and features are presented here for informational purposes only, as some users may not have the manual data analysis expertise to use these features or the time to spend reviewing plots. While data visualization is not appropriate for all users, understanding historical data using techniques that help summarize the data are useful for increasing the understanding of system operation.

Table $7 \quad$ Raw data visualization methods and features

\begin{tabular}{|c|c|c|c|c|c|c|c|c|c|c|}
\hline & & $\begin{array}{l}\text { Time } \\
\text { series }\end{array}$ & $\begin{array}{c}\text { Advance } \\
\text { time } \\
\text { series } \\
\end{array}$ & $X-Y$ & 3D & $\begin{array}{l}\text { Daily } \\
\text { profile }\end{array}$ & $\begin{array}{l}\text { Load } \\
\text { duration }\end{array}$ & Filter & $\begin{array}{c}\text { Real- } \\
\text { time }\end{array}$ & Aggregate \\
\hline \multicolumn{2}{|c|}{ ENFORMA } & $\sqrt{ }$ & $\sqrt{-}$ & $\checkmark$ & & $\checkmark$ & & $\sqrt{ }$ & & \\
\hline \multicolumn{2}{|c|}{ UCB Tools } & $\sqrt{ }$ & & $\sqrt{ }$ & & $\sqrt{ }$ & $\sqrt{ }$ & & & \\
\hline \multicolumn{2}{|c|}{ UT (PG\&E) } & $\sqrt{ }$ & $\sqrt{-}$ & & & & & $\sqrt{+}$ & & \\
\hline \multirow{2}{*}{ WBD } & WBE & & & & & & & & $\begin{array}{l}\text { hourly } \\
\text { update }\end{array}$ & \\
\hline & OA/E & & & & & & & & $\begin{array}{l}\text { hourly } \\
\text { update }\end{array}$ & \\
\hline \multicolumn{2}{|c|}{ PACRAT } & $\sqrt{ }$ & $\sqrt{ }$ & $\sqrt{ }$ & $\sqrt{ }$ & $\sqrt{+}$ & $\sqrt{ }$ & $\sqrt{ }$ & & $\sqrt{ }$ \\
\hline \multicolumn{2}{|c|}{ EEM Suite } & $\sqrt{ }$ & $\sqrt{ }$ & $\sqrt{ }$ & $\sqrt{ }$ & $\sqrt{+}$ & $\sqrt{ }$ & $\sqrt{ }$ & $\sqrt{ }$ & $\sqrt{ }$ \\
\hline \multicolumn{2}{|c|}{$\begin{array}{l}\text { IMDS/ } \\
\text { Electric Eye }\end{array}$} & $\sqrt{ }$ & $\checkmark$ & $\sqrt{ }$ & $\sqrt{ }$ & $\sqrt{ }$ & $\sqrt{ }$ & $\sqrt{ }$ & $\sqrt{ }$ & $\sqrt{ }$ \\
\hline
\end{tabular}

Definitions:

Advanced time series: $\quad$ Scroll and zoom capabilities. $(\checkmark-)$ indicates zoom only.

$X-Y$ scatter:

Daily profile:

Plot of two points against each other to visualize their relationship.

Data point plotted against hours of the day, overlaying multiple days $(\checkmark)$ or calculating average and peak profiles. $\left(\checkmark_{+}\right)$

Load duration: $\quad$ Sort and bin data for plotting load (or load factor) versus hours at each load.

Filters: $\quad$ User-defined filtering by day, time, versus another point. $\left(\checkmark_{+}\right)$indicates advanced capabilities.

Real-time: $\quad$ Monitoring with continuous update of data.

Aggregate: $\quad$ Sum data across system levels or time.

Raw time-series visualization allows manual identification of scheduling problems. Timeseries data can be viewed using all tools except the WBD, which focuses on graphical displays of the results of the automated diagnostics, rather than providing data visualization features. The tools with visualization of time-series (trended) data vary in their ability to scroll through the data or zoom for detail. The IMDS uses Electric Eye visualization software, which is included here as an example of an advanced data visualization tool. For example, Electric Eye can display large datasets, up to 8 points of 1-minute frequency data for over year on a single plot. An example screen for Electric Eye time-series data visualization is shown in Figure B2 in 
Appendix B. Figure B3 in the Appendix shows EEM Suite's time-series plot, which includes current data as well as the previous day and the averages in the previous week.

X-Y scatter plots are useful to determine the effect of one variable on another, such as chiller efficiency ( $\mathrm{kW} /$ ton) versus load (tons). The ENFORMA software automatically creates scatter plots and has the ability to easily define additional plots using drop-down menus. The UCB Tools contain pre-defined scatter plots. The EEM Suite Data Analyst module includes linear regression, average value, and standard deviation for each scatter plot. Electric Eye has the most advanced scatter plot features, with the ability to view multiple scatter plots on one screen.

Three-dimensional plots are displayed in PACRAT and the EEM Suite Data Analyst Module, plotting one point (Y-axis) versus date and time of day, displaying a daily profile over time. PACRAT also generates 3-D plots of chiller performance surfaces. Electric Eye can also display two-dimensional slices of the 3-D surfaces it creates.

Daily profiles plot a data point against the hours of the day, and are especially important in evaluating electric load shapes and temperatures. The ENFORMA software, the UCB Tools, and Electric Eye include plots that overlay data from multiple days, while PACRAT and EEM Suite can calculate average and peak daily profiles for a specified date range, as shown in Figure 2 for the EEM Suite.

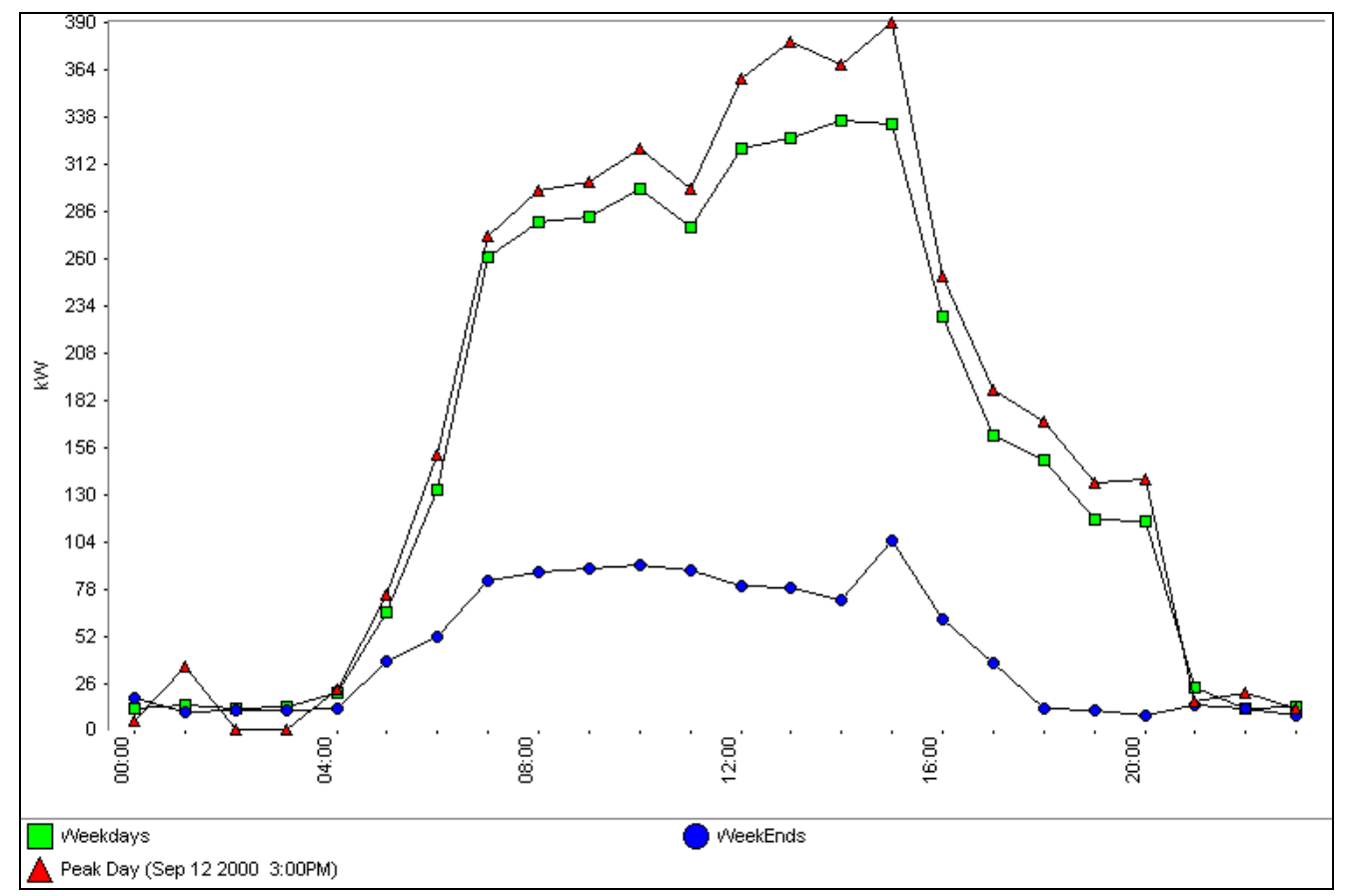

Source: Silicon Energy Data Analyst Module functional summary

Figure 2

EEM Suite 24-hour Line Plot, average hourly load profile by day type 
PACRAT and the EEM Suite include load duration graphs, plotting the number of hours at each binned range of load. The UCB Tools provide motor load factor duration plots (percent of full load motor power) in their fan performance analysis tool, shown here in Figure 3.

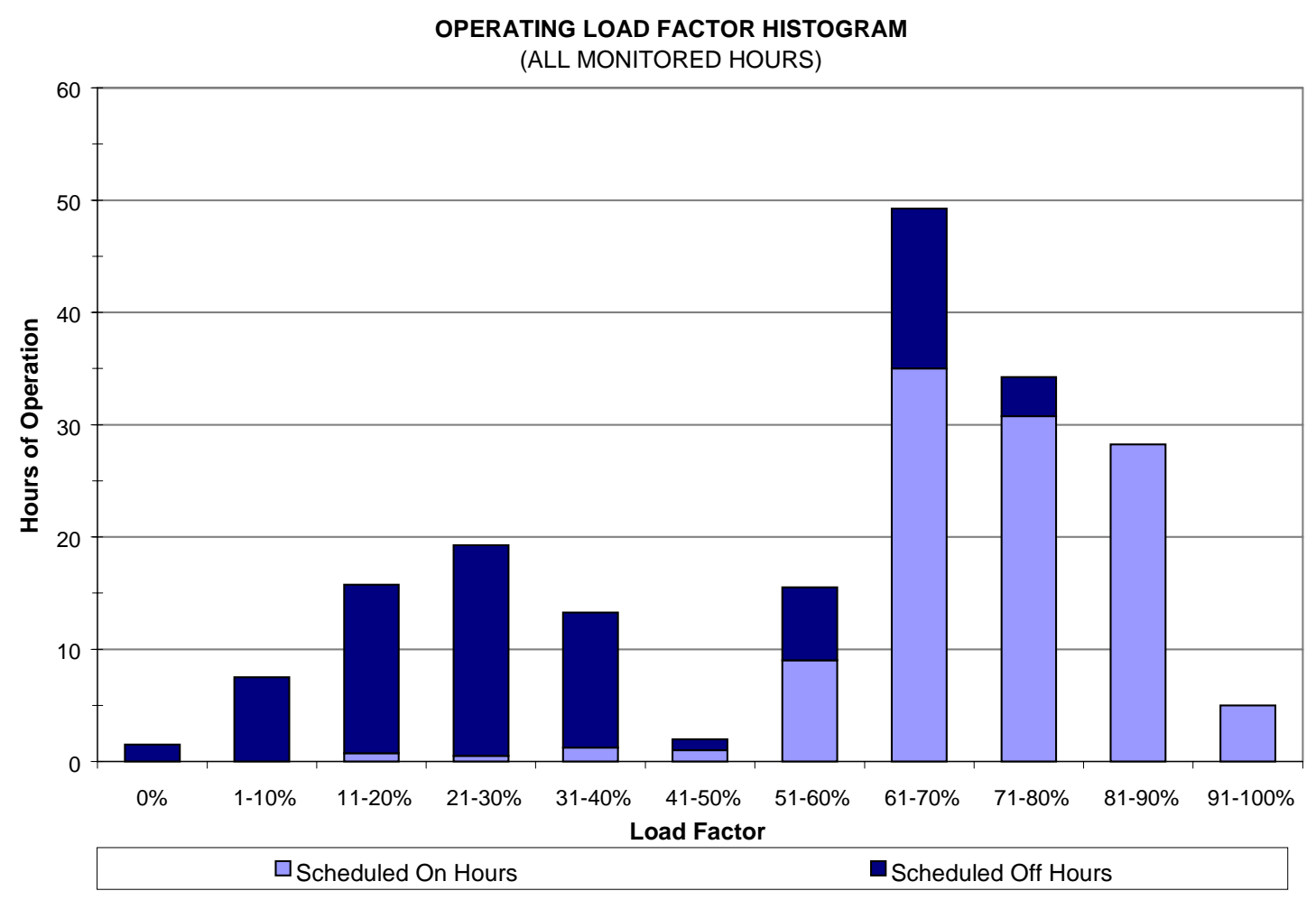

Figure 3 UC Berkeley Fan System Analysis Tools, Motor Load Factor Plot

Filtering in this context is the ability for the user to filter raw data by day type, time period, or another point. This process aids the visualization of problems that do not occur in all time periods. The UT's manual filtering capabilities are extensive, with flexibility in creating detailed schedules and filters based on another data point. These filters have the capability to define holidays and discontinuities in daily schedules. The user can also define a filter based on the on/off status of another data point and based on user-defined thresholds. The ENFORMA software also has broad filtering capabilities, and the developers consider this a strength of the tool. Like the UT, data can be filtered by day type (occupied/unoccupied), date range, time of day, day of week, or based on another data stream. The UCB tool filters for operating schedule.

PACRAT has filtering based on schedule and on the value of another point to aid the diagnostic algorithms. For example, the simultaneous heating and cooling analysis is not run when humidity is above a specified percentage since the cooling coil is performing necessary dehumidification prior to heating of the supply air stream. In the EEM Suite Data Analyst module, any points can be filtered for a date range and by type of day (weekend, weekday), and day of week, but not by hours of the day. The WBD has filters for HVAC operating schedule. 
Real-time data visualization allows a user to view each data point as it is collected. Real-time data from multiple control vendors is provided by the EEM Suite through EMCS gateways. The WBD can be implemented in real-time or semi-real-time, depending on the connection to the EMCS. PACRAT generally processes data in batch files as often as desired. The IMDS has been configured for real-time data visualization.

Aggregating data over time (hourly, daily, and monthly) and through all levels of the hierarchy tree (building, system, and component-level) is helpful when assessing building performance. The tree view groups data points from individual pieces of equipment by system and groups systems by location. For example, cooling load (or load/sq ft) can be aggregated and compared across buildings. PACRAT and EEM Suite aggregate energy consumption using tree views, creating a new point for each layer in the hierarchy, shown below in Figure 4. PACRAT also aggregates energy cost waste at each level of the hierarchy. The user can aggregate data with the ENFORMA software and Electric Eye by creating calculated points.

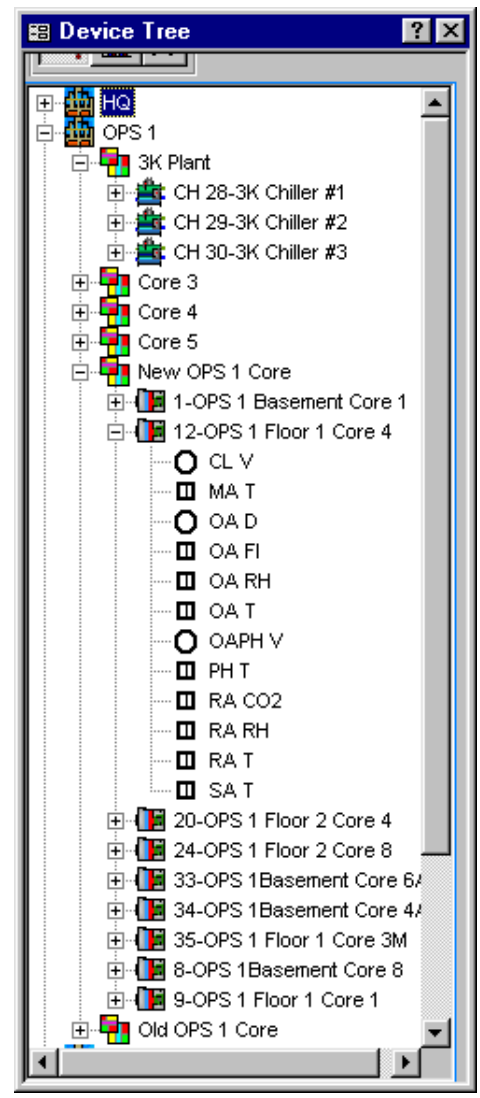

Figure 4

PACRAT Tree View: Buildings (HQ; OPS1), Groupings (collection of systems), Systems (chillers and air handlers), and Inputs/Outputs (V=valve; $T=$ temp) 


\subsubsection{Diagnostics Background}

All detection methods need a baseline to compare measured data against in order to detect deviations from normal, or "correct" operations. This baseline can be derived from an individual's knowledge (manual diagnostics) or from standard operations and procedures, or from a set of expert or first-principle-based rules that are imbedded in the software (automated diagnostics). Rule-based diagnostics explain how the system should behave using a combination of logic statements and statistical methods. Expert rules are developed from field experience and can be thought of as "rules of thumb". First principle-based rules are derived from physical concepts, for example, the first law of thermodynamics. First-principle and expert rules are implemented in the diagnostic tools we studied through decision trees with logic programmed at each step.

Automated diagnostics also includes quantitative models such as neural networks (empirical), component curve fits, and first principles models to determine the baseline performance (Haves, 1999). Models that use empirical methods are highly dependent on the quality and quantity of the data used to train them.

Benchmarking is a term that has been used in performance measurement in a variety of ways in different contexts. As discussed in Section 1.4, benchmarking uses metrics to gauge performance externally to others in a similar class. Benchmarking is sometimes used to describe the comparison of a building to a small set of similar buildings such as a campus of buildings in one company. This practice will be referred to as self-benchmarking. Benchmarks should not be confused with baselines, which compare a building against itself over time (Sartor et al., 2000). Benchmarks and baselines are often normalized to account for variations in weather or occupancy. Indexing is the simplest method of normalization, where all data are divided by a normalizing variable like square footage or degree-days. Single variable regression for energy and temperature is another commonly used normalizing technique, as well as multi-variable bin analysis or neural networks to normalize consumption simultaneously for multiple variables such as temperature, occupancy, and humidity. For diagnostic tools, we consider benchmarking to be the coarsest level of diagnostics. Benchmarking may be used to detect when energy consumption and other metrics are abnormal relative to other buildings.

In addition to the underlying methods, each tool must have a user interface to communicate diagnostic information. The manual diagnostic tool interface consists of the organization of the automatically created graphs, statistics, and metrics. The automated diagnostics interface is more complex, as the tool must convey the results of the analysis.

As discussed in Section 1.2, manual diagnostic tools aid diagnostics by extracting information from raw data. Manual diagnostic tools require that users have the knowledge to identify problems using the plots and information automatically generated by the tool. Manual detection goes beyond the raw data visualization techniques summarized in Table 7 to aid problem detection, using methods such as performance metrics and reference plots.

Alternatively, automated diagnostics requires less user analysis of data since the tool specifies the problem and automatically supplies a list of possible causes with appropriate remedies. This may be particularly important for less experienced users or users with little time for data 
analysis. With an understanding of these definitions, the manual and automated diagnostic methods that each of the tools utilize are presented in Sections 5.3.4 and 5.3.5.

\subsubsection{Manual Diagnostic Methods}

Data visualization is a powerful method for extracting information from EMCS data. The following section presents the methods used to manually detect and diagnose building energy waste.

Table 8 displays the methods used for detection and diagnosis of problems. The methods are further divided in to manual and automated categories. The diagnostic tools use many different methods for manual detection. In automated detection, we include rule-based methods, empirical modeling of baselines from historical data, and calculation of the cost of energy waste. The tools diagnose the cause of the problem using expert rules derived from knowledge about why these faults tend to occur.

Table 8 Manual and Automated Diagnostic Methods

\begin{tabular}{|c|c|c|c|c|c|c|c|c|c|c|c|}
\hline & \multicolumn{9}{|c|}{ Detection } & \multirow{2}{*}{$\begin{array}{l}\text { Diag- } \\
\text { nosis } \\
\text { Expert } \\
\text { Rules }\end{array}$} \\
\hline & & $\begin{array}{c}\text { Bench- } \\
\text { mark }\end{array}$ & $\begin{array}{l}\text { Ref. } \\
\text { line }\end{array}$ & $\begin{array}{c}\text { Raw } \\
\text { data } \\
\text { visual }\end{array}$ & Stats & $\begin{array}{l}\text { Perf. } \\
\text { Metric }\end{array}$ & Guide & Rules & $\begin{array}{l}\text { Model } \\
\text { Base- } \\
\text { line }\end{array}$ & Cost & \\
\hline & & \multicolumn{6}{|c|}{ Manual } & \multicolumn{4}{|c|}{ Automated } \\
\hline \multicolumn{2}{|c|}{ ENFORMA } & & $\sqrt{ }$ & $\sqrt{ }$ & & $\sqrt{ }$ & $\sqrt{ }$ & & & & \\
\hline \multicolumn{2}{|c|}{ UCB Tools } & & $\sqrt{ }$ & $\sqrt{ }$ & $\sqrt{ }$ & $\sqrt{ }$ & $\sqrt{ }$ & & & & \\
\hline \multicolumn{2}{|c|}{ UT (PG\&E) } & & $\sqrt{ }$ & $\sqrt{ }$ & $\sqrt{ }$ & $\sqrt{-}$ & & $\sqrt{-}$ & & & $\sqrt{-}$ \\
\hline \multirow{2}{*}{ WBD } & WBE & & & & & $\sqrt{ }$ & & & $\sqrt{ }$ & $\sqrt{ }$ & \\
\hline & OA/E & & & & & & & $\sqrt{ }$ & & $\sqrt{ }$ & $\sqrt{ }$ \\
\hline \multicolumn{2}{|c|}{ PACRAT } & $\sqrt{ }$ & & $\sqrt{ }$ & $\sqrt{ }$ & $\sqrt{+}$ & & $\sqrt{+}$ & $\sqrt{ }$ & $\sqrt{ }$ & $\sqrt{ }$ \\
\hline \multicolumn{2}{|c|}{ EEM Suite } & $\sqrt{ }$ & & $\sqrt{ }$ & $\sqrt{ }$ & $\sqrt{ }$ & & note 1 & & & \\
\hline
\end{tabular}

Note 1: The user can program conditional alarms that act as expert rules.

$\left(\checkmark_{+}\right)$indicates advanced capabilities. $\quad\left(\checkmark_{-}\right)$indicates limited capabilities.

\section{Definitions:}

Raw data visual

Reference line

Benchmark

Statistics

Performance Metrics

Guidelines

Rules

Modeled baseline

Cost
Manual detection using predefined plots.

Comparison plots that help visualize correct operation.

Comparison across database of buildings or multiple buildings on site.

Summary statistics ( $\max , \min$, average, standard deviation, run-time)

Summarize performance (i.e., energy use intensity, chiller efficiency)

Companion document to aid in interpretation of plots.

Decision tree of expert knowledge and/or basic principles used to detect and diagnose problems.

Historical baseline formulated through a model, to which measured data are compared and deviation is assessed.

The cost of energy waste is calculated. 
Reference plots or reference lines overlaid on data can help the user visualize correct operation for the manual detection of problems. The ENFORMA software's main aid to detection is their use of reference plots, with over 150 pre-defined plots available based on system configuration. Their reference plots consist of sample plots of various operational scenarios, which can be used to compare to the measured data. The reference plots can be scaled to match the measured data, but since the reference plots are pre-defined and not based on measured data, they are most useful to help assess the appropriate shape of a performance curve. Figure 5 displays one of the ENFORMA software's economizer diagnostic plots, mixed air temperature versus outside air temperature.

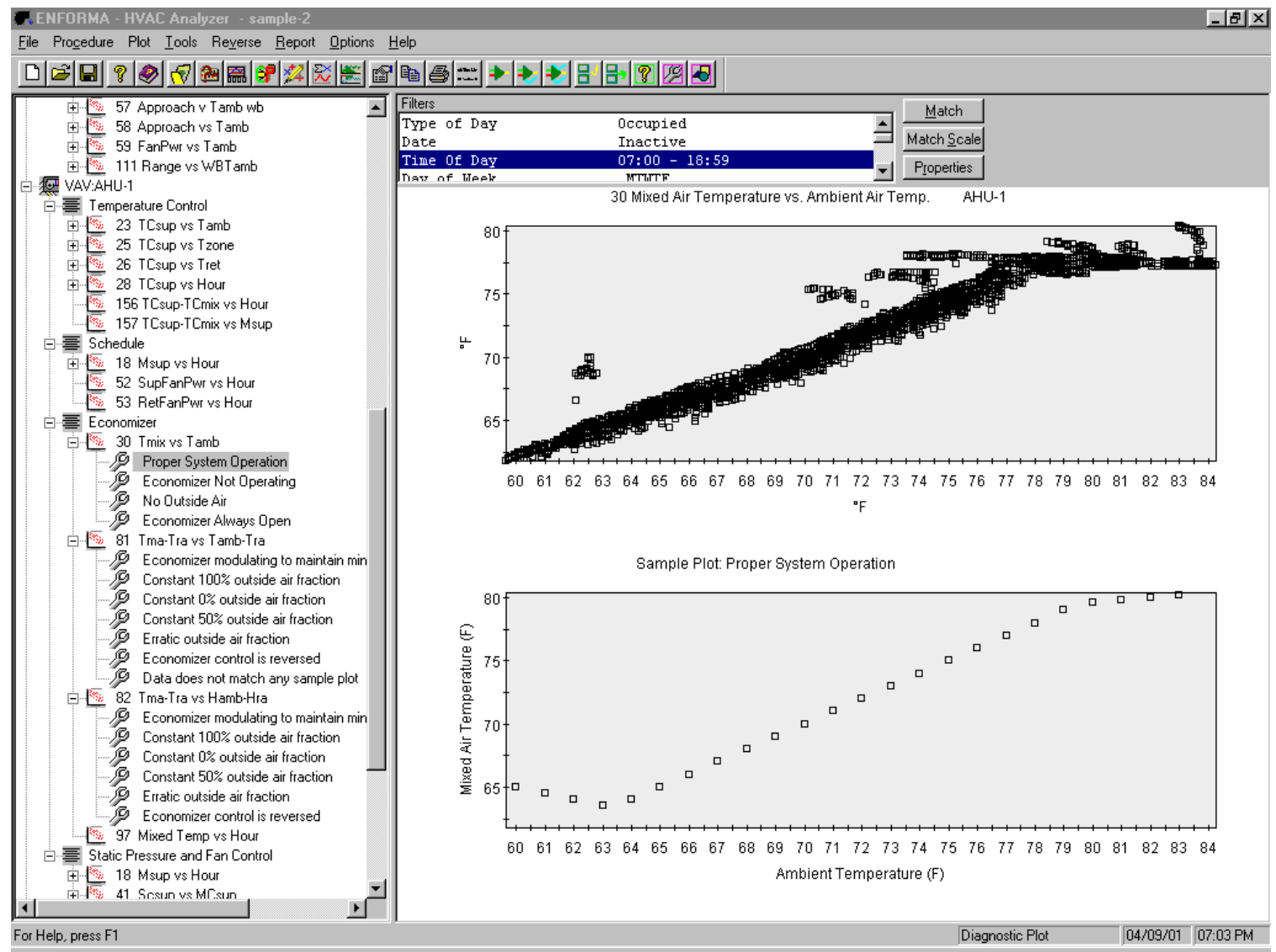

Figure $5 \quad$ ENFORMA software economizer plot with example reference plot

Other tools draw reference lines based setpoints or measured data. The UCB Tools draw reference lines from user-input economizer high/low limits and the minimum outdoor air fraction. In the UT's economizer diagnostic plot of mixed air temperature versus outside air temperature, average return air temperature, the supply air setpoint, and the minimum outdoor air fraction are used to create reference lines, shown below in Figure 6. 


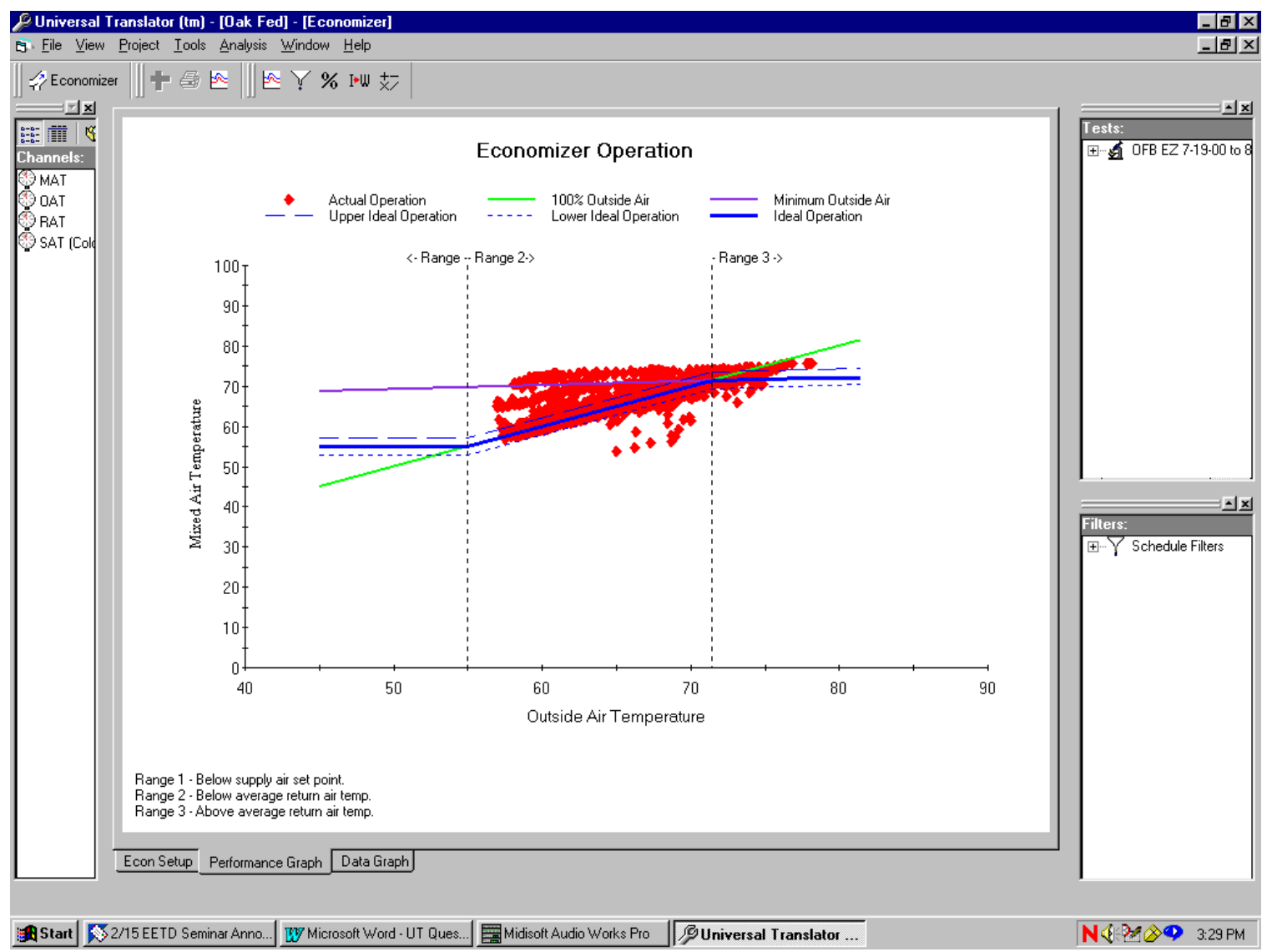

Figure 6 Universal Translator's Performance Graph, Economizer Diagnostic Module

Reference lines in the UT's performance graph are structured around three distinct zones of economizer operation, defined as follows:

zone 1: $\quad$ OAT < SAT setpoint (modulated if cooling is required);

Outside air fraction minimum defined by user.

zone 2: $\quad$ SAT setpoint < OAT < average RAT;

Economizer cooling with $100 \%$ outside air.

zone 3: $\quad$ RAT < OAT ; minimum OA

Benchmarking is employed by the tools in the context of "self-benchmarking", which we define as the comparison of data across buildings within a site or company (as opposed to an external source). The EEM Suite can self-benchmark across remote facilities and may index the data by any variables. One EEM Suite module also normalizes monthly energy and cost for weather. PACRAT self-benchmarks efficiency and consumption across buildings using performance metrics.

Statistics provide a useful way to summarize large amounts of data. Several tools have statistics for max, min, average, and standard deviation. The UCB Tools go further to create bar charts of system temperatures (SAT, RAT, MAT) at minimum and maximum outdoor air temperatures. The UT run-time analysis can be used to detect equipment cycling and loading 
problems for any power measurement by calculating the number of times a point crosses a threshold and the runtime below each threshold. The EEM Suite also includes run-time analysis for use with digital points, which totals the changes in state (i.e., on/off) and the cumulative time in each state. PACRAT reports statistics within the performance characterization module for zones, ventilation rates, and cooling and heating loads.

The UT provides some statistics within the economizer analysis to quantify the difference between measured and ideal operation. Here, the UT outputs the ideal slope and intercept for the three regions of the performance graph and calculates the measured slope and intercept for comparison.

Performance metrics are a general feature that consist of summarizing key calculated points such as chiller $\mathrm{kW} /$ ton and cooling load/sq ft. PACRAT, EEM Suite, the ENFORMA software, and the UT give the user the ability to define metrics using calculated data points, while the WBE generates one pre-defined metric, energy use intensity. In PACRAT, EEM Suite, and the ENFORMA software, the metrics are defined in the configuration as permanent calculated points, whereas in the UT metrics must be re-defined for each processing run. One strength of PACRAT is that it automatically archives numerous performance metrics. For example, PACRAT's plot of chiller tons, efficiency, and run-time versus outside air temperature is used to diagnose chiller performance and the temperature-dependence of building loads, shown below in Figure 7. The WBD's WBE module archives an energy consumption index as a measure of performance.

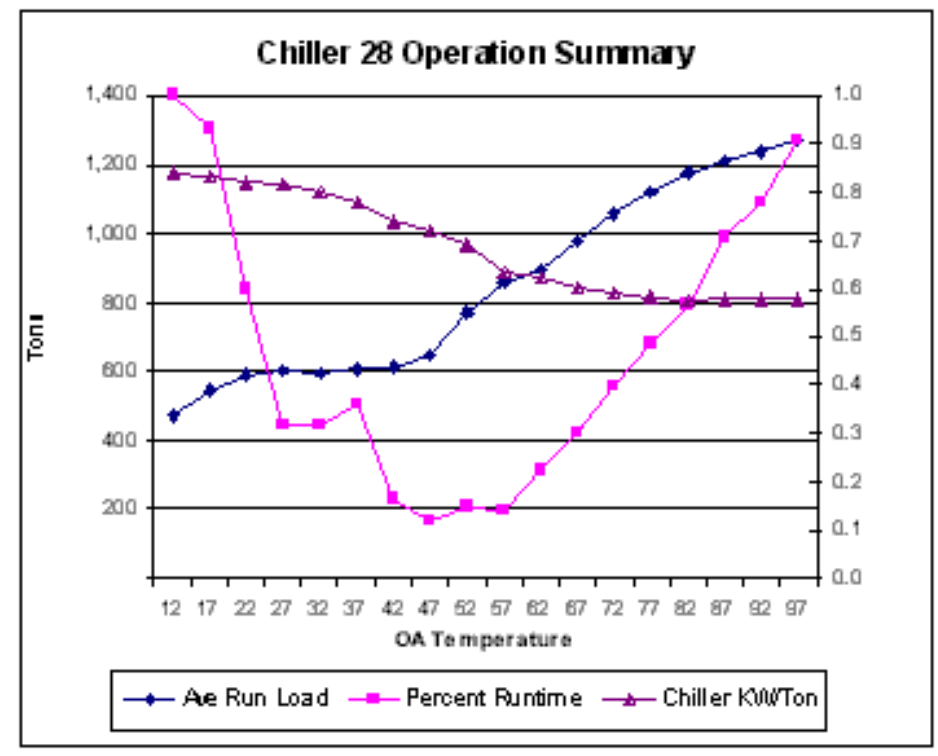

(Santos, 2000)

\section{Figure $7 \quad$ PACRAT chiller performance plot}

Diagnostic guides can aid manual detection. The ENFORMA software has extensive help files that outline diagnostic procedures, summarize the available predefined reference plots, and briefly describe relevant data patterns. The UCB Tools also provides written diagnostic guidelines, with short descriptions accompanying examples of each diagnostic plot. The UCB 
Tools set forth guidelines and information in the form of a protocol to address measurement accuracy issues for sensor location and instrumentation.

\subsubsection{Automated Diagnostic Methods}

The WBD, PACRAT, and the UT are the three tools that automate both problem detection and at least partially automate diagnosis. These tools perform automated diagnostics through the use of expert rules or modeled baselines, as reported in Table 7. When problems are detected, each tool uses different methods to notify the user and prioritize the problems.

Diagnostic rules embed system knowledge from field experience and qualitative rules into an automated decision tree to detect and diagnose problems. PACRAT, the WBD, and the UT compare data points in a series of rules that characterize system operation. PACRAT identifies and reports problems, referred to as anomalies, and provides a direct link from the anomaly screen to a time-series plot at the time of the event. Figure 8 presents the anomaly interface. PACRAT estimates the deviation from normal operation and the associated energy waste for each data collection interval, and sums the cost waste over a specified duration. In addition to aggregating the cost waste over time, PACRAT lists possible causes and associated resolutions with each anomaly.

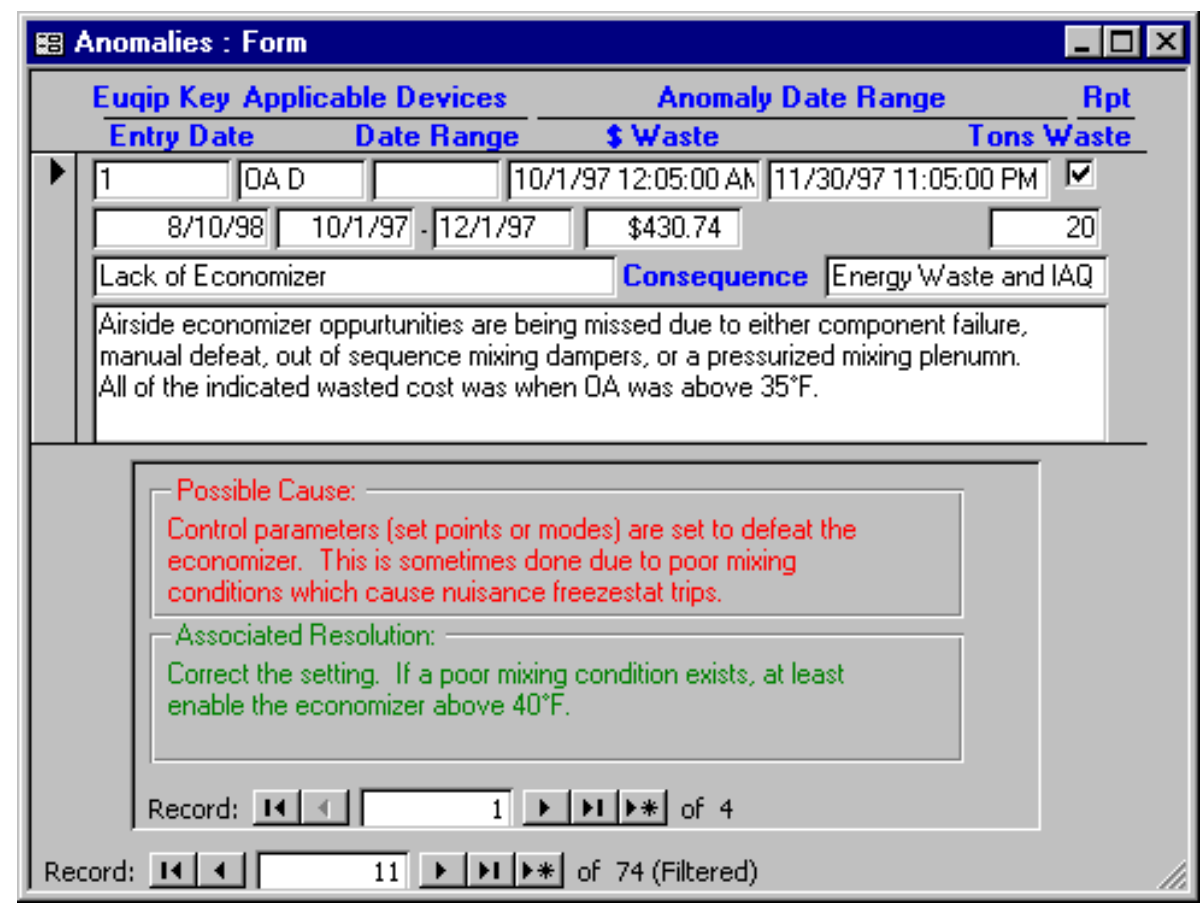

\section{Figure $8 \quad$ PACRAT Anomaly Form}

The WBD outdoor air economizer (OA/E) module's decision tree diagnoses over 20 economizer or ventilation states, using qualitative rules based on first-principles (e.g., thermodynamics) and statistical methods in problem detection. The tool relies on a color map for notification and identification of problem states. The color map includes columns for each day, displaying one 
week to one year of hourly data, and is divided into rows for each hour. Each block is shaded a specific color if the economizer is in a problem state for a given hour (ventilation low, high energy, other, incomplete or no diagnosis.) Figure 9 below shows the WBD's color map.

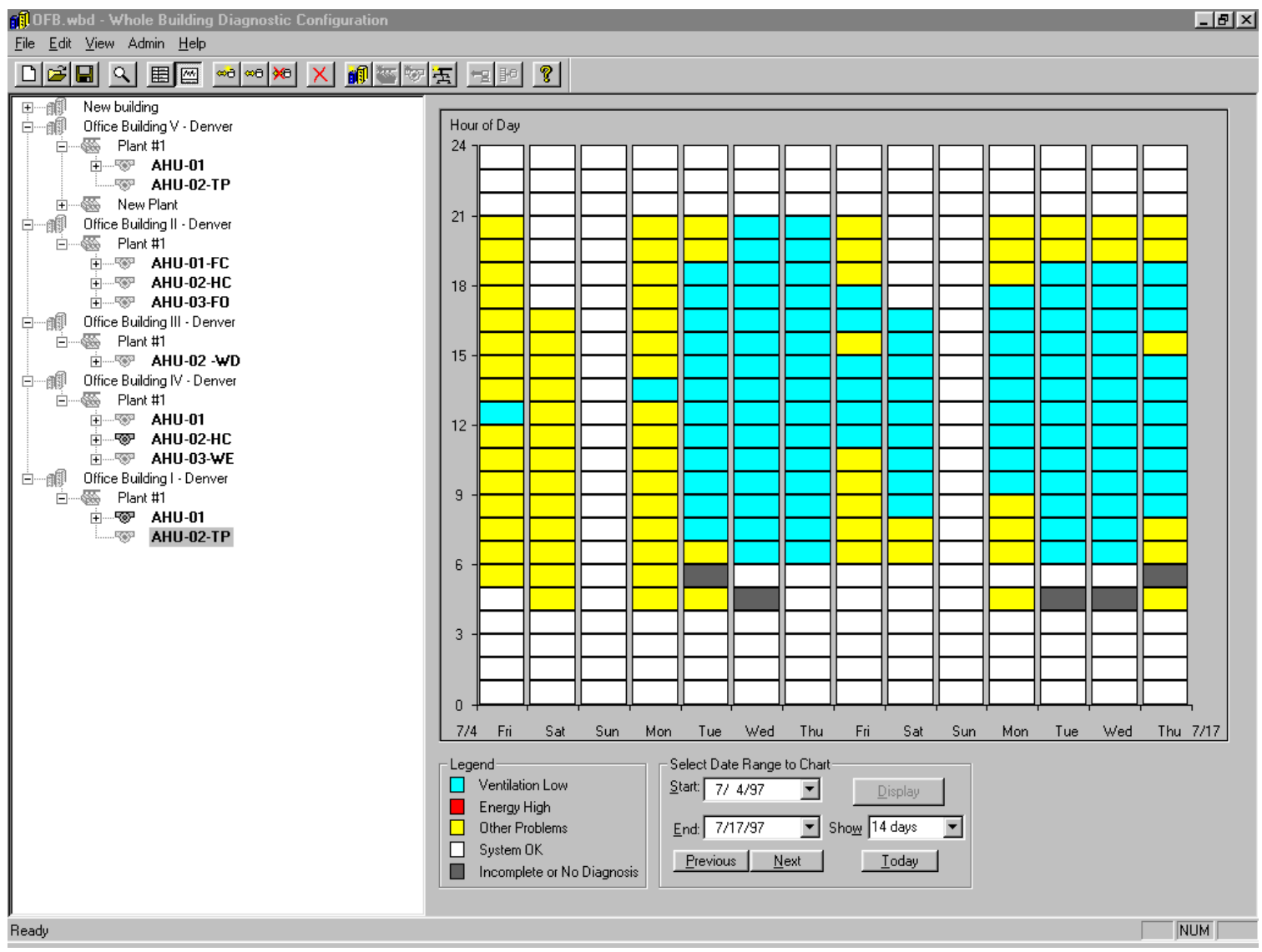

Figure 9 The WBD's Outdoor air economizer (OA/E) module problem state notification

The user can click on each block to learn more about the problem detected, including energy cost waste for that hour and potential causes and suggested actions (see Figure B4 in Appendix $\mathrm{B}$ for an example diagnosis screen). The OA/E also uses expert rules to diagnose problems and has an algorithm that narrows down the cause for the problem over time by a statistical evaluation of combinations of conditions that could not exist simultaneously. For both the WBE module and the OA/E module, cost waste is not aggregated over time. Instead, the hourly cost waste is extrapolated over 7 days assuming 24-hour operation. The cost waste for each hour block is used as a rough indicator of the relative importance of the fault.

The UT utilizes outdoor air fraction in a decision tree to detect economizer faults. This is the only diagnostic automation provided by the UT.

There is little diagnostic automation within the EEM Suite, however users can program the EEM Suite Alarm Manager for alarm events based on their own knowledge of diagnostic rules and point high/low thresholds. The EEM Suite's Alarm Manager can display and sort alarm events by chronology, severity, and priority. In addition to historical alarm reporting, the module 
allows dispatch of alarms to operators by e-mail or pager, and comments relating to each alarm state can be logged. There is no calculation of energy cost waste.

Modeled performance baselines are utilized in both PACRAT and the WBD's WBE module using multi-variable binning technique. Each tool can report deviations from the modeled baseline. To use such a technique to detect energy waste, the building ideally should be properly commissioned first, to create a model of correct operation. The WBD has the capability for multiple baseline models of thermal and electric energy consumption. The tool bins the energy data by hour of the week, ambient temperature, and relative humidity. PACRAT's methodology allows for any third variable in addition to the hour of day and day of the week, typically ambient temperature. PACRAT's module can create both whole building and component level energy consumption baselines.

The WBE notifies the user of a deviation from the modeled baseline energy use by plotting an energy consumption index, the ratio of measured energy consumption to expected consumption obtained from the baseline (ECI, where 1.0 is expected energy consumption from baseline model). If the measured data deviate by a prescribed amount, the point for that hour is highlighted in the time-series plot of ECI, shown below in Figure 10. PACRAT notifies the user when measured data deviates from the model using an anomaly form similar to Figure 8.

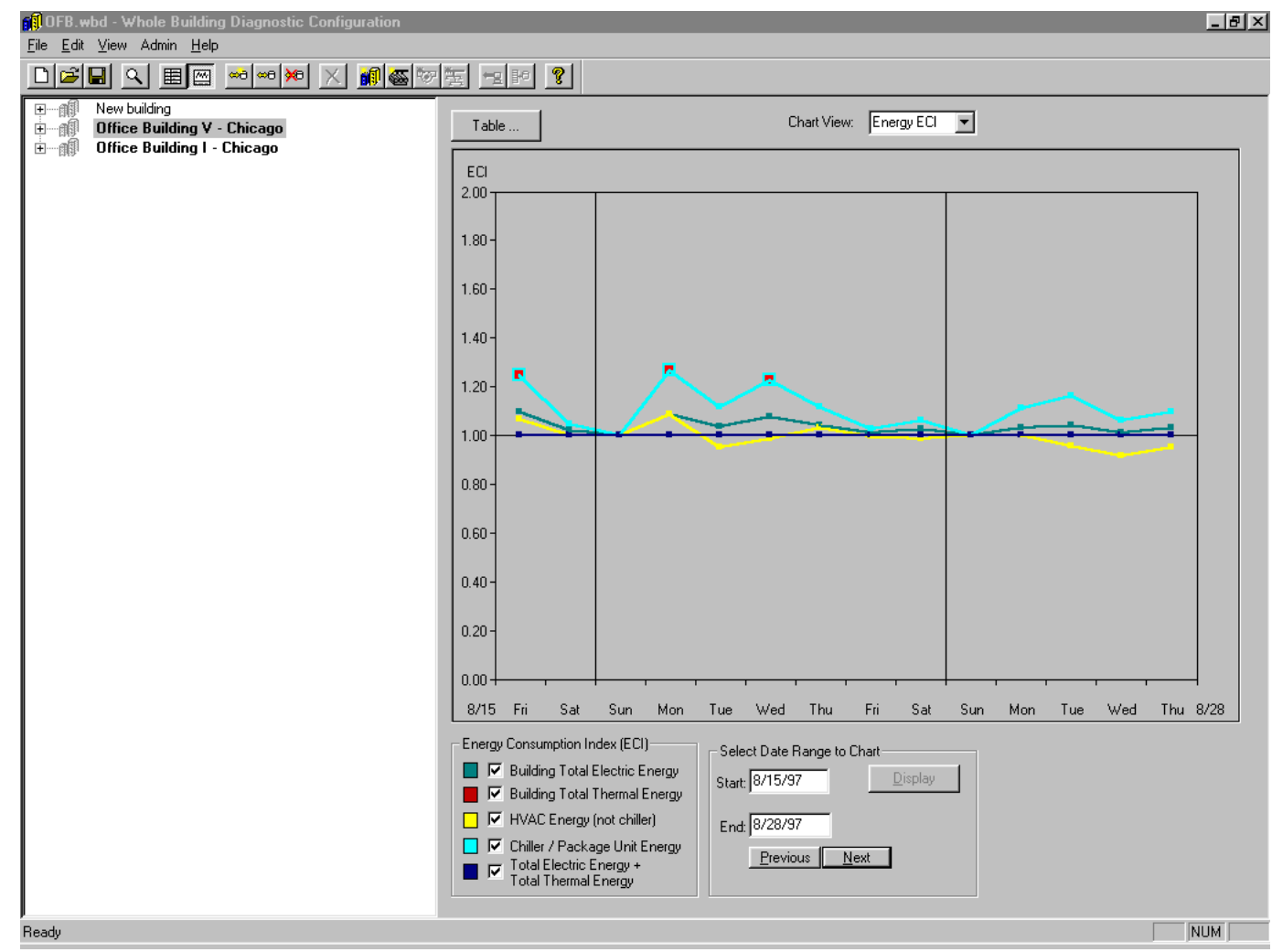

Figure 10 WBD's Whole Building Energy Module Energy Consumption Index (ECI) 
Energy cost waste is a method for prioritizing the problems detected through diagnostic rules and modeled baselines. Both the WBD and PACRAT calculate energy cost waste for each hour separately, and PACRAT sums this cost over time for each system anomaly identified. Both PACRAT and the WBD utilize full utility rate schedules input by the user.

\subsubsection{Treatment of Uncertainty}

A critical issue in diagnostic techniques is the level of confidence in the diagnostic output. This confidence is directly related to sensor measurement error due to calibration problems, poor sensor location, and limited sensor measurement sensitivity. Most often, the tools are implemented without verification that sensors are in calibration. The diagnostic tools treat uncertainty in a variety of ways.

Both PACRAT and WBD avoid false diagnoses stemming from data uncertainty by incorporating algorithms that limit the number of faults that are detected. These tools have sensitivities that can be manually set by the user. Initially, the diagnostics can be coarse, estimating large uncertainty in the sensor outputs. If no problems are detected, or after the major problems are identified, the sensitivity of the diagnostic analysis can be increased. PACRAT accomplishes this through tolerances that create a problem detection deadband. Users can vary the deadband by changing the tolerances on certain measurements. The WBD has five pre-defined sensitivity settings that assign tolerances to all measurements and then propagate the uncertainty through the evaluation of rules. The tool developers have based these sensitivity settings on their experience using the WBD, and the individual measurement tolerances cannot be modified. The WBD then judges whether a conclusion is significant based on an estimate of the probability it is incorrect.

In the WBD's outdoor air economizer module and in PACRAT, sensor error is one problem detected. The tools detect this error by assessing the data for impossible or improbable states. For example, thermodynamically, the mixed air temperature cannot be colder than both the outdoor and return air temperatures, so a sensor error is a possible cause.

The UT provides a single field for the user to input an uncertainty associated with the temperature sensors. The sensor uncertainty is displayed on the economizer performance plot as an error band to help assess the fit of the actual data to the line for proper economizer operation.

\subsection{Tool Development Plans}

As discussed in Section 4.4 on marketing issues, these tools are new and undergoing development. Since PACRAT and EEM Suite are privately funded tools, some of their plans for development are proprietary.

The PG\&E Pacific Energy Center will keep the UT code open to the public, with an open platform and programmers notes to allow users to program their own analysis modules. They also plan to add an energy cost waste analysis to the economizer module. Help screens and a tutorial are planned to give tool users assistance. 
The UCB Tool developers plan to exercise the tools to determine which diagnostic plots are most useful. Eventually, the developers would like to collaborate with a third party to commercialize the tools. Their vision for the tools is to develop a more robust platform using a database and a web-based environment to facilitate gathering information from a large population of fans for their Fan Performance Benchmarking Tool (not evaluated in this report.

PNNL has created the WBD prototype with operators as target users, but developers anticipate additional applications for the tool. Currently, PNNL is assessing private sector commercialization for the core software with different user interfaces and features for operators, engineers, HVAC service providers, and commissioning agents. In the future, the WBD developers predict that diagnostic tools will be embedded in EMCS software, but currently tools are only available as third party software. As a part of the CEC PIER program, PNNL is also working on providing the user with the flexibility to select explanatory variables for baseline formation in the WBE.

The WBD and ENFORMA software developers are currently collaborating through the CEC PIER project, with efforts to automate pattern-based fault detection and diagnosis procedures. The ENFORMA software may incorporate some of this work in future development.

PACRAT is in the process of extending their terminal unit diagnostic capabilities, as well as supplementing and refining diagnostic capabilities in other areas.

\section{$5.5 \quad$ Summary of Automation}

Table 9 summarizes the levels of automation in each of these steps for all the tools. This table is an overview of the details presented in Chapter 5 .

Table $9 \quad$ Tool Automation Summary

\begin{tabular}{|c|c|c|c|c|c|}
\hline & & $\begin{array}{c}\text { Data } \\
\text { Acquisition }\end{array}$ & $\begin{array}{l}\text { Archive and } \\
\text { Pre-process }\end{array}$ & Detection & Diagnosis \\
\hline \multicolumn{6}{|c|}{ ENFORMA } \\
\hline \multicolumn{6}{|c|}{ UCB Fan Tool } \\
\hline \multicolumn{6}{|c|}{ UT (PG\&E) } \\
\hline \multirow{2}{*}{ WBD } & WBE & & & & \\
\hline & OA/E & & & & \\
\hline \multicolumn{6}{|c|}{ PACRAT } \\
\hline \multicolumn{6}{|c|}{ EEM Suite } \\
\hline
\end{tabular}




\subsection{Tool Evaluation}

The characterization in Section 5.0 gave an overview of tool characteristics. While it is difficult to directly compare tools with differing intent and scope, it is important to understand each tool's strengths and limitations. Based on our experience operating the tools and detailed demonstrations, in Chapter 6 we inform tool users and developers of important strengths as well as the areas that limit the usability of each tool.

We have not studied the appropriateness of tool features, since this depends on the goals of the user. For example, expert users may value a low-cost manual tool with less diagnostic applications over an automated high-cost tool if they have the diagnostic experience to evaluate raw data and are interested in only specific applications. Our evaluation does not assess the level of tool sophistication appropriate for and valued by different users, but focuses on presenting the overall capabilities of the tools. We first describe the air-side economizer diagnostics specifically, since economizers are the most common system evaluated by the tools. Next, a general set of strengths and limitations are discussed. Last, the challenges and barriers to the practical use of the tools are touched upon.

\subsection{Economizer Diagnostic}

Five of the six tools perform economizer diagnostics, each with different analysis methods. Our evaluation of the economizer diagnostics focuses on three features:

- diagnostic methods

- visualization and notification

- cost analysis

While it would be valuable to assess the ease of configuration and use of the economizer diagnostic, such an assessment is not within the scope of this study. Ease of use would depend on several factors such as the user's knowledge of the tool and the training they received, diagnostic expertise, and familiarity with the building. Therefore, this analysis would require interviews with tool users. First, we describe the proper operation of an airside economizer. Then we discuss the diagnostic features of each tool.

A properly functioning airside economizer strategy uses outdoor air for ventilation when the outdoor air temperature (OAT) is cool enough to replace or reduce mechanical cooling. Dampers control the amount of outdoor and return air entering the mixing box, which is measured as the mixed air temperature (MAT). Due to incomplete mixing, the MAT is often detected using an average of temperatures at different points in the mixing box. The air from the mixing box is then cooled or heated and supplied to the building. We provide a simple diagram of an economizer in Figure 11 for reference. 


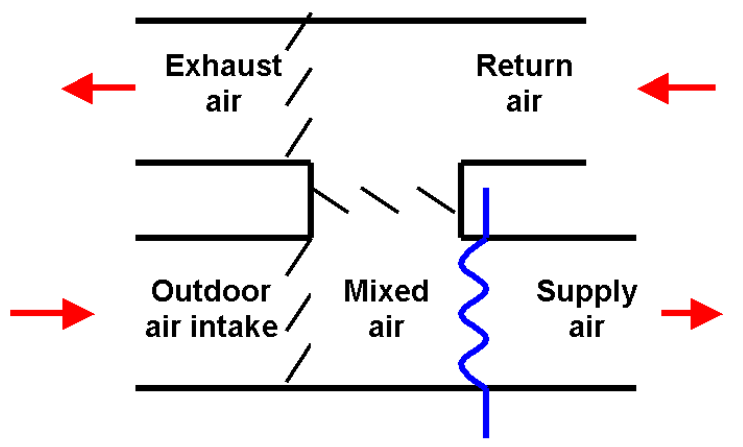

Figure $11 \quad$ Air-side economizer

Two common economizer control strategies exist, one is "differential", where OAT is compared to RAT, and the other is "high-limit", where the OAT is compared to a setpoint. For dry-bulb temperature controlled economizers, one-hundred percent outdoor air should typically be supplied (all return air exhausted) when outdoor air temperatures are below the return air temperature (RAT), but above the supply air temperature (SAT). When the OAT is below the SAT, outdoor air dampers should be modulated to help meet the cooling load, or closed to the minimum position when cooling is not needed. A third economizer strategy, "enthalpycontrolled", uses humidity measurements to assure the total energy content of the outside air is below that of the return air as a condition to initiate economizer operation. In the differential and enthalpy-controlled strategies, when OAT is above the RAT, the outside air dampers should be closed to their minimum position required for ventilation. The state of economizer operation is most easily determined by calculating the outdoor air fraction (OAF) using system temperatures:

$$
\mathrm{OAF}=(\mathrm{MAT}-\mathrm{RAT}) /(\mathrm{OAT}-\mathrm{RAT})
$$

Each of the five diagnostic tools compares the OAT, RAT, and MAT to detect faulty economizer operation. The UC Berkeley Tools and the ENFORMA software do not have automated detection using the OAF, but simply help visualize economizer performance using plots. The WBD, UT, and PACRAT calculate outdoor air fraction for use in automated problem detection. Small uncertainties in temperature sensors lead to large uncertainty in OAF. Therefore, false diagnoses are avoided using statistical methods or expert rules to determine a deadband for which the tool will not report a problem.

Using automated rules and statistical analysis, the WBD's OA/E module and PACRAT identify the following economizer and related ventilation problem states:

1. Lack of economizer cooling: damper partially or fully closed when outdoor air should be used for cooling

2. Excess outdoor air: in heating mode or when outdoor temperatures are too high

3. Inadequate outdoor air ventilation: less than minimum OAF for indoor air quality

4. Mechanical cooling: used when outdoor conditions can meet full cooling load.

5. Miscalibrated temperature sensors: detected when a state is not thermodynamically attainable. 


\section{PACRAT}

PACRAT has a sophisticated economizer fault detection method and extensive energy cost waste analysis. The tool uses physical and expert rules to identify problem states (anomalies) and provide possible causes and resolutions, while linking the anomalies directly to time-series graphs. Time-series data can also be viewed using a variety of plotting features. The problems detected can be sorted in multiple ways over a user-defined time period. PACRAT is the only tool that uses the outdoor air damper signal in addition to system temperatures in order to separate economizer control problems from mechanical problems.

PACRAT calculates cost waste for each data collection interval, then sums the cost waste over time. The user can compare cost waste across different system levels. For example, cost waste from all problems detected can be aggregated for each air handler or for the entire building over a given time period. A drawback to the diagnostic tool is that the logic tree is proprietary, so the methods cannot be evaluated externally. Figure 8 shows an example of a problem notification screen for the economizer diagnostic.

\section{WBD's Outdoor Air Economizer Module}

The WBD's economizer diagnostic uses physical rules and statistical methods to detect problems and expert rules to diagnose their cause. The tool uses time-series data to continuously assess and eliminate possible causes over time. The WBD's extensive logic tree includes twenty different diagnostic end states (Katipamula et al., 1999). The logic tree is expected to be public information, which is important for transparency of the tool's methods.

The WBD utilizes a color map with "problem state" cells (see Figure 9 in Section 5.3.5, Automated Diagnostic Methods) to notify the user of problems with economizer and ventilation operation. This method allows for broad visualization of the hourly diagnostic results. A user is not able to see plots of time-series data to support the automated analysis. The "problem state" cells are linked to lists of possible causes, remedial actions, and the temperatures used in the calculation of outdoor air fraction for that hour. The color map allows the user to differentiate the results for various categories of problems, including "ventilation low", "energy high", "other problems", and "incomplete diagnosis". The high energy use (red) cell is displayed both when the economizer should be fully open but is partially or fully closed and when the economizer should be at minimum position but is open.

The WBD presents energy cost waste for each hour, but does not aggregate the energy waste from problem states over the day. To use the cost waste presented by the tool to prioritize problems, the costs must be compared manually across problem state cells. 


\section{Universal Translator}

The UT's economizer diagnostic relies on its advanced filtering capabilities and two plots to convey diagnostic information. Filters are used to exclude data during unoccupied hours from the analysis. The user must input the minimum outdoor air fraction and SAT setpoint for use in creating a reference line of correct operation. The tool automatically creates graphs and outputs general diagnostic phrases such as "economizer damper is stuck open" based on a logic tree that assesses only the outdoor air fraction.

The first graph, the "data graph", is a time-series plot with MAT, OAT, RAT, and SAT on an upper x-axis with a percent outside air scatter plot below on a second x-axis (see Figure B5 in Appendix B). The second graph, the "performance graph", shows MAT vs. OAT, with reference lines based on user inputs and a calculated average return air temperature (see in Figure 6 in Section 5.3.4). This use of reference lines to visualize correct operation is a simple way to compare measured data to "ideal" operation. Reporting of the slope and y-intercept of the actual and ideal economizer lines for each zone aid the comparison of raw data to the reference lines. These statistics coarsely quantify the difference between ideal and actual operation without calculating energy cost waste.

\section{ENFORMA}

The ENFORMA software requires manual comparison of measured economizer data to reference plots, so the user must be trained in detecting economizer faults. The reference plots allow manual comparisons for a number of economizer operational states. The user is able to match the axes scales of the real data and reference plots, but since the reference plots are predefined using typical data and not based on measured data, a literal comparison of points is not relevant. In contrast, the UC Berkeley Fan Tool and the UT require input of the minimum outside air percentage to create tailored reference lines. The ENFORMA software includes a plot of MAT versus OAT, shown in Figure 5 in Section 5.3.3, and a plot of (MAT-RAT) versus (OAT-RAT) that includes reference lines that represent $100 \%, 50 \%$ and $0 \%$ outside air fraction. Since the detection of economizer problems is manual with this tool, the tool does not calculate the magnitude of deviation from proper economizer operation.

\section{UC Berkeley Fan Tool}

The UC Berkeley Fan Tool also assists manual detection of economizer problems through the use of reference lines that represent ideal operation. The tool includes two economizer plots. First, the MAT vs. OAT plot shows data for scheduled periods in comparison to reference lines, shown below in Figure 12. The references lines for ideal operation are based on user inputs of economizer high/low limits and minimum outside air fraction. Second, the scatter plot of MAT and OAT vs. hour of day shows the daily temperature profile. Summary statistics are presented (min, max, average, and standard deviation) for all system temperatures (SAT, MAT, RAT, OAT) as bar charts. In addition, the system temperatures at minimum and maximum outdoor air temperature help to quickly assess operation. For example, the MAT at minimum OAT should not be more than a few degrees less than the supply air temperature (allowing for fan 
heat gain). When the maximum OAT is greater than the RAT, the MAT should be close to the RAT, since full return air with minimum outside air for ventilation should be used.

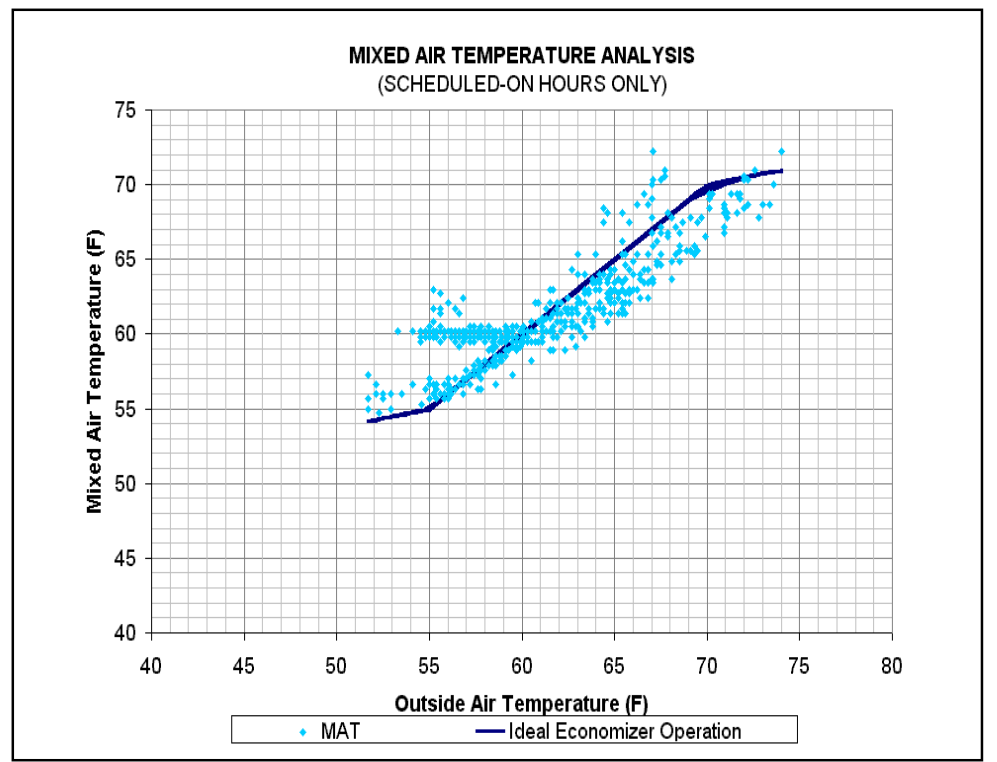

Figure 12 UC Berkeley Fan Tool Economizer Diagnostic Plot, MAT vs. OAT 
This section sets forth areas where each tool excels, as well as features that may limit use of the tool. Each user may associate different levels of importance to these strengths and limitations. Each tool will be discussed separately, followed by critique common to all tools.

\section{ENFORMA}

The ENFORMA software is flexible for use with many types of systems, providing automatic selection of predefined diagnostic plots to use as a comparison to real data. The software also has extensive help files that act as a diagnostic manual to guide the user through the use of the predefined reference plots and the selection of additional plots and filters. The user-defined filtering capabilities are advanced compared with most of the diagnostic tools. The key limitation to the ENFORMA software's diagnostic abilities is the reliance on manual detection and diagnosis. The user must have the technical abilities to understand what improper operation looks like and time to spend analyzing plots. To implement the tool with EMCS data, files must be formatted in a specific way. Each data point must be listed sequentially, without a timestamp. The data are assumed to be complete, which may be problematic for EMCS data.

\section{UC Berkeley Fan Tools}

The strength of the UCB Tools lies in the summary statistics and guidelines to analyzing the diagnostic plots. Fan benchmarking is the main focus of the tool, but was not assessed since it utilizes one-time performance measurements rather than time-series data. The UCB Tools are simple to use a straightforward framework to facilitate spreadsheet analysis, but limits a user to manual detection and diagnosis. The tool is free and available to the public.

\section{Universal Translator}

The UT has a capability in data processing that is not found in the other tools: the synchronization of time stamps through time-weighted averages. This feature is especially useful with data from different sources or different sampling times and frequencies. The userdefined filtering capabilities are the most flexible of all the tools. Since the UT has limited data visualization and system diagnostics, it may be useful to run the data through the UT for filtering and synchronization, and then export to another diagnostic tool. In addition to the economizer analysis, the UT offers a run-time analysis that determines the data cycling rate relative to threshold values. This procedure allows cycling to be detected and quantified. The developers are in the process of providing documented, open code, giving users the opportunity to add their own diagnostic modules and features.

\section{Whole Building Diagnostician}

The WBD is an advanced prototype tool for a set of automated diagnostics. The tool utilizes real-time (hourly) data acquisition with an automated link to EMCS data. The economizer module employs a "cause-reduction" strategy that uses statistics to narrow down the cause of a problem over time. The economizer tool also employs an extensive diagnostic tree that is expected to be public, and is therefore useful for the development of similar tools or to facilitate 
understanding of how the diagnostics function. The whole building energy module can create up to four multivariable baseline models from historical data using a bin technique. Changes in the normalized usage are visually signaled and hourly cost waste is reported. These diagnostics can alert a user to the degradation of equipment or significant changes in total energy consumption.

The WBD's economizer module was designed for use by operators with little time to assess time series data, so no raw data visualization functions are included. Instead, the results to the diagnostic analysis (problem notification screen) can be visualized for up to one year. This notification presents a user with a useful overview of the diagnostic findings over time. The use of average hourly data in both the economizer and whole building energy modules dampens any spikes in energy and temperature. This feature reduces false diagnoses due to data collection problems, and also reduces the ability to detect peaks in usage (energy module) or oscillating economizer control. The ability to calculate energy cost waste is a strength, but the WBD does not aggregate waste over multiple data collection periods. Instead, for each fault detected in a certain hour, the tool calculates weekly cost waste by assuming the fault occurs for 24 hours a day, seven days a week.

\section{PACRAT}

PACRAT has the most extensive automation of expert rules to assess HVAC system performance. Over fifty problems can be detected for air handlers, chillers, zones, and the hydronic distribution system. The tool's multi-variable baseline model can be used for any data point. The model reports deviations from baseline operation and estimates cost waste. PACRAT archives performance measures such as load shapes, chiller performance (load, lift, and power), and peak load. The hierarchy tree for system points provides flexibility in viewing and aggregating performance metrics both across time and across systems, such as monthly cooling load and energy cost waste at each air handler. PACRAT can periodically (in batch processing) assess system performance and help prioritize maintenance based on cumulative cost waste over time.

The nature of PACRAT requires commitment by building staff to help gather system information for the configuration process. This process tends to force a detailed examination of existing operations. Overall, PACRAT can be used to assess HVAC system operation and the root causes of many problems, summarizing relevant performance characteristics and targeting repair to the most costly problems. The automation of diagnostics coupled with visualization techniques makes the tool functional for many types of users. Experts can use the tool to streamline detection and provide data visualization capabilities for manual diagnostics, while novice users may rely entirely on the diagnostic output. One technical limitation to PACRAT is a lack of transparency in its methods, since the expert rules have not been published.

\section{Silicon Energy EEM Suite}

The EEM Suite's strength lies in its web-based data acquisition with gateways linking building data for archiving on a remote server. Comparing facilities within a campus or within a company's distributed group of buildings, or "self-benchmarking", is facilitated by this web platform. The tool has high quality data visualization with summation of hourly, daily, and 
monthly totals available for standard data types such as energy, cost, and cooling loads. EEM Suite can display three years of monthly data on a single screen. Aggregation also occurs for energy and demand at all levels of the system hierarchy. Average, peak, and minimum daily loads can be filtered for each day type (weekend, weekday, etc.) to aid analysis of unoccupied operation and load shapes.

The lack of diagnostic automation is EEM Suite's main limitation as a diagnostic tool, with userdefined conditional alarms as the only method of automated detection. The tool extends beyond EMCS alarm capabilities by adding long-term archiving and advanced visualization features. The data visualization features are generally good, except when axis increments are not in whole numbers or intuitive increments (factors of 10). The EEM Suite Energy Analyst module's use as a benchmarking tool is limited to simple indexes such as dividing by floor area or degree days, rather than correcting for weather or schedule changes. Another EEM Suite module, the Utility Accountant, normalizes monthly utility usage for outdoor air temperature, thus enabling more accurate comparisons across multiple years. Overall, the EEM Suite provides a robust platform for whole building energy analysis and manual diagnostics.

\section{General Evaluation}

In general, the diagnostic tools analyzed in this study help organize data and aid the user in determining examples of appropriate plots to assess building performance. The tools' organization and analysis provide needed data management and problem prioritization. Since the focus of this study is EMCS data, a limitation of these tools is that they are all dependent on the quality of the EMCS data. A limitation to manual analysis is that none of the tools with X-Y scatter plots have drill-down capabilities where the user can click on a point and find the time and date it occurred, which makes it harder to pinpoint the time of the problematic data without using trial and error filtering.

\subsection{Challenges in Diagnostic Tool Use}

Based on our study of the characteristics and features of the tools, challenges to tool implementation are apparent. Three key problems are listed here and described in further detail below.

- Opportunities for retro-commissioning of existing buildings need to be recognized.

- Understanding tool capabilities and performing installations can be time-consuming.

- Challenges exist to fixing the problems diagnosed.

One of the initial barriers to using the diagnostic tools is the recognition by potential tool users that there are energy saving opportunities available through retro-commissioning. As was stated in Section 1.1 of the introduction, an average of 5-15\% of total energy could be saved in full commissioning of existing buildings (Gregerson, 1997). Potential users from operators to engineering consultants need to be made aware that diagnostic tools exist to aid in the realization of these energy savings. This report provides the background motivation for using diagnostic tools with EMCS data for continuous performance assessment. 
Second, the time invested initially in understanding diagnostic tool options and performing the configuration can be considerable. A significant learning curve exists for a detailed understanding of diagnostic tool features and capabilities. Energy managers or operators typically do not spend time studying such tools, which is a barrier to their utilization by these users. Most diagnostic tools are so new that manuals and marketing materials have not been extensively developed, and potential users may be unaware that they exist. This report attempts to lessen the severity of the learning curve by explaining and comparing diagnostic tool features.

The tools require an initial time investment for configuration and training. The continuous analysis tools demand a regular time investment to analyze diagnostic output. The tool set-up procedures were not specifically assessed in this report, but it is clear that some tools are difficult to configure and involve significant set-up time invested by the tool developers. The configuration of more sophisticated tools like PACRAT, EEM Suite, and the WBD can be complicated by proprietary EMCS communications. Therefore, developers are working to streamline the implementation process for users to more easily reap the benefits of continuously monitoring building performance.

Third, diagnostic output does not result in savings until there are actions taken to correct the fault. The operator or engineer must investigate causes and have the resources available to fix the problem. Automated tools are intended to require less time for pinpointing the problem, but the possible causes must still be investigated in the building. One time-saving feature provided by two tools is the calculation of energy cost waste, which gives the user a sense of the severity of the problem.

Even when cost waste is well defined, the institutional structures in place may not provide adequate incentives for timely action. Building performance assessment may be difficult when occupant complaints and equipment maintenance monopolize an operator's day. Diagnostics training may not be available or management may not be supportive of exploratory diagnostics. Studying the organizations that operators and energy managers work within is an important topic that could lead to an increased awareness of these challenges and changes in incentive structures. 


\subsection{Conclusions}

This study has presented the features and capabilities of diagnostic tools through a comparative analysis and evaluation. In this section, through our investigation and use of the tools, we characterize the current state of the diagnostic tools industry, present key tool attributes, and propose directions for future work to assess and improve the tools.

\subsection{Current State of Diagnostic Tools}

The creation of diagnostic software tools is an emerging industry with great potential to save energy in building operations. These tools make use of new and ever-improving information technology to organize and assess time series data. Today, diagnostic tools focus most directly on air handlers, but the opportunity exists for broadening the scope of the tools to include all major HVAC systems. The main value in using these tools lies in reducing the data management and analysis time necessary to obtain valuable information on building performance from EMCS data. This information could enable a user to a take an active approach to improving operational control while decreasing building energy consumption. As building HVAC systems continue to become more complex and diagnostic tools continue to develop, using these tools will help operators, managers, and engineers more easily assess performance.

Each tool evaluated provides unique diagnostic capabilities for particular applications. There is little overlap in the current tools, as all have been developed with different designs. For example, PACRAT has a wide range of automated diagnostics that can help facility managers and operators evaluate problems by energy cost waste, type of anomaly, system or component involved, building, or other installation-specific item such as cost center, technician responsible. Silicon Energy's EEM Suite is a sophisticated tool for tracking energy use and related timeseries data in large distributed groups of buildings due to its web-based monitoring and benchmarking capabilities. As a prototype tool, the WBD has important core economizer and whole building energy diagnostics developed for use by operators. The UT is a unique, shortterm analysis tool that focuses on management of data from multiple sources. The ENFORMA tool is geared toward manual detection of the widest range of system types, but requires expertise to detect and diagnose problems. The UCB Fan Tools help automate spreadsheet analysis by generating useful plots and statistics for short-term data collection, and also are unique in their one-time data fan benchmarking concept (not reviewed).

\subsection{Tool Research and Development Perspectives}

In the emerging diagnostic tool industry, it is important to assess both the current state of the tools and the needs for future development. The features of an "ideal" tool depend on the intended user, and this paper has emphasized users interested in continuous analysis. There are multiple levels of sophistication and automation in the steps to diagnostics (data acquisition, data pre-processing and archiving, detection, and diagnosis) that add to the complexity of tool implementation. 
The following section is a compilation of the features and recommended practices for diagnostic tools that appear to be of greatest significance. None of the tools we studied incorporate all of these features.

Data acquisition, pre-processing, and archiving

- Maximize the automation of data acquisition, tool set-up, and data management. Diagnostic tools need to provide efficient data acquisition and management before diagnostics can be performed. Synchronization, filling in missing data, and detection of erroneous data are useful capabilities for processing EMCS data of variable quality.

- Archives should organize large datasets. The data collected for diagnostic tools can be large, especially when high frequencies (such as 1-minute) are collected. The diagnostic results (detected problems, performance metrics, alarms) should be archived as well.

- Store data from multiple systems in a single location with remote access. Remote access to data (raw and processed) and the diagnostic tool allows multiple users to view and analyze building performance. The diagnostic output can be made available to both the operators and managers that need to communicate and act upon the information.

\section{Detection and Diagnosis}

- Clearly communicate problems detected before they become too costly. Simple visual indicators such as color maps can help alert the user of persistent problems and avoid sifting through reports.

- Automated detection and diagnosis should be accurate and reliable. If false detection occurs often, the tool loses credibility. The tool should identify sensor problems that are crucial to the accuracy of diagnosis.

- Use data visualization to complement automated diagnostics. For advanced users, features such as time-series viewing, filtering, $X-Y$ scatter plots and daily profiles can be useful in verifying diagnostic output and understanding building performance over time. Aggregation of data over time and systems and performance metrics are fundamental aids to summarizing large amounts of data. The practical importance of data visualization is highly dependent on the user preferences.

- Present possible causes of problems and recommended remedial actions. Create "smart" diagnoses by continually using time-series data to narrow down the possible causes over time.

\section{General}

- Verify that tools are cost effective. See section 7.3 for a discussion of the importance of detailed case studies. 
- Allow for flexibility in tool use, but various users may require different techniques and interfaces. Ideally, the tool interface and features should meet the needs of varying user levels, from a novice to an advanced user. If the techniques are programmed in a modular way, some users could ignore certain features, while utilized by others. Another means for flexibility is variable settings on the sensitivity of diagnostic algorithms to allow control over the coarseness of the analysis. Initially, the user may wish to use a course screen for faults, and then increase the sensitivity as major problems are solved.

- Approach diagnostics using both bottom-up and top-down analysis for a complete understanding of the overall system. The tool should track high-level benchmarking and performance metrics, along with component specific information to aid in identifying and fixing problems.

\subsection{Future Work to Assess and Improve Tools}

Diagnostic tools will change as the market demands. Thus, this emerging market should be periodically reassessed for new entrants and additions to tool capabilities in the existing tools. Through detailed case studies, user interviews, and research on the quality of the diagnostics, the tools characterized in this report should be further assessed.

\section{Case Studies}

One important issue to future tool assessment is verifying their cost effectiveness. Does the tool provide valuable services that outweigh the cost of purchase and implementation? Currently, the few case studies that exist were performed by the developers and do not analyze costs. A logical next step is to investigate these case study sites to understand details about tool deployment, including cost (labor, software, training), savings, ease of use, and the most utilized tool features.

In the future, the tools should be studied in additional buildings and system types. These case studies would provide detailed information about the problems found through tool implementation, and the costs and benefits of fixing the problems. While the quantification of non-energy benefits such as improved system control and occupant comfort is difficult, it is important to qualitatively assess these issues in these case studies. Through these efforts, we can learn about the ability of diagnostic tools to save time and enhance building performance.

\section{User Interviews}

In addition to case studies, investigation is needed to understand the value of the tools to different levels of users. If the preferences and perspectives of each type of user are well understood, the tools could be tailored to operators, energy managers, HVAC engineers, and ESCOs. The level of automation desired depends on a user's proficiency with manual detection and their retro-commissioning goals. It may be difficult to gain valuable information from short-term user interviews, as it takes time for potential users to understand diagnostic tool capabilities well enough to assess their importance. Therefore, current users rather than potential users may need to be interviewed to accurately assess the value of a tool. It would be 
valuable to understand how time-series data are utilized for diagnostics both before and after the implementation of a diagnostic tool.

\section{Diagnostics Research}

To improve a tools' diagnostic quality, research is needed. In the near term, the data quality from EMCS should be evaluated for its effect on the reliability of the tools' diagnostics. For example, PG\&E has studied the effect of HVAC sensor accuracy on building performance as well as appropriate data collection frequencies to facilitate problem detection. These measurement issues are important to understand and improve the quality of diagnostics.

Little systematic research exists on the capabilities of existing EMCS data acquisition. Anecdotally, we find significant variation in the ability of EMCS to collect high frequency data, since control communications can be adversely affected. Data storage formats also vary, which can require significant pre-processing before use in a diagnostic tool. Studies are needed to better understand the abilities and limitations of EMCS to reliably collect the data necessary for use in diagnostic tools.

Many diagnostic tool developers plan to continue adding new diagnostic modules to their existing tools to broaden the capabilities beyond air handlers to other major HVAC systems and components. As tools become more widespread, it will be easier to assess the quality of diagnostics. Investigating each problem that an automated tool detects and diagnoses will help determine the accuracy of the diagnostic procedures (which may not be public). To supplement this field testing, the development of independent verification methods could set a standard for quantifying how well tools detect problems.

\subsection{Future for Diagnostic Tools}

In the future, diagnostic tools could be incorporated directly into EMCS front-ends for use by operators or third-party engineering services. One long-term vision for the direction of diagnostic tools is to run physical energy analysis models in real-time to automatically detect deviation from expected system behavior (Haves, 2000). With a building life cycle perspective, the automated diagnostics of the future could be linked back to design intent and commissioning data for performance tracking over the entire building life (Hitchcock et al., 1998). Diagnostics could be incorporated into maintenance management software to automatically generate maintenance requests. There is also opportunity to supplement diagnostic tools with information from on-line occupant feedback surveys. Many of these issues are being tested in a remote monitoring network created for General Services Administration (GSA) buildings, called the GSA Energy and Maintenance Network (Piette et al., 2001a).

The possibilities for incorporating diagnostic tools into advanced performance monitoring may take many years to move forward in today's fragmented and typically conservative buildings industry. Studies of the benefits of retro-commissioning have shown large energy savings from "tuning up" existing equipment. The tools evaluated in this report can help perform the diagnostics necessary for commissioning on either a short-term or continuous basis. 
Diagnostic software tools are an emerging industry with great potential to save energy in building operations. A key value in using these tools lies in reducing the data management and analysis time necessary to obtain valuable information from EMCS data, thus enabling operators, managers, and engineers to efficiently assess building performance. By using continuous time-series data and emerging software tools, the power of information technology to support building operations has only begun to be tapped.

\section{Acknowledgements}

We are grateful for the ongoing information provided by the following tool designers: Tom Webster with UC Berkeley, Stuart Waterbury with Architectural Energy Corporation, Ryan Stroupe with the Pacific Energy Center, Michael Brambley and Teresa Fettkether with Pacific Northwest National Laboratory, Lon Brightbill and Larry Lister with Facility Dynamics Engineering, and Matt Owens with Silicon Energy. We are thankful to Philip Haves, Priya Sreedharan, and Satkartar Kinney at Lawrence Berkeley National Laboratory, and to Martha Brook from the California Energy Commission, for their assistance and support. This work was partially by the Assistant Secretary for Energy Efficiency and Renewable Energy, Office of Building Technology, State and Community Programs, Office of Building Research and Standards of the U.S. Department of Energy under Contract No. DE-AC03-76SF00098. 


\section{Sources Cited}

\section{Diagnostics Background}

Anderson, D., L. Graves, W. Reinert, et al., "A Quasi-real-time Expert System for Commercial Building HVAC Diagnostics", ASHRAE Transactions, Vol. 95, Part 2, pp. 954-960, 1989.

Benouarets, M., A. L. Dexter, R.S. Fargus, P. Haves, T.I. Salsbury, and J.A. Wright, "ModelBased Approaches to Fault Detection and Diagnosis in Air-Conditioning Systems", Proceedings of the Conference on System Simulation in Buildings 1994, Liège, Belgium, December 1994.

Brambley, M. and R. Pratt, "Using Automated Diagnostic Tools to Provide Energy Services". Proceedings of the ACEEE 2000 Summer Study on Energy Efficiency in Buildings, Washington D.C., August 2000, 7.11-7.21.

Claridge, D., C. Culp, M. Liu, S. Deng, W.D. Turner, J.S. Haberl, “Campus-wide Continuous CommissioningSM of University Buildings," Proceedings of the ACEEE 2000 Summer Study on Energy Efficiency in Buildings, Washington D.C., August 2000.

Dodds, D., C. Dasher, and M. Brenneke, "Building Commissioning: Maps, Gaps, and Directions", Proceedings of the ACEEE 2000 Summer Study on Energy Efficiency in Buildings, Washington D.C., Commercial Buildings, 4.133-4.143, August 1998.

U.S. Energy Information Administration, Commercial Buildings Energy Consumption Survey (CBECS) Data, 1995. http:/ / www.eia.doe.gov/emeu/cbecs/

Fromberg, R., F. Mayhew, E. Kolderup, R. Kammerud, M. D'Albora, and J. Blessent, “Method for Determining Measurement Accuracy and Storage Frequency for Improved Building Energy Efficiency", Prepared by PG\&E for the California Energy Commission, September 1999.

Fryer, L., Tapping the Value of Energy Use Data: New Tools and Techniques. ESource Strategic Memo, March 1996.

Gregerson, Joan, “Commissioning Existing Buildings”, E Source Tech Update TU-97-3, March 1999.

Haberl, J.S., L.K. Norford, J.V. Spadaro, "Diagnosing Building Operational Problems", ASHRAE Journal, Vol. 31, no. 6, pp. 20-30, June 1989.

Haves, P., "Overview of Diagnostic Methods," Proceedings of the Workshop on Diagnostics for Commercial Buildings: From Research to Practice, June 16-17, 1999, Pacific Energy Center, San Francisco. http://poet.lbl.gov/diagworkshop/proceedings

Haves, P., and S. Khalsa, "Model-based Performance Monitoring: Review of Diagnostic Methods and Chiller Case Study", Proceedings of the ACEEE 2000 Summer Study on Energy Efficiency in Buildings, Washington D.C., August 2000, 3.161-3.172. 
Heinemeier, K., "Marketability Requirements for Fault Detection and Diagnostics in Commercial Buildings," Proceedings of the ACEEE 1998 Summer Study on Energy Efficiency in Buildings, Washington D.C., August 1998.

Heinemeier, K., "User and Market Factors that Influence Diagnostic Tool Development". Proceedings of the Workshop on Diagnostics for Commercial Buildings: From Research to Practice, June 16-17, 1999, Pacific Energy Center, San Francisco.

http:/ / poet.lbl.gov/diagworkshop/proceedings

Heinemeier, K., The Use of Energy Management and Control Systems to Monitor the Energy Performance of Commercial Buildings, Ph.D. Thesis, Dept. of Architecture, UC Berkeley, December 1994.

Hitchcock, R., M.A. Piette, S. Selkowitz, "Documenting Performance Metrics in a Building Lifecycle Information System", Proceedings of the Green Building Challenge '98, October 26-28, 1998, Vancouver, British Columbia, Canada.

House, J., and G. Kelly, "An Overview of Building Diagnostics” Proceedings of the Workshop on Diagnostics for Commercial Buildings: From Research to Practice, June 16-17, 1999, Pacific Energy Center, San Francisco. http:/ / poet.lbl.gov/diagworkshop/proceedings

Kreider, J.F., X.A. Wang, "Artificial Neural Networks demonstrated for Automated Generation of Energy Use Predictors for Commercial Buildings", ASHRAE Transactions, Vol 97, Part 2, pp. 775-779, 1991.

Norford, L.K., A. Allgeier, J.V. Spadaro, “Improved Energy Information for a Building Operator - Exploring the Possibilities of a Quasi-real-time Knowledge-based System", ASHRAE Transactions, Vol. 96, Part 1, pp. 1515-1523, 1990.

Piette, S. Khalsa, and P. Haves, "Use of an Information Monitoring and Diagnostic System to Improve Building Operations," Proceedings of the ACEEE 2000 Summer Study on Energy Efficiency in Buildings, Washington D.C., August 2000, 7.101-7.112.

Piette, M.A., S. Kinney, and H. Friedman, "EMCS and Time-Series Energy Data Analysis in a Large Government Office Building", Proceedings of the $9^{\text {th }}$ National Conference on Building Commissioning, May 9-11, 2001(a).

Piette, M.A, S. Kinney, B. Nordman and A. Meier, CAL-ARCH Software Specifications Document. Report for California Energy Commission's Public Interest R\&D Program: High Performance Commercial Building Systems, Element 2 - Life Cycle Tools, Project 2.1 Benchmarking and Performance Metrics Draft February 8, 2001(b).

Rossi, T., and J.E. Braun, "A Statistical, Rule-based Fault Detection and Diagnostic Method for Vapor Compression Air Conditioners”, HVACER Research, Col 3, No. 1, pp. 19-37, January 1997. 
Sartor, D., M.A. Piette, W. Tschudi, and S. Fok, "Strategies for Energy Benchmarking In Cleanrooms and Laboratory-Type Facilities," Proceedings of the ACEEE 2000 Summer Study on Energy Efficiency in Buildings, Washington D.C., August 2000.

Sebald, A. and M.A. Piette, "Diagnostics for Building Commissioning and Operation", Lawrence Berkeley National Laboratory Report, LBNL-40512, December 1997.

\section{Tool overview}

Brambley, M., R. Pratt, and S. Katipamula, “Use of Automated Tools for Building Commissioning", Proceedings of the $7^{\text {th }}$ National Conference on Building Commissioning, Portland, Oregon, May 3-5 1999.

Friedman, H., and M.A. Piette, "Comparison of Emerging Diagnostic Tools for Large Commercial HVAC Systems", Proceedings of the 9th National Conference on Building Commissioning, Cherry Hill, NJ, May 9-11, 2001(a). LBNL-47698.

Friedman, H., and M.A. Piette, "Evaluation of Emerging Diagnostic Tools for Commercial HVAC Systems", Proceedings of the International Conference for Enhanced Building Operations, Austin, Texas, July 17-18, 2001(b). LBNL-47966.

Portland Energy Conservation, Inc., California Commissioning and Market Characterization Study. Final Report and Task 1 Literature Review. Prepared for PG\&E, November 2000.

\section{PACRAT}

Santos, J. and L. Brightbill. "Automated Diagnostics from DDC Data - PACRAT," Proceedings of the $8^{\text {th }}$ National Conference on Building Commissioning, Kansas City, MO, May 3-5 2000.

Santos, J., “Automated Diagnostics From EMCS Data”, Presentation at ESource, 2000.

PACRAT website: $\underline{w w w . f a c i l i t y d y n a m i c s . c o m / S o f t w a r e / P A C R A T / P A C R A T . h t m ~}$

\section{WBD}

Brambley, M., R. Pratt, D. Chassin, S. Katipamula, "Automated Diagnostics for Outdoor Air Ventilation and Economizers." ASHRAE Journal, Vol. 40, No. 10, pp. 49-55, October 1998.

Katipamula, S., R. Pratt, D. Chassin, Z.T. Taylor, K. Gowri, and M. Brambley, “Automated Fault Detection and Diagnostics for Outdoor-Air Ventilation Systems and Economizers: Methodology and Results from Field Testing", ASHRAE Transactions, V.105, Pt 1, pp. 555-567, 1999.

Pratt, R., S. Katipamula, M. Brambley, and S. Blanc, "Field Results from Application of the Outdoor-Air/Economizer Diagnostician for Commissioning and O\&M", Proceedings of the $8^{\text {th }}$ National Conference on Building Commissioning, Kansas City, MO, May 3-5 2000.

WBD website: $\underline{\text { www.buildings.pnl.gov:2080/wbd/content.htm }}$ 


\section{ENFORMA}

Arney, M, D. Frey, “Long-Term Energy Efficiency Strategy: Building Tune-ups and Performance-based Maintenance", Proceedings of the $7^{\text {th }}$ National Conference on Building Commissioning, May 3-5 1999.

ENFORMA Software Marketing Materials, "Portable Diagnostic Solutions Case Histories" and "Pilot Diagnostic Project for a 60,000 Square Foot Office Building in Baltimore, Maryland", 1999. Available on ENFORMA website.

ENFORMA HVAC Analyzer User's Guide, Version 3.11 for Windows 95M , 1999.

Frey, D., "Diagnostics Based on Short-Term Monitoring," Proceedings of the Workshop on Diagnostics for Commercial Buildings: From Research to Practice, June 16-17, 1999, Pacific Energy Center, San Francisco. http://poet.lbl.gov/diagworkshop/proceedings

Waterbury, S., D. Frey, and K. Johnson, "Commercial Building Performance Evaluation System for HVAC Diagnostics and Commissioning", Proceedings of the ACEEE 1994 Summer Study on Energy Efficiency in Buildings, Washington D.C., August 1994.

ENFORMA website: $\underline{\text { www.archenergy.com/AECHome/ENFORMA/enforma.htm }}$

\section{UC Berkeley Fan Tools}

Webster, T., C. Huizenga, R. Martin, E. Ring, F. Bauman, E. Arens “Commercial Thermal Distribution Systems: Reducing Fan Energy in Built-up Fan Systems Final Report: Phase III," prepared for the California Energy Commission and the California Institute for Energy Efficiency by the Center for Environmental Design Research, University of California, Berkeley, CEDR-03-99, Fall 1999.

Webster, T., E. Ring, Q. Zhang, C. Huizenga, F. Bauman, E. Arens, “Commercial Thermal Distribution Systems: Reducing Fan Energy in Built-up Fan Systems Final Report: Phase IV," prepared for the California Energy Commission and the California Institute for Energy Efficiency by the Center for Environmental Design Research, University of California, Berkeley, CEDR-04-99, Fall 1999.

\section{Universal Translator}

Stroupe, R., "Lessons from the Tool Lending Library," Proceedings of the $8^{\text {th }}$ National Conference on Building Commissioning, Kansas City, MO, May 3-5 2000.

\section{EEM Suite}

Silicon Energy Marketing Materials, February 2001. EEM Suite. www.siliconenergy.com Silicon Energy Corporation. March 2001. EEM Suite 
EEM Suite website: $\underline{w w w . s i l i c o n e n e r g y . c o m / h t m l / p r o d u c t s . h t m l ~}$

\section{Additional Internet Resources}

Electric Eye: www.eeye.com.sg/

Information Monitoring and Diagnostic System: http://eetd.lbl.gov/ea/iit/diag/index.html 


\section{Appendix A Abbreviations}

\begin{tabular}{|c|c|}
\hline $\mathrm{AEC}$ & Architectural Energy Corporation \\
\hline $\mathrm{AHU}$ & Air handling unit \\
\hline CEC & California Energy Commission \\
\hline CFM & Cubic feet per minute air flow \\
\hline $\mathrm{CHW}$ & Chilled water \\
\hline CIEE & California Institute for Energy Efficiency \\
\hline $\mathrm{CT}$ & Cooling tower \\
\hline $\mathrm{CV}$ & Constant volume \\
\hline CW & Condenser water \\
\hline EEM Suite & Enterprise Energy Management Suite \\
\hline EMCS & Energy management control system \\
\hline ESCO & Energy service company \\
\hline $\mathrm{HP}$ & Heat pump \\
\hline HVAC & Heating, ventilation, and air conditioning \\
\hline $\mathrm{HW}$ & Hot water \\
\hline $\mathrm{M} \& \mathrm{~V}$ & Monitoring and verification \\
\hline MAT & Mixed air temperature \\
\hline $\mathrm{OA}$ & Outdoor air \\
\hline $\mathrm{OA} / \mathrm{E}$ & Outdoor Air Economizer (WBD module) \\
\hline OAT & Outdoor air temperature \\
\hline PACRAT & Performance and Continuous Recommissioning Analysis Tool \\
\hline PIER & Public Interest Energy Research \\
\hline RAT & Return air temperature \\
\hline RF & Return fan \\
\hline RH & Relative humidity \\
\hline RT & Return temperature \\
\hline SAT & Supply air temperature \\
\hline SF & Supply fan \\
\hline SP & Static pressure \\
\hline ST & Supply temperature \\
\hline UT & Universal Translator \\
\hline VAV & Variable air volume \\
\hline VP & Velocity pressure \\
\hline VSD & Variable speed drive \\
\hline WBD & Whole Building Diagnostician \\
\hline WBE & Whole Building Energy Module (WBD module) \\
\hline ZAT & Zone air temperature \\
\hline
\end{tabular}




\section{Appendix B Supplementary Figures}

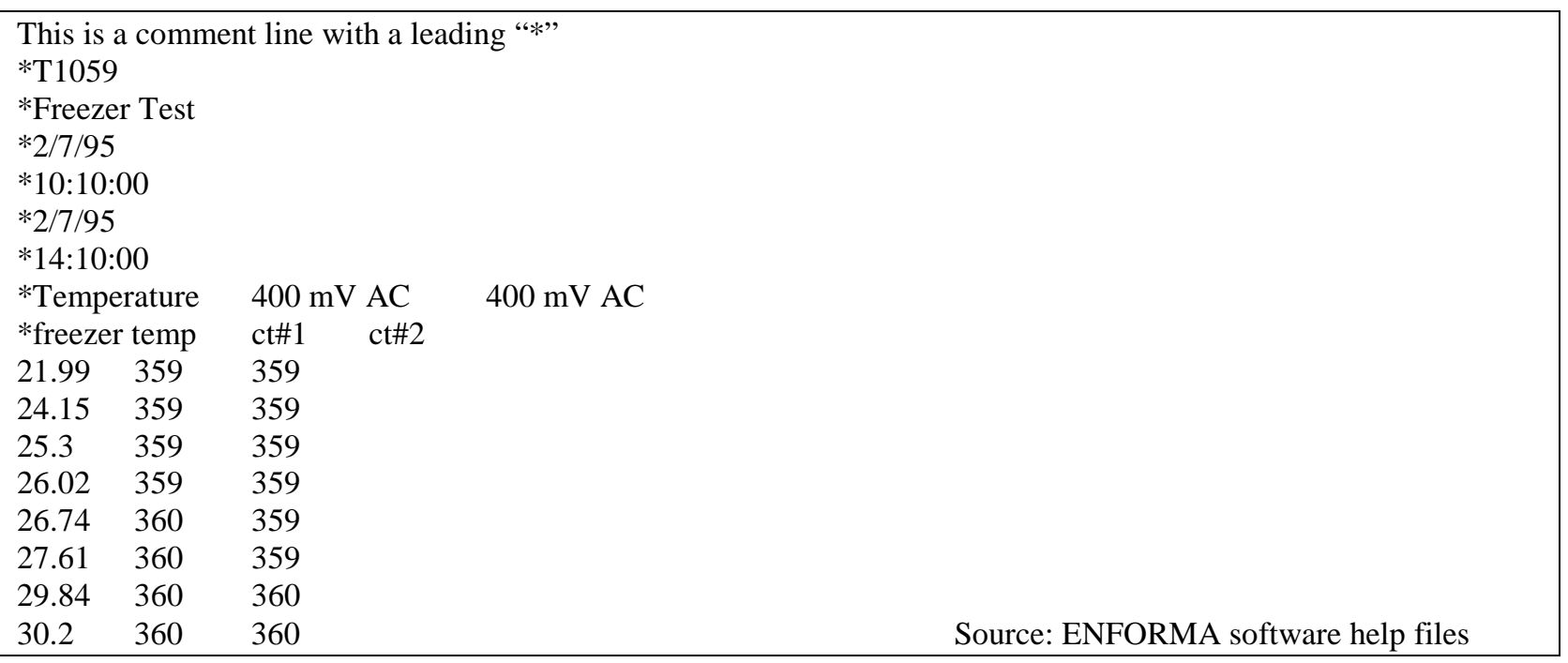

Figure B1 Sample ASCII input file for the ENFORMA software "Retrieve from file" utility

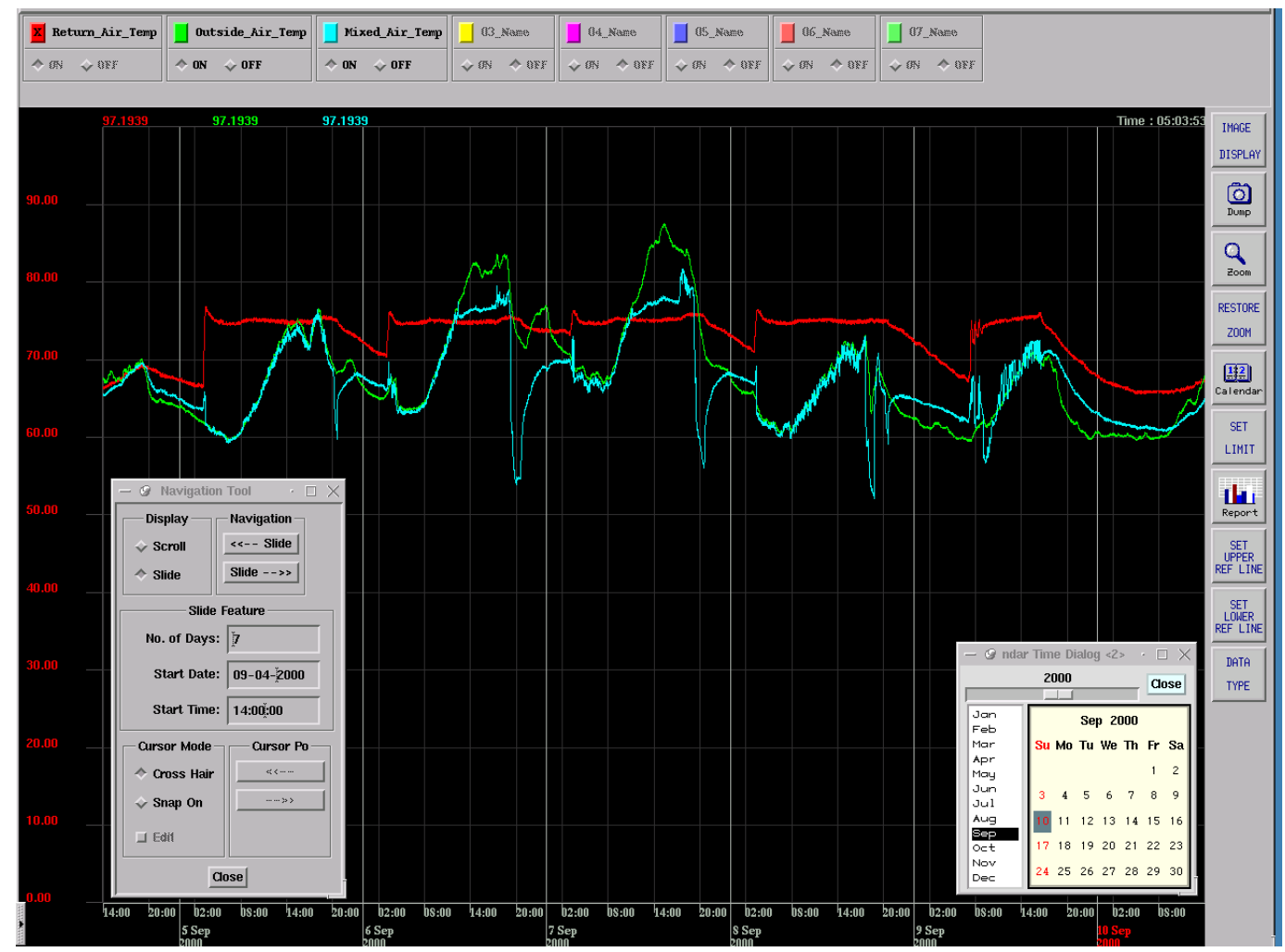

Figure B2 Electric Eye time-series data visualization 


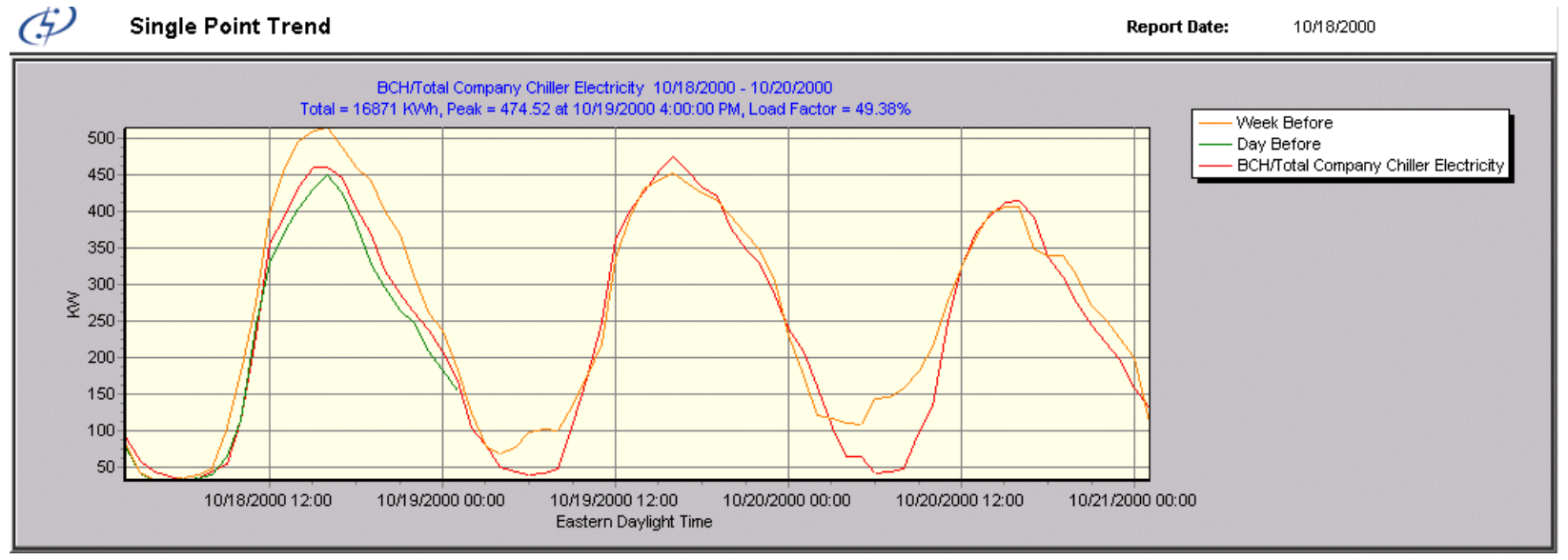

Figure B3 EEM Suite, Single point time-series trending with historical data

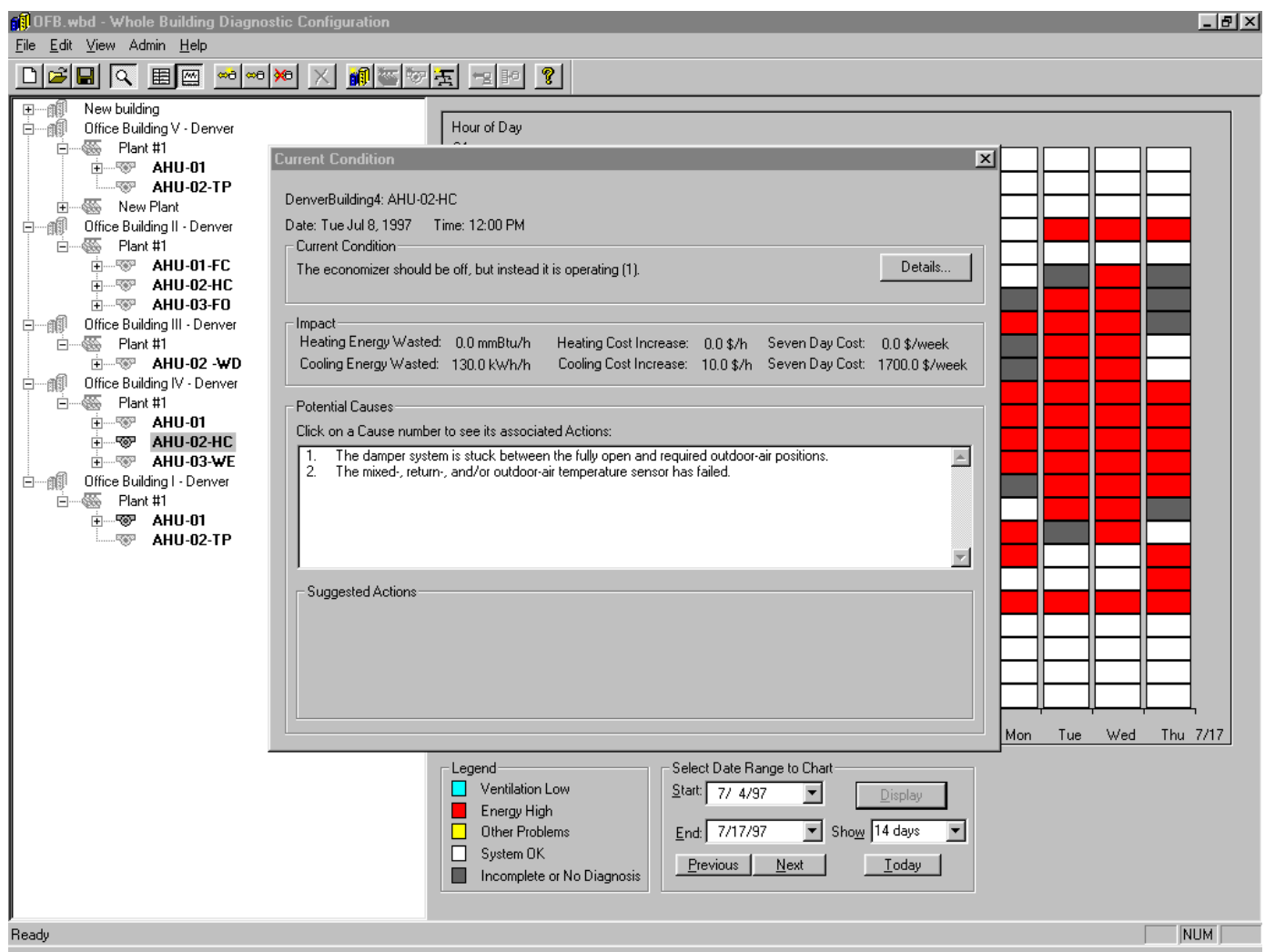

Figure B4 WBD outdoor air economizer diagnosis screen 


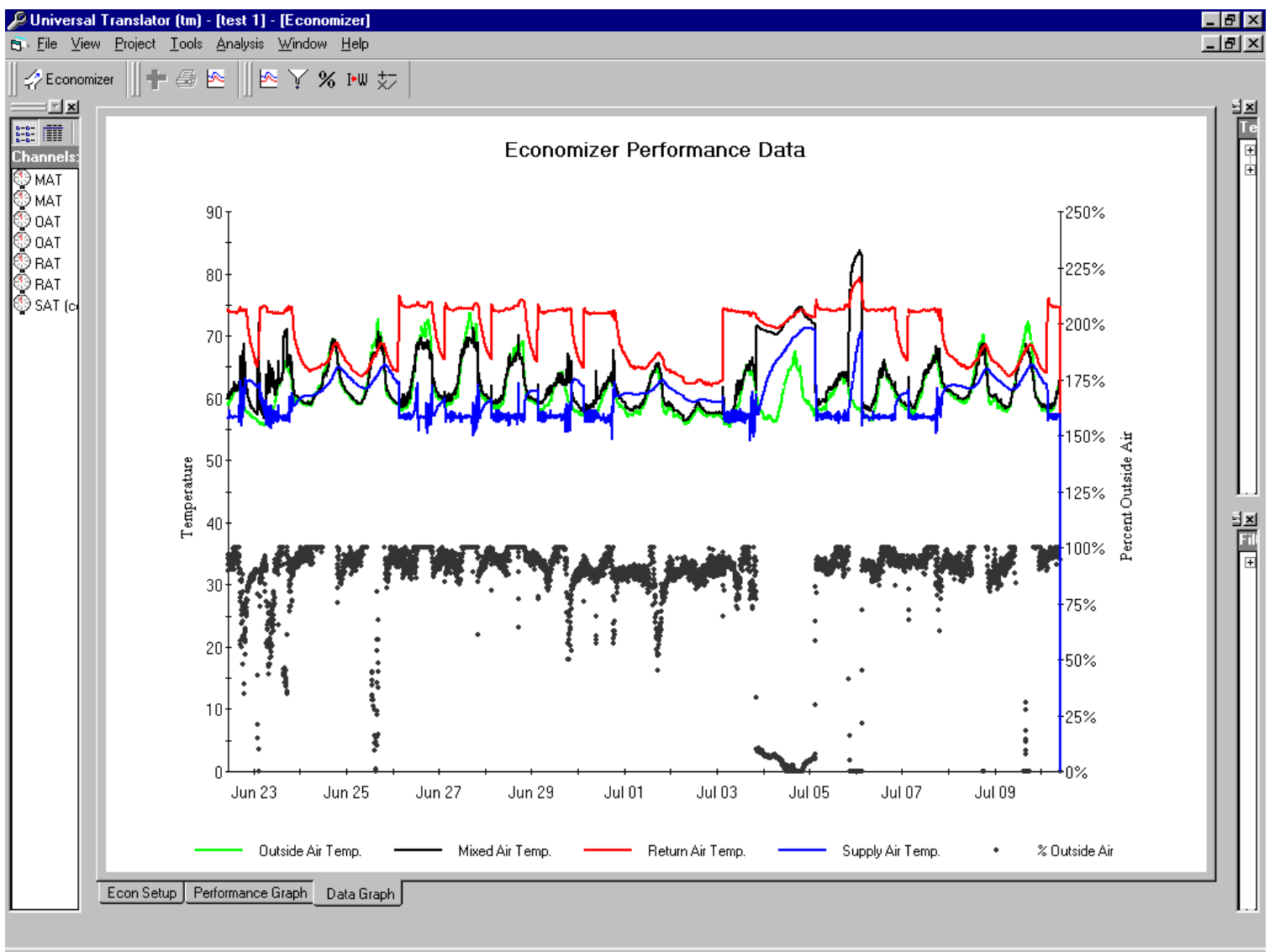

Figure B5 Universal Translator economizer module data graph 


\section{Appendix C Tool Summaries}

\section{ENFORMA software}

\section{Tool overview}

\begin{tabular}{|c|c|}
\hline Developer & $\begin{array}{l}\text { Architectural Energy Corporation, Boulder, CO } \\
\text { (HVAC engineers and computer programmers) }\end{array}$ \\
\hline Funding & Electric Power Research Institute and private funding \\
\hline Target Systems & $\begin{array}{l}\text { - Central plant } \\
\text { - Air distribution: VAV, CV, dual duct, multizone } \\
\text { - Water distribution } \\
\text { - Zones } \\
\text { - Zone-level systems: single zone HP or fan coil }\end{array}$ \\
\hline Diagnostic approach & Bottom-up \\
\hline Level of automation & $\begin{array}{l}\text { Manual data importing, automatically created standard plots, } \\
\text { automated data pre-filtering (range checking), manual detection } \\
\text { and diagnosis using pre-defined reference plots for comparison. }\end{array}$ \\
\hline $\begin{array}{l}\text { Monitoring period: } \\
\text { Short-term or } \\
\text { continuous }\end{array}$ & Short-term (about 2 weeks of 15 minute data) \\
\hline Software platform & Data stored in binary format within the software. \\
\hline Data sources & $\begin{array}{l}\text { Short-term using dataloggers or EMCS data. Formatting is required } \\
\text { for EMCS data. }\end{array}$ \\
\hline Target audience & $\begin{array}{l}\text { Engineers and operators with extensive HVAC knowledge. } \\
\text { ESCO for M\&V projects, identification of savings. }\end{array}$ \\
\hline Cost & Software $\$ 495$, configuration and training $\$ 800 /$ day + travel \\
\hline $\begin{array}{l}\text { Method for } \\
\text { configuration }\end{array}$ & Training session included. Consulting work as needed. \\
\hline $\begin{array}{l}\text { Extent of } \\
\text { commercialization }\end{array}$ & $\begin{array}{l}\text { Commercialized in December 1996. 50+ software licenses. Applied } \\
\text { by AEC to } 300 \text { buildings. }\end{array}$ \\
\hline $\begin{array}{l}\text { Additional features } \\
\text { beyond diagnostics }\end{array}$ & $\begin{array}{l}\text { ENFORMA Lighting evaluation system: estimate annual savings } \\
\text { from lighting retrofits, retrofit analysis }\end{array}$ \\
\hline Service available & Additional AEC consulting services for fee. \\
\hline
\end{tabular}


Enforma software, continued

Operational Use

\begin{tabular}{|c|c|}
\hline Informational inputs & $\begin{array}{l}\text { Schedule: Data start/stop time, data collection frequency, daily } \\
\text { occupation schedule } \\
\text { System: central plant/air distribution/zone equipment } \\
\text { configuration }\end{array}$ \\
\hline $\begin{array}{l}\text { Monitoring points by } \\
\text { system }\end{array}$ & $\begin{array}{l}\text { Whole building: none } \\
\text { Economizer: SAT, OAT, RAT, MAT, RH (ambient and return) } \\
\text { Other air handler: SF/RF amps, Supply air: SP, VP, RH, cfm } \\
\text { Central plant: Chiller amps, CHWST, CHWRT, CHW pump amps, } \\
\qquad \text { CT sump T, CWRT, CT fan amps, HWST, HWRT, } \\
\text { HW pump amps, OAT, RH } \\
\text { Zones: ZAT, coil SAT, zone supply VP } \\
\text { Recommended trending frequency: } 2-3 \text { minutes }\end{array}$ \\
\hline Standard plots & $\begin{array}{l}140 \text { pre-defined reference plots, each with an automatically created } \\
\text { plot using measured data. }\end{array}$ \\
\hline Archiving & $\begin{array}{l}\text { Datasets are imported into each project and saved in a binary } \\
\text { format within the software. Can save multiple project files as an } \\
\text { archive. }\end{array}$ \\
\hline Pre-processing & $\begin{array}{l}\text { Assumes sequential data, does not import timestamps. Pre-filtering } \\
\text { for erroneous data. }\end{array}$ \\
\hline Problems detected & $\begin{array}{l}\text { - Unoccupied operation } \\
\text { - Temperature control } \\
\text { - Cooling tower (CT) capacity } \\
\text { - Condenser performance } \\
\text { - Interlock with AHU and CT } \\
\text { - Chiller kW temp dependence } \\
\text { - Lack of economizer cooling } \\
\text { - Simultaneous heating/cooling } \\
\text { - Humidifier operation } \\
\text { - Evaporative cooler performance } \\
\text { - Static pressure \& fan control } \\
\text { - Duct heat gain/loss } \\
\text { - Terminal unit operation }\end{array}$ \\
\hline $\begin{array}{l}\text { Data visualization } \\
\text { features }\end{array}$ & $\begin{array}{l}\text { Time-series (mainly user-defined) with zoom, X-Y scatter, daily } \\
\text { profile (multiple days in scatter plot), filtering (day type, occupied, } \\
\text { date range, time of day, day of week, or based on another data } \\
\text { point). Create calculated points (use this feature to aggregate data). }\end{array}$ \\
\hline Diagnostic Methods & $\begin{array}{l}\text { Reference plots, reference lines, statistics, performance metrics, help } \\
\text { files (tool guide) }\end{array}$ \\
\hline $\begin{array}{l}\text { Uncertainty } \\
\text { quantification }\end{array}$ & None \\
\hline Problem notification & None \\
\hline Problem prioritization & None \\
\hline
\end{tabular}




\section{The Universal Translator}

\section{Tool overview}

\begin{tabular}{|c|c|}
\hline Developer & $\begin{array}{l}\text { Pacific Energy Center, Pacific Gas and Electric } \\
\text { (HVAC engineers, architects, and computer programmers) }\end{array}$ \\
\hline Funding & California Public Goods Charges (ratepayer) \\
\hline Target Systems & $\begin{array}{l}\text { - Air-side economizer } \\
\text { - Equipment for cycling and run-time analysis }\end{array}$ \\
\hline Diagnostic approach & Bottom-up \\
\hline Level of automation & $\begin{array}{l}\text { Manual data importing, automated synchronization routine, } \\
\text { automatically created standard plots for economizer, limited level } \\
\text { of automation to economizer problem detection and diagnosis with } \\
\text { diagnostic rules. }\end{array}$ \\
\hline $\begin{array}{l}\text { Monitoring period: } \\
\text { Short-term or } \\
\text { continuous }\end{array}$ & Short-term (about a month of 15 minute data) \\
\hline Software platform & SQL (Microsoft Access) databases \\
\hline Data sources & $\begin{array}{l}\text { Short-term dataloggers or EMCS data (no specific formatting } \\
\text { required) }\end{array}$ \\
\hline Target audience & $\begin{array}{l}\text { Engineers and operators with HVAC knowledge. } \\
\text { ESCO for monitoring and verification projects, identification of } \\
\text { savings. }\end{array}$ \\
\hline Cost & Free \\
\hline $\begin{array}{l}\text { Method for } \\
\text { configuration }\end{array}$ & $\begin{array}{l}\text { Written tutorial available and free training is periodically offered at } \\
\text { the Pacific Energy Center. }\end{array}$ \\
\hline $\begin{array}{l}\text { Extent of } \\
\text { commercialization }\end{array}$ & $\begin{array}{l}\text { Beta testing in } 2000 \\
50+\text { users }\end{array}$ \\
\hline $\begin{array}{l}\text { Additional features } \\
\text { beyond diagnostics }\end{array}$ & $\begin{array}{l}\text { Retrofit analysis: occupancy sensors for lighting and plugload } \\
\text { control }\end{array}$ \\
\hline Service available & None \\
\hline
\end{tabular}




\section{Universal Translator, continued}

\section{Operational Use}

\begin{tabular}{|l|l|}
\hline Informational inputs & Schedule, SAT setpoint, \% minimum outside air \\
\hline Monitoring points & $\begin{array}{l}\text { Whole building: none } \\
\text { Economizer: SAT, OAT, RAT, MAT } \\
\text { Other air handler: any power data } \\
\text { Central plant: any power data } \\
\text { Recommended trending frequency: 5-15 minutes }\end{array}$ \\
\hline Standard plots & 2 standard plots in air-side economizer module. \\
\hline Archiving & $\begin{array}{l}\text { Data are not saved in each project file, they are accessed from } \\
\text { another location. }\end{array}$ \\
\hline Pre-processing & $\begin{array}{l}\text { Synchronization using time-weighted average, searches for } \\
\text { repeated timestamps (must be manually corrected), manual } \\
\text { application of time shifts, slope, and offset adjustments. }\end{array}$ \\
\hline Problems detected & $\begin{array}{l}\text { - Lack of economizer cooling } \\
\text { - Run-time and cycling analysis }\end{array}$ \\
\hline $\begin{array}{l}\text { Data visualization } \\
\text { features }\end{array}$ & $\begin{array}{l}\text { Time-series (mainly user-defined) with up to 4 points on two Y- } \\
\text { axes with zoom, advanced filtering capabilities, with detailed } \\
\text { scheduling. No X-Y scatter plots. Schedules can be defined for } \\
\text { multiple years and filters can be based on a data point status or on } \\
\text { threshold values. }\end{array}$ \\
\hline Diagnostic Methods & $\begin{array}{l}\text { Reference lines. Statistics help to show the quality of the data fit to } \\
\text { the reference line. }\end{array}$ \\
\hline Uncertainty methods & $\begin{array}{l}\text { User inputs temperature sensor accuracy and a reference line error } \\
\text { band is created. }\end{array}$ \\
\hline Problem notification & None \\
\hline Problem prioritization & None \\
\hline
\end{tabular}




\section{UC Berkeley Fan Tools}

\section{Tool overview}

\begin{tabular}{|l|l|}
\hline Developer & $\begin{array}{l}\text { UC Berkeley, Center for Environmental Design Research } \\
\text { (HVAC engineers and researchers) }\end{array}$ \\
\hline Funding & CIEE, CEC PIER Program \\
\hline Target Systems & Built-up Fan Systems \\
\hline Diagnostic approach & Bottom-up \\
\hline Level of automation & $\begin{array}{l}\text { Manual data acquisition, pre-processing, archiving. Automatically } \\
\text { created diagnostic plots for manual detection. }\end{array}$ \\
\hline $\begin{array}{l}\text { Monitoring period: } \\
\text { continuous }\end{array}$ & Short-term (about 2 weeks of 15 minute data) \\
\hline Software platform & Excel spreadsheet \\
\hline Data sources & Short-term dataloggers or EMCS data (specific formatting required) \\
\hline Target audience & $\begin{array}{l}\text { Engineers and operators with HVAC knowledge. } \\
\text { ESCO for monitoring and verification projects, identification of } \\
\text { savings. }\end{array}$ \\
\hline Cost & Free \\
\hline $\begin{array}{l}\text { Method for } \\
\text { configuration }\end{array}$ & $\begin{array}{l}\text { Detailed background calculations and explanation of plots available } \\
\text { in reports. }\end{array}$ \\
\hline $\begin{array}{l}\text { Extent of } \\
\text { commercialization }\end{array}$ & $\begin{array}{l}\text { Prototype in 1999. Currently no users (plans for demonstration } \\
\text { projects). }\end{array}$ \\
\hline $\begin{array}{l}\text { Additional features } \\
\text { beyond diagnostics }\end{array}$ & $\begin{array}{l}\text { Fan performance benchmarking: one-time power, flow, pressure, } \\
\text { and fan speed measurements for benchmarking against fans of } \\
\text { similar type. The Fan Performance Analysis tool compares speed- } \\
\text { corrected fan metrics for measured and design data to calculate fan } \\
\text { efficiency, motor load factor, system operating point, flow density } \\
\text { (cfm/sq ft), specific fan power (watts /cfm), and fan efficiency ratio } \\
\text { (measured efficiency/design efficiency). }\end{array}$ \\
\hline Service available & None \\
\hline
\end{tabular}




\section{UC Berkeley Fan Tools, continued}

\section{Operational Use}

\begin{tabular}{|c|c|}
\hline Informational inputs & $\begin{array}{l}\text { Setpoints: ZAT, SAT, SP, economizer limits, \% outside air. } \\
\text { HVAC schedule, fan motor nameplate data }\end{array}$ \\
\hline Monitoring points & $\begin{array}{l}\text { Whole building: none } \\
\text { Economizer: SAT, OAT, RAT, MAT } \\
\text { Other air handler: SF kW or amps, OAT, fan SP } \\
\text { Central plant: none } \\
\text { Zones: ZAT, HWST, HWRT, OAT } \\
\text { Recommended trending frequency: } 15 \text { minutes }\end{array}$ \\
\hline Standard plots & $\begin{array}{l}\text { - Many standard plots in each of the five modules: } \\
\text { - Fan power analysis } \\
\text { - System temperature analysis } \\
\text { - Zone temperature analysis } \\
\text { - Reheat analysis } \\
\text { - Static pressure }\end{array}$ \\
\hline Archiving & $\begin{array}{l}\text { Maximum of about two weeks of } 15 \text { minute data input and saved in } \\
\text { each module. }\end{array}$ \\
\hline Pre-processing & None \\
\hline Problems detected & $\begin{array}{l}\text { - Lack of economizer cooling } \\
\text { - Motor load factor problems } \\
\text { - Static pressure } \\
\text { - Run-time } \\
\text { - Reheat operations } \\
\text { - Temperature control }\end{array}$ \\
\hline $\begin{array}{l}\text { Data visualization } \\
\text { features }\end{array}$ & $\begin{array}{l}\text { Time-series, X-Y, daily profile (scatter), load duration (\# hours vs. } \\
\text { motor load factor in bins) }\end{array}$ \\
\hline Diagnostic Methods & Reference lines, statistics. \\
\hline Uncertainty methods & $\begin{array}{l}\text { User inputs temperature sensor accuracy and a reference line error } \\
\text { band is created. }\end{array}$ \\
\hline Problem notification & None \\
\hline Problem prioritization & None \\
\hline
\end{tabular}




\section{Whole Building Diagnostician}

\section{Tool overview}

\begin{tabular}{|l|l|}
\hline Developer & $\begin{array}{l}\text { Pacific Northwest National Laboratory, Honeywell, University of } \\
\text { Colorado, (researchers and computer programmers) }\end{array}$ \\
\hline Funding & Department of Energy \\
\hline Target Systems & $\begin{array}{l}\text { Economizer } \\
\text { Whole building electric, HVAC electric, thermal }\end{array}$ \\
\hline Diagnostic approach & Bottom-up (OA/E) and top-down (WBE) \\
\hline Level of automation & $\begin{array}{l}\text { Automated data importing, filtering for erroneous data, and } \\
\text { averaging. Automated economizer problem detection and } \\
\text { diagnosis, automated detection of deviation from baseline. }\end{array}$ \\
\hline $\begin{array}{l}\text { Monitoring period: } \\
\text { Short-term or } \\
\text { continuous }\end{array}$ & Continuous \\
\hline Software platform & SQL (Microsoft Access) database \\
\hline Data sources & EMCS data (use BASLink to automate the data connection) \\
\hline $\begin{array}{l}\text { Target audience } \\
\text { Operators (current user interface target) }\end{array}$ \\
\hline Cost & To be determined \\
\hline $\begin{array}{l}\text { Method for } \\
\text { configuration }\end{array}$ & Developers configure, perform initial analysis. \\
\hline $\begin{array}{l}\text { Extent of } \\
\text { commercialization }\end{array}$ & $\begin{array}{l}\text { Pilot sites began in 1998. 10 sites, 200 buildings (100 at district } \\
\text { heating and cooling plant) }\end{array}$ \\
\hline $\begin{array}{l}\text { Additional features } \\
\text { beyond diagnostics }\end{array}$ & M\&V - HVAC or whole building \\
\hline Service available & On a pilot project basis. \\
\hline
\end{tabular}




\section{Whole Building Diagnostician, continued}

\section{Operational Use}

\begin{tabular}{|l|l|}
\hline Informational inputs & $\begin{array}{l}\text { WBE: Schedule, cost per kWh } \\
\text { OA/E: Schedule, economizer control strategy and setpoints, } \\
\text { cost per kWh }\end{array}$ \\
\hline Monitoring points & $\begin{array}{l}\text { Whole building: Whole building electric, OAT, RH } \\
\text { Economizer: SAT, OAT, RAT, MAT, RH, SF on/off, HW valve, } \\
\text { CHW valve } \\
\text { Other air handler: none } \\
\text { Central plant: Whole building gas, HVAC (other than chiller) } \\
\text { electric, and chiller electric, OAT, RH } \\
\text { Recommended trending frequency: User defined, but converted to } \\
\text { hourly averages or sums }\end{array}$ \\
\hline Standard plots & Hourly data automatically archived in database. \\
\hline Archiving & $\begin{array}{l}\text { Pre-filtering for erroneous data, creating hourly averages or sums } \\
\text { for the diagnostic modules. }\end{array}$ \\
\hline Pre-processing & $\begin{array}{l}\text { WBE module } \\
\text { - Whole building electric and gas deviation from baseline model } \\
\text { OChiller electric deviation from baseline model } \\
\text { OA/E module } \\
\text { Problems detected } \text { Lack of economizer cooling } \\
\text { - Outdoor air excess, inadequate } \\
\text { - Mechanical cooling unnecessary }\end{array}$ \\
\hline Pailed/miscalibrated sensors
\end{tabular}




\section{PACRAT}

\section{Tool overview}

\begin{tabular}{|c|c|}
\hline Developer & $\begin{array}{l}\text { Facility Dynamics Engineering } \\
\text { (HVAC controls engineers) }\end{array}$ \\
\hline Funding & Private \\
\hline Target Systems & $\begin{array}{l}\text { - Air handlers } \\
\text { - Chillers } \\
\text { - Hydronic system } \\
\text { - Whole building energy } \\
\text { - Zone distribution }\end{array}$ \\
\hline Diagnostic approach & Bottom-up \\
\hline Level of automation & $\begin{array}{l}\text { Automated data importing, automated pre-processing and } \\
\text { archiving, automated problem detection and diagnosis. }\end{array}$ \\
\hline $\begin{array}{l}\text { Monitoring period: } \\
\text { Short-term or } \\
\text { continuous }\end{array}$ & Continuous. \\
\hline Software platform & SQL (Microsoft Access) databases \\
\hline Data sources & EMCS data \\
\hline Target audience & Building engineers and operators. \\
\hline Cost & $\begin{array}{l}\text { Software: } \$ 10,000-\$ 30,000 \text { (with training), } \\
\text { configuration }(\$ 400-\$ 800 / \text { system) }\end{array}$ \\
\hline $\begin{array}{l}\text { Method for } \\
\text { configuration }\end{array}$ & Developers configure, perform initial data processing. \\
\hline $\begin{array}{l}\text { Extent of } \\
\text { commercialization }\end{array}$ & Commercialized in 1999. 10 sites, 50 buildings. \\
\hline $\begin{array}{l}\text { Additional features } \\
\text { beyond diagnostics }\end{array}$ & $\begin{array}{l}\text { Archived metrics from the performance characterization module } \\
\text { used to inform future design decisions. } \\
\text { Monitoring and verification of performance contracts. }\end{array}$ \\
\hline Service available & Developers can run PACRAT analysis and send results. \\
\hline
\end{tabular}


PACRAT, (2 of 4)

\section{Operational Use}

\begin{tabular}{|l|l|}
\hline Informational inputs & $\begin{array}{l}\text { Schedule, AHU configurations, fan rated HP and cfm, high/low } \\
\text { operational limits for each point, setpoints, utility rate structure, } \\
\text { index variables for M\&V baseline (square footage, occupancy) }\end{array}$ \\
\hline Monitoring points & $\begin{array}{l}\text { Whole building: Whole building electric + up to 3 additional } \\
\text { normalizing variables } \\
\text { Economizer: SAT, OAT, RAT, MAT, SF status, SF cfm or \% VSD, HW } \\
\text { valve, CHW valve, OA damper Optional: RH } \\
\text { Other air handler: SF CFM or \% VSD, SF on/off, OA damper, HW } \\
\text { valve, CHW valve. Optional: OA cfm, OA CO2, RA CO2, } \\
\text { RA RH } \\
\text { Central plant and distribution: Primary and secondary loops: } \\
\text { CHWST, CHWRT, CHW flow. Chiller amps or kW, CWST, } \\
\text { CWRT, chiller status, pump status, chiller command, valve } \\
\text { outputs, loop DP } \\
\text { Zones: ZAT, Optional: zone RH, setpoints, and CO2 } \\
\text { Recommended trending frequency: user defined, developers } \\
\text { recommend 15 minute to 1 hour }\end{array}$ \\
\hline Standard plots & $\begin{array}{l}\text { Numerous standard plots for each diagnostic area, especially } \\
\text { performance metrics. }\end{array}$ \\
\hline Access database. \\
\hline Pre-processing & $\begin{array}{l}\text { Keeps the real timestamp with each data point or can join data by } \\
\text { converging onto one interval or changing the timestamp to the } \\
\text { beginning of the interval. Automatically filters data and includes } \\
\text { algorithms that fill and recreate data through interpolation, } \\
\text { distribution, or based on the difference between values. }\end{array}$ \\
\hline
\end{tabular}


PACRAT, (3 of 4)

\begin{tabular}{|c|c|}
\hline Problems detected & $\begin{array}{l}\text { AUTOMATED DIAGNOSTICS } \\
\text { Whole building: } \\
\text { - Utility deviation from baseline model (kWh, therms, ton-hours) } \\
\text { Chiller diagnostics: } \\
\text { - Chilled water temp control } \\
\text { - Poor load factor } \\
\text { - Poor condenser, evaporator performance } \\
\text { - Chiller efficiency degradation } \\
\text { - Excess cycling } \\
\text { - Chiller electric deviation from baseline model } \\
\text { Hydronic distribution } \\
\text { - Failed valve } \\
\text { - Struggling pumps, valves } \\
\text { - Primary/secondary system } \\
\text { Air Handler } \\
\text { - Lack of economizer cooling } \\
\text { - Outdoor air excess or inadequate } \\
\text { - Simultaneous heating/cooling } \\
\text { - Leaking/struggling coils } \\
\text { - Control instability, excess cycling of all controlled components } \\
\text { Zones } \\
\text { - Space temperature, humidity } \\
\text { - CO2 control } \\
\text { General Across Systems: } \\
\text { - Unoccupied operation } \\
\text { - Failed/miscalibrated sensors } \\
\text { - Run-time threshold met } \\
\text { - Deviation from baseline } \\
\text { - Alarm occurrence } \\
\text { - Override occurrence } \\
\text { - Additional proprietary diagnostic algorithms } \\
\text { MANUAL DIAGNOSTICS: } \\
\text { Performance metrics, data visualization } \\
\text { - }\end{array}$ \\
\hline $\begin{array}{l}\text { Data visualization } \\
\text { features }\end{array}$ & $\begin{array}{l}\text { Advanced time-series (zoom, scroll, slide), X-Y scatter, 3D } \\
\text { Filtering (occupancy, other points, day type) } \\
\text { Daily profile (average and peak day), load duration. } \\
\text { Batch processing (not real-time). } \\
\text { Automatically aggregate energy consumption with tree view. }\end{array}$ \\
\hline
\end{tabular}


PACRAT, (4 of 4)

\begin{tabular}{|l|l|}
\hline Diagnostic Methods & $\begin{array}{l}\text { MANUAL DIAGNOSTICS } \\
\text { - Benchmarking (internal across buildings or equipment type) } \\
\text { - Statistics (min/avg/max): temp, RH, CO2, ventilation cfm, } \\
\text { cfm/person; cooling load, heating load } \\
\text { - Performance metrics: For example, cooling load/sq ft, chiller } \\
\text { kW/ton } \\
\text { AUTOMATED DIAGNOSTICS } \\
\text { - Expert rules: Logic tree based on many data points. Problems } \\
\text { are detected, cost waste calculated, and possible causes and } \\
\text { associated resolutions presented. The problems are also linked } \\
\text { to time-series plots. } \\
\text { - Modeled baseline: Data is binned by hour of day, day of week, } \\
\text { and any third variable (usually OAT). Deviations from baseline } \\
\text { are detected. Cost waste is calculated. }\end{array}$ \\
\hline Uncertainty methods & $\begin{array}{l}\text { Avoids false diagnosis stemming from data uncertainty by } \\
\text { incorporating deadbands into the diagnostic rules for which no } \\
\text { faults are detected. Can vary these deadbands based on sensitivity } \\
\text { desired. }\end{array}$ \\
\hline Problem notification & Anomaly reports. \\
\hline Problem prioritization & $\begin{array}{l}\text { Problems can be sorted by type, system or component involved, } \\
\text { magnitude of energy cost waste, location, or other installation- } \\
\text { specific item such as cost center or technician responsible. } \\
\text { Automated aggregation of energy/cost waste over time and at all } \\
\text { levels of hierarchy tree. }\end{array}$ \\
\hline
\end{tabular}




\section{EEM Suite}

\section{Tool overview}

\begin{tabular}{|c|c|}
\hline Developer & $\begin{array}{l}\text { Silicon Energy } \\
\text { (engineers, computer programmers) }\end{array}$ \\
\hline Funding & Venture capital \\
\hline Target Systems & $\begin{array}{l}\text { Whole building loads (benchmarking, energy tracking) } \\
\text { No specific diagnostic target. }\end{array}$ \\
\hline Diagnostic approach & $\begin{array}{l}\text { Top-down energy tracking; bottom up capabilities with EMCS data } \\
\text { collection. }\end{array}$ \\
\hline Level of automation & $\begin{array}{l}\text { Automated data importing, automated synchronization and } \\
\text { archiving, programmable alarms for automated detection (no } \\
\text { previously embedded knowledge). }\end{array}$ \\
\hline $\begin{array}{l}\text { Monitoring period: } \\
\text { Short-term or } \\
\text { continuous }\end{array}$ & Continuous \\
\hline Software platform & $\begin{array}{l}\text { SQL databases on remote server. OLAP (on-line analytical } \\
\text { processing) technology - roll data into hourly, daily, and monthly } \\
\text { bins. Third-party graphing tool. }\end{array}$ \\
\hline Data sources & EMCS data, utility power data \\
\hline Target audience & Engineers and operators with HVAC knowledge. \\
\hline Cost & $\begin{array}{l}\text { Software: } \$ 40,000-\$ 50,000 \text { basic, additional modules } \$ 10,000-25,000 \\
\text { each. } \\
\text { Configuration/training: } 35 \% \text { of software cost } \\
\text { Upgrades and support: } 18 \% \text { of software cost }\end{array}$ \\
\hline $\begin{array}{l}\text { Method for } \\
\text { configuration }\end{array}$ & Silicon Energy links EMCS data to the tools through gateways. \\
\hline $\begin{array}{l}\text { Extent of } \\
\text { commercialization }\end{array}$ & $\begin{array}{l}\text { Commercialized in 1998. } 25 \text { utilities and energy service providers } \\
\text { and } 15 \text { end-users. } 1000 \text { sites and } 2500 \text { buildings. }\end{array}$ \\
\hline $\begin{array}{l}\text { Additional features } \\
\text { beyond diagnostics }\end{array}$ & $\begin{array}{l}\text { Energy accounting, procurement, bills analysis and verification, } \\
\text { rate analysis, load curtailment communications, two-way control } \\
\text { capability. }\end{array}$ \\
\hline Service available & No HVAC diagnostic services. \\
\hline
\end{tabular}


EEM Suite, continued

Operational Use

\begin{tabular}{|c|c|}
\hline Informational inputs & $\begin{array}{l}\text { Index variables } \\
\text { (square footage, occupancy) }\end{array}$ \\
\hline Monitoring points & $\begin{array}{l}\text { Trend any EMCS system points. } \\
\text { Whole building: Whole building electric, OAT } \\
\text { trending frequency: user defined }\end{array}$ \\
\hline Standard plots & Benchmarking bar charts. \\
\hline Archiving & $\begin{array}{l}\text { Archives the raw data at user-defined intervals and the alarm states } \\
\text { on a remote server database }\end{array}$ \\
\hline Pre-processing & $\begin{array}{l}\text { Keeps the real timestamp with each data point or synchronizes data } \\
\text { by changing the timestamp to the nearest synchronous value. Data } \\
\text { are usually kept with the true timestamp, except for plots that need } \\
\text { coincident timestamps for multiple data streams (X-Y scatter, 3-D). }\end{array}$ \\
\hline Problems detected & $\begin{array}{l}\text { MANUAL DIAGNOSTICS } \\
\text { - High energy } \\
\text { - Unoccupied operation } \\
\text { - Run-time } \\
\text { AUTOMATED DIAGNOSTICS } \\
\text { Program conditional alarms for any data point. }\end{array}$ \\
\hline $\begin{array}{l}\text { Data visualization } \\
\text { features }\end{array}$ & $\begin{array}{l}\text { Advanced time-series (user-defined with scroll and zoom) } \\
\text { X-Y user-defined, 3-D } \\
\text { Daily profile (peak day, weekday average, weekend average) } \\
\text { Load duration } \\
\text { User-defined filters (date range, type of day, day of week), } \\
\text { Real-time web-access, } \\
\text { Automatically aggregate energy consumption with tree view. }\end{array}$ \\
\hline Diagnostic Methods & $\begin{array}{l}\text { MANUAL DIAGNOSTICS } \\
\text { Benchmarking (indexing, weather normalized) } \\
\text { Statistics (run-time for digital points) } \\
\text { Performance metrics (user defined through calculated points) } \\
\text { AUTOMATED DIAGNOSTICS } \\
\text { Diagnostic rules can be programmed as alarms by the user. }\end{array}$ \\
\hline Uncertainty methods & None \\
\hline Problem notification & Programmable alarms, can automatically page or e-mail a contact. \\
\hline Problem prioritization & The alarm types can be programmed for priority level. \\
\hline
\end{tabular}

